\title{
Preliminary Reconnaissance of the May 20, 2013 Newcastle-Moore Tornado in Oklahoma
}
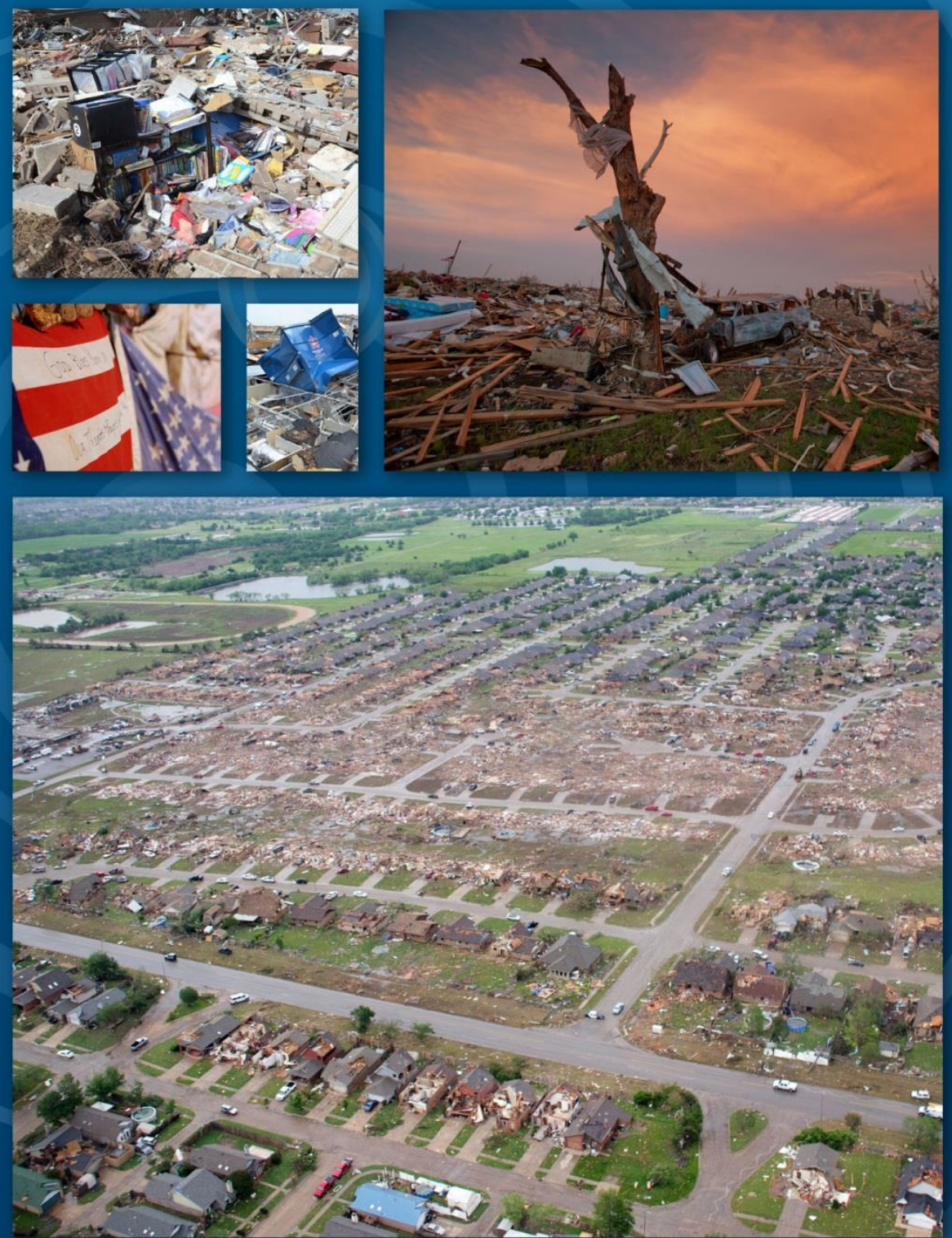

http://dx.doi.org/10.6028/NIST.SP.1164

\section{NGT}





\title{
NIST Special Publication 1164
}

\section{Preliminary Reconnaissance of the May 20, 2013, Newcastle-Moore Tornado in Oklahoma}

\author{
Erica D. Kuligowski \\ Long T. Phan \\ Marc L. Levitan \\ Engineering Laboratory \\ National Institute of Standards and Technology \\ David P. Jorgensen \\ Warning R\&D Division \\ National Severe Storms Laboratory \\ National Oceanic and Atmospheric Administration
}

http://dx.doi.org/10.6028/NIST.SP.1164

December 2013

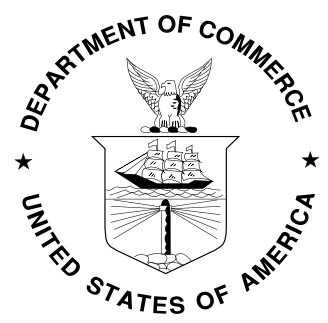

U.S. Department of Commerce

Penny Pritzker, Secretary

National Institute of Standards and Technology Patrick D. Gallagher, Under Secretary of Commerce for Standards and Technology and Director 
Disclaimer No. 1

Certain commercial entities, equipment, or materials may be identified in this document in order to describe an experimental procedure or concept adequately. Such identification is not intended to imply recommendation or endorsement by the National Institute of Standards and Technology, nor is it intended to imply that the entities, materials, or equipment are necessarily the best available for the purpose.

\title{
Disclaimer No. 2
}

NIST takes no position as to whether the design or construction of any building discussed in this report was compliant with any code.

\section{Disclaimer No. 3}

The policy of NIST is to use the International System of Units in all publications. In this document, however, units are presented in the system prevalent in the relevant discipline, although in some cases more than one system of units may be presented.

\section{$\underline{\text { Use in Legal Proceedings }}$}

No part of any report resulting from a NIST investigation into a structural failure or from an investigation under the National Construction Safety Team Act may be used in any suit or action for damages arising out of any matter mentioned in such report (15 U.S.C. 281a, as amended).

\section{Copyright}

This NIST publication is a work of the United States Government not subject to copyright protection within the United States under Title 17 United States Code $\S 105$. This publication may include copyrighted content (such as photographs) used with permission of the credited copyright holder. Reproduction, redistribution or reuse of such copyrighted content apart from this publication may require permission, which should be sought from the credited copyright holder. Where no copyright holder or source is credited for a figure or table in this publication, the source is NIST, which would appreciate attribution.

\author{
National Institute of Standards and Technology Special Publication 1164 \\ Natl. Inst. Stand. Technol. Spec. Publ. 1164, 81 pages (December 2013) \\ CODEN: NSPUE2 \\ http://dx.doi.org/10.6028/NIST.SP.1164
}




\section{ACKNOWLEDGEMENTS}

The National Institute of Standards and Technology (NIST) would like to gratefully acknowledge the assistance of all who provided data and information in support of this preliminary reconnaissance. NIST has received considerable cooperation and information from Federal, State, and local authorities and the private sector. Local authorities providing information include Moore Emergency Management, Moore Community Development Department, Moore Fire Department, Moore Police Department, Moore Public School District, Oklahoma City Clerk, Oklahoma City Fire Department, and mutual aid first responders from the Tulsa Fire Department and the Weatherford Fire Department. State authorities providing information include the Oklahoma Department of Insurance. Federal authorities providing information include the National Oceanic and Atmospheric Administration, the National Severe Storms Laboratory and the National Weather Service Norman Forecast Office. Private sector organizations providing information include the Norman Regional Health System, JHBR Architecture, and Bearing Tree Land Surveying.

NIST also gratefully acknowledges the assistance of teachers and staff of Plaza Towers and Briarwood Elementary Schools, staff of the Moore Medical Center, and first responders, who provided information through interviews.

We would additionally like to acknowledge the technical assistance provided during the field deployment by Charlie Carter of the American Institute of Steel Construction, and technical and institutional support provided by our NIST colleagues who worked diligently to make the preliminary reconnaissance successful. These include Howard Harary, Eric Letvin, Jason Averill, Steve Cauffman, Rena Elkin, Fahim Sadek, Frank Lombardo, Sonum Chaudhari, Kirk Dohne, Andrew Mundy, Carolyn Rowland, S. Shyam Sunder, Kellie Beall, Rose Van Camp, and Bessmarie Young from the NIST's Engineering Laboratory; Michael Newman from the NIST's Public and Business Affairs Office; and Henry Wixon from the NIST Director's Office. 
The page intentionally left blank. 


\section{TABLE OF CONTENTS}

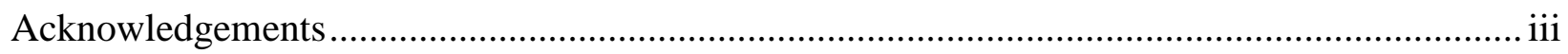

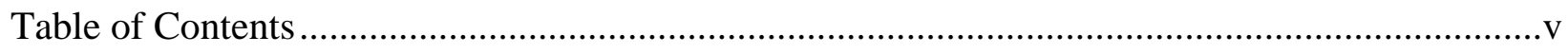

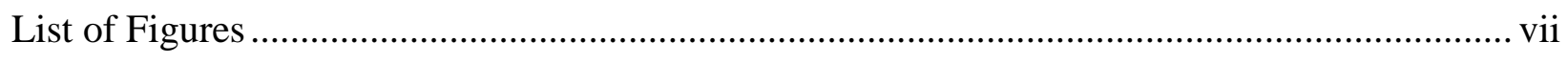

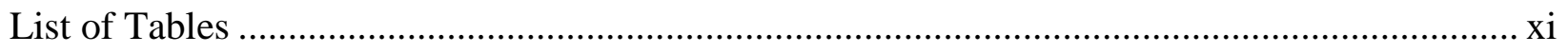

List of Acronyms, Abbreviations, and Conversion Factors................................................. xii

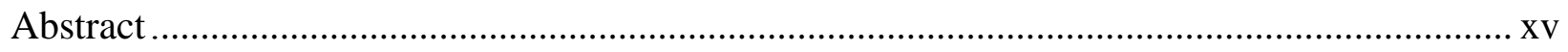

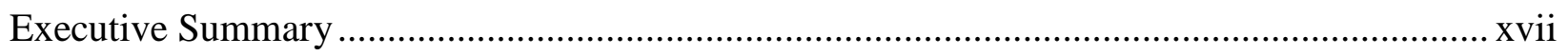

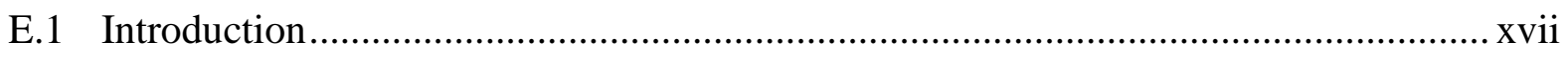

E.2 NIST Response and Scope of the Preliminary Reconnaissance .............................. xvii

E.3 Hazard Context ............................................................................................. Xviii

E.4 Observations of the Preliminary Reconnaissance ................................................ xviii

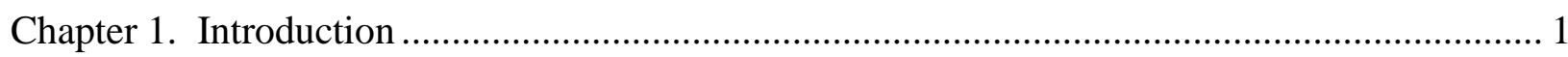

1.1 Event Overview ........................................................................................... 1

1.2 Overview of Damage and Impacts...................................................................... 2

1.3 Overview and Scope of NIST Preliminary Reconnaissance ..................................... 2

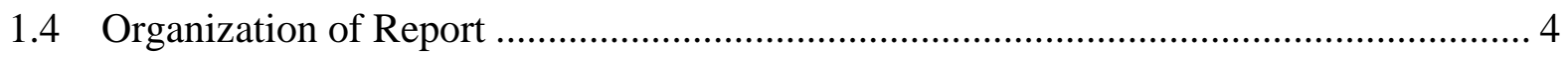

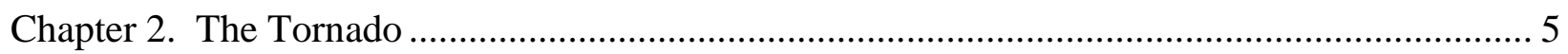

2.1 Moore Tornado History and Preparedness ........................................................ 5

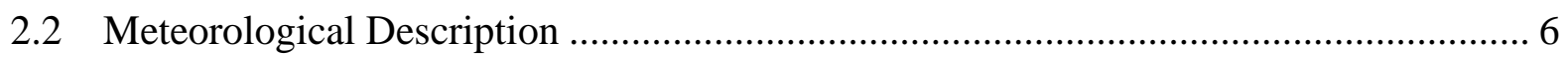

2.3 Estimated Wind Speeds and Observed Damage ............................................... 10

Chapter 3. Emergency Communications in Moore, Oklahoma ............................................ 17

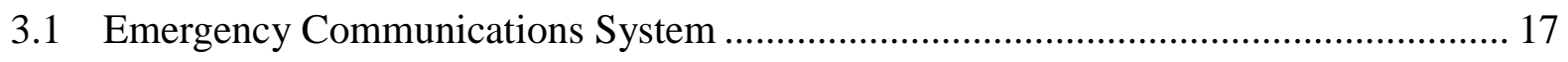

3.2 Emergency Communications on May 20, 2013 ................................................ 19

Chapter 4. Building Performance, Emergency Operations, and Life Safety Outcomes ............. 25

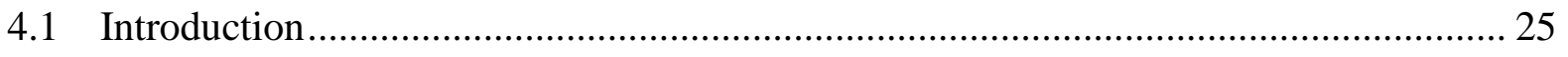




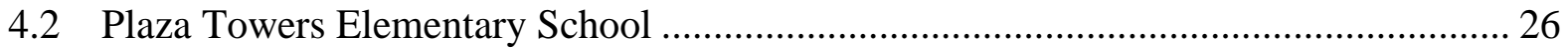

4.3 Briarwood Elementary School ................................................................................... 34

4.4 Moore Medical Center ............................................................................... 42

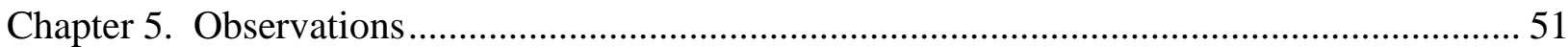

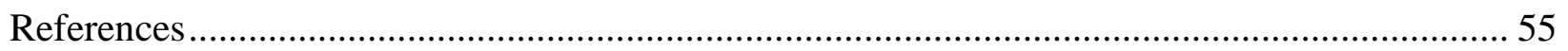

Appendix. Tornado Emergency Procedures for Surveyed Facilities ..................................... 57 


\section{LIST OF FIGURES}

Figure 2-1. NOAA/NWS/SPC Convective outlook for Monday, May 20, 2013 issued at 1:17 AM CDT May 20, 2013, showing highest risk for EF-2 - EF-5 tornadoes to be central Oklahoma. The black dot indicates the approximate location of Moore, $\mathrm{OK}$.

Figure 2-2. Storm-based tornado warning polygon (red lines) issued at 2:40 PM CDT Monday, May 20, 2013 (top) and tornado emergency polygon issued at 3:01 PM CDT (bottom). Background colors are radar reflectivity from the KTLX radar.... 9

Figure 2-3. Estimated centerline of tornado damage path (in red) and locations of three critical and educational facilities surveyed. Tornado locations and times estimated from NWS radar data are also shown.(red dots; every 5 minutes).

Figure 2-4. Tornado damage path map showing point estimates of EF damage at specific locations (triangles) and swaths for EF-0 (turquoise), EF-1 (green), EF-2 (yellow), EF-3 (brown), EF-4 (red) and EF-5 (purple) intensity damage (data source NOAA/NWS). The locations where damage was evaluated represents only a small percentage of the number of buildings damaged or destroyed by the tornado.

Figure 2-5. Two spans of the historic trestle bridge on US 62 running parallel to I-44 were destroyed. The bridge had been closed to traffic since 1963 but carried water pipes across the Canadian River.

Figure 2-6. Aerial view (facing east) of damage to the Moore Medical Center (upper left), with heavily damaged residential neighborhood immediately west of the medical center in the foreground....

Figure 2-7. EF rated damage by NWS west of Interstate 35 in the vicinity of Briarwood and Plaza Tower Elementary Schools and the Moore Medical Center. The triangles indicate locations where damage was assessed and the triangle color indicates the EF number assigned to each assessment. The red rectangle shows the approximate field of view of the aerial photo in Figure 2-6. 15

Figure 3-1. Map showing location of sirens in Moore. .18

Figure 3-2. Seven-day forecast published on Thursday, May 16, 2013, indicating 'Significant Severe Storms Possible' for May 19-20. 20

Figure 3-3. Severe thunderstorm warning polygon issued at 2:12 pm CDT, including Moore.

Figure 3-4. Tornado warning polygon issued at 2:40 pm CDT, including Moore ................... 22 
Figure 4-1. Aerial overview, after the tornado, showing NIST-surveyed facilities relative to the estimated center of the tornado damage path (red line) ...............................26

Figure 4-2. Aerial photograph of Plaza Towers Elementary School prior to the tornado....... 27

Figure 4-3. Designated areas of safety for tornadoes for the Plaza Towers Elementary School. The yellow shaded areas indicate the locations of the bathrooms used for shelter on May 20, 2013. The area shaded in red indicated where seven children died. . 28

Figure 4-4. Aerial photograph of Plaza Towers Elementary School and proximity to estimated center of tornado damage path. 30

Figure 4-5. Post-tornado aerial view (looking northeast) of the Plaza Towers Elementary School taken May 21, 2013. Much of the debris was already moved by the time of this photograph as part of the search and rescue operations 30

Figure 4-6. Damage to the hallway and classrooms of the new main classroom building (complete loss of roof and many walls) where the 7 fatalities occurred (most of the debris has already been removed). Note: this hallway area was a designated area of safety.

Figure 4-7. Collapsed southwest wing of original main classroom building. ...................... 32

Figure 4-8. Damaged interior of a classroom in the original main classroom building. ......... 33

Figure 4-9. Collapsed Gymnasium building (Note the interior Gym Office surrounded by a CMU wall remained standing).

Figure 4-10. Aerial overview of the Briarwood Elementary School before the tornado. 34

Figure 4-11. Tornado safety areas for Briarwood Elementary School. The students and staff generally sheltered according to the tornado plan (gray shaded areas), except the use of the bathrooms in the 400 building (yellow shaded area).

Figure 4-12. Bathrooms used for shelter in the 400 building.

Figure 4- 13. Aerial photograph of Briarwood Elementary School and proximity to estimated center of tornado damage path (red line).

Figure 4-14. Collapsed Multipurpose Building 39

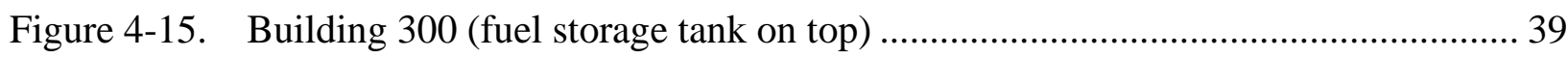

Figure 4-16. Building 200 (complete demolition with only boy's and girl's bathrooms remain standing) 
Figure 4-17. Cafeteria. Complete structural failure with only the interior bathroom remained standing. 40

Figure 4-18. An interior view of a classroom in the 400 Building where portion of the building's metal roof system was lost.

Figure 4-19. Hallway of Building 400 after the tornado (designated tornado safety area and initial location of Building 400 occupants before moving to the bathrooms just before the tornado struck)

Figure 4-20. Aerial photograph of Moore Medical Center before the tornado.

Figure 4-21. Cafeteria located on the first floor interior of the hospital where hospital patients sheltered during the tornado.

Figure 4-22. Physicians were relocated from the cafeteria to the walk in freezers for anticipated additional level of protection for staff that would be needed for response and recovery 46

Figure 4- 23. Aerial photograph of Moore Medical Center shortly after the tornado struck showing estimated centerline of tornado track (in red) 46

Figure 4- 24. Aerial view of the heavily damaged Moore Medical Center (looking south-east). Circled locations indicate areas of roof deck damage.

Figure 4-25. Damage to the building envelope of Moore Medical Center 47

Figure 4-26. Damage to the envelope of Moore Medical Center (glazing) ........................... 48

Figure 4-27. Damage to the interior due wind and debris infiltration. 48

Figure 4-28. Impact damage to roof bar joists from steel trash dumpster and loss of steel roof decking.

Figure 4-29. Examples of broken interior doors. 
The page intentionally left blank. 


\section{LIST OF TABLES}

Table 2-1. Enhanced Fujita Scale .............................................................................. 11 
The page intentionally left blank. 


\section{LIST OF ACRONYMS, ABBREVIATIONS, AND CONVERSION FACTORS}

$\begin{array}{ll}\text { Acronyms } & \\ \text { BOCA } & \text { Building Officials and Code Administrators } \\ \text { BTS } & \text { box-type system } \\ \text { CDT } & \text { central daylight time } \\ \text { CMU } & \text { concrete masonry unit } \\ \text { EF } & \text { Enhanced Fujita } \\ \text { EOC } & \text { Emergency Operations Center } \\ \text { FEMA } & \text { Federal Emergency Management Agency } \\ \text { GIS } & \text { geographic information system } \\ \text { IBC } & \text { International Building Code } \\ \text { ICC } & \text { International Code Council } \\ \text { IRC } & \text { International Residential Code } \\ \text { MOB } & \text { Medical Office Building } \\ \text { NIST } & \text { National Institute of Standards and Technology } \\ \text { NOAA } & \text { National Oceanic and Atmospheric Administration } \\ \text { NSF } & \text { National Science Foundation } \\ \text { NSSL } & \text { National Severe Storms Laboratory } \\ \text { NWS } & \text { National Weather Service } \\ \text { OGE } & \text { Oklahoma Gas and Electric } \\ \text { SPC } & \text { Storm Prediction Center } \\ \text { WCM } & \text { Warning Coordination Meteorologist } \\ \text { WFO } & \text { Weather Forecast Office } \\ & \end{array}$

\section{Abbreviations and Conversion Factors}

$\mathrm{ft}$

foot, feet

$\mathrm{km}$

kilometer(s)

$\mathrm{m}$

meter(s), $1 \mathrm{~m}=3.281 \mathrm{ft}$

$\mathrm{m} / \mathrm{s}$

meter(s) per second, $0.447 \mathrm{~m} / \mathrm{s}=1 \mathrm{mph}$

$\mathrm{mph}$

mile(s) per hour 
The page intentionally left blank. 


\section{ABSTRACT}

This is a report on the National Institute of Standards and Technology (NIST) reconnaissance to collect information on the performance of one critical facility and two educational facilities in the May 20, 2013, Newcastle-Moore tornado in Oklahoma. The information collected includes the physical performance of buildings and designated safe areas of the surveyed facilities (the Moore Medical Center and Plaza Towers and Briarwood Elementary Schools), emergency communications systems and emergency operations during and after the tornado, and life safety outcomes. The report describes the environmental conditions, warning information transmitted to the public, as well as emergency response operations, observed building damage, and fatalities and injuries that occurred at each of the three surveyed facilities.

Following the EF-5 tornado that tore through Moore, Oklahoma and surrounding areas on May 20, 2013, causing substantial loss of life and widespread damage, NIST, as part of its Disaster and Failure Studies Program, deployed a team on May 22, 2013, to conduct a Preliminary Reconnaissance. The scope of the reconnaissance was limited, and was undertaken to support the NIST technical investigation, then in progress, of the $2011 \mathrm{EF}-5$ tornado that devastated Joplin, Missouri. The reconnaissance was conducted in cooperation with the National Oceanic and Atmospheric Administration's National Severe Storms Laboratory (NOAA's NSSL). The team consisted of three researchers from NIST's Engineering Laboratory, with expertise in structural engineering, wind engineering, and disaster sociology, and a researcher from NSSL, with expertise in meteorology and severe storm predictions and warnings.

This report provides an account of the tornado and the warning information transmitted to the public, a description of the pre-event emergency plans and procedures and specific actions taken at the surveyed facilities in response to the tornado, information on the construction and physical performance of the buildings at the facilities, and life safety outcomes (fatalities and injuries) at each location. The report concludes with observations on the performance of the emergency communications system during the May 20, 2013, Newcastle-Moore tornado, and for the specific facilities studied, on the performance of emergency operations and physical performance of their buildings and designated safe areas.

Keywords: Building performance, designated safe area, emergency communications, fatalities, emergency response, injuries, tornado, tornado shelter, warning. 
The page intentionally left blank. 


\section{EXECUTIVE SUMMARY}

\section{E.1 Introduction}

This report documents observations of the National Institute of Standards and Technology (NIST) Preliminary Reconnaissance of the May 20, 2013, Newcastle-Moore tornado, to collect information on the performance of one critical facility and two educational facilities. The information collected includes the physical performance of buildings and designated safe areas of the three facilities, emergency communications systems and emergency operations during and after the tornado, and life safety outcomes. The reconnaissance was conducted in cooperation with the National Oceanic and Atmospheric Administration's National Severe Storms Laboratory (NOAA's NSSL).

This work complements an ongoing NIST technical investigation of the May 22, 2011, tornado in Joplin, Missouri, which killed 161 people and damaged or destroyed approximately 8,000 buildings. Disasters such as those in Moore and Joplin, while tragic, do provide an important opportunity to learn from the performance of emergency communications systems and buildings and infrastructure during catastrophic events. Lessons derived from such disasters can lead to improvements in standards, codes, and practices that will reduce fatalities, injuries, and property losses in future events.

\section{E.2 NIST Response and Scope of the Preliminary Reconnaissance}

At the time of the May 20, 2013, Newcastle-Moore tornado, NIST was nearing completion of its technical investigation ${ }^{1}$ of the EF-5 tornado that struck Joplin, MO on May 22, 2011. The decision was made by NIST to conduct a Preliminary Reconnaissance of the May 20, 2013, Newcastle-Moore tornado, to identify any information that might be relevant to certain aspects of the Joplin tornado investigation. The objectives of the Newcastle-Moore Tornado Preliminary Reconnaissance were therefore limited to:

1. Collect data and information on the performance of the emergency communications systems immediately prior to and during the tornado; and

2. Collect data and information on the response of critical and educational facilities (specifically, the Moore Medical Center and Briarwood and Plaza Towers Elementary Schools) to the tornado, including emergency operations, the physical performance of the buildings and designated safe areas, and life safety outcomes.

The Preliminary Reconnaissance was conducted in cooperation with the NOAA's NSSL. The reconnaissance team consisted of three researchers from NIST's Engineering Laboratory, with expertise including structural engineering, wind engineering, and disaster sociology, and a researcher from NSSL, having expertise in meteorology and severe storm predictions and warnings. All team members had experience in conducting disaster studies following tornadoes

\footnotetext{
${ }^{1}$ See http://www.nist.gov/el/disasterstudies/weather/joplin_tornado_2011.cfm for information on the NIST technical investigation of the Joplin tornado.
} 
and other hazards. The team arrived in Moore on May 22, 2013, and collected data through May 24, 2013.

\section{E.3 Hazard Context}

Early Monday afternoon, May 20, 2013, severe thunderstorms began to develop in the area southwest of Oklahoma City. These storms were part of a larger outbreak of severe weather that affected the central United States on May 18-20, including 77 tornadoes across the Midwest. At 2:56 pm CDT, a tornado touched down in the rural northwest area of the City of Newcastle, Oklahoma. It rapidly increased in size and intensity after crossing the Canadian River and moved through rural southwest Oklahoma City. The tornado had grown to EF-5 intensity on the Enhanced Fujita Scale, with estimated 200+ mph winds based on damage indicators, by the time it reached the more densely populated City of Moore, Oklahoma, at around 3:15 pm. The milewide tornado then moved to the east northeast across Moore at a little more than $20 \mathrm{mph}$, destroying neighborhoods, schools, and the only hospital in this city of 57,810 people. The tornado finally dissipated about 4.8 miles east of Moore, at around 3:35 pm, for a total path length of 14 miles and approximately 39 minutes on the ground.

The May 20, 2013, Newcastle-Moore tornado caused 24 fatalities, including seven children who died when the elementary school classroom building in which they took shelter collapsed. Three hundred eighty-seven people were treated for injuries at local hospitals. Fatalities occurred despite (1) early identification of potential severe weather in Moore several days in advance; (2) longer warning time than the national average warning lead time $(\sim 16$ minutes versus $\sim 14$ minutes ${ }^{2}$ ); and, (3) for the seven fatalities at the Plaza Towers Elementary School, sheltering action taken at the designated safe area within the school.

An estimated 2,393 structures were impacted by the tornado, including 1,128 structures that were destroyed and 335 that sustained major damage. Residential buildings took the brunt of the storm's damage, with non-residential buildings accounting for 85 of the damaged structures.

\section{E.4 Observations of the Preliminary Reconnaissance}

Observations based on data and information collected during the course of this Preliminary Reconnaissance are presented below. They are arranged in five groups, the first three providing context, and the last two addressing the specific objectives of the Preliminary Reconnaissance.

\section{Tornado History and Preparedness}

- The City of Moore (and surrounding areas) have had much experience in recent years with tornado disasters, including strikes by one F-2, two F-4/EF-4, and two F-5/EF-5 tornadoes since 1998 (a Fujita Scale F-2 tornado in 1998, an F-5 tornado in1999, an F-4

\footnotetext{
${ }^{2}$ NWS average for 2008 (www.nws.noaa.gov/cfo/program_planning/doc/FY2009\%20NOAA's\%20NWS\%20National\%20Performance\%20Measures\%20-\%20Graph\%20Update.pdf).
} 
tornado in 2003, an Enhanced Fujita Scale ${ }^{3}$ EF-4 tornado in 2010, and the May 20, 2013, Newcastle-Moore EF-5 tornado). Moore is one of just a few communities nationwide to have ever been struck by two F-5/EF-5 tornadoes.

- Moore's work to prepare for tornadoes has included implementing storm monitoring and education and training programs, becoming a NWS certified StormReady Community in 2001, and maintaining that certification since. It was most recently recertified in 2012. Elements of the program include maintaining a 24-hour emergency operations center; having multiple methods to receive severe weather warnings and forecasts and to alert the public; promoting the importance of public readiness through community seminars; and maintaining a formal hazardous weather plan, which includes training severe weather spotters and holding emergency exercises.

- While some research has shown that high false alarm rates can contribute to complacency by the public in response to warnings, the false alarm rate for official tornado warnings in Moore in recent years was considerably lower than the national average. During the era of storm-based warning polygons (as opposed to earlier county-wide warnings), between October 2007 and May 19, 2013, 16 official tornado warnings were issued for all or some parts of Moore, 12 of which were followed by verified tornadoes. This yielded a false alarm rate for the Moore area of 25 percent (4 false alarms out of 16 warnings), compared to the national average false alarm rate of 74 percent for 2010 .

\section{Building Codes and Storm Shelters}

- Moore had adopted national model codes governing design and construction of buildings, and was enforcing the 2009 International Code Council (ICC) International Building Code (IBC) and the 2009 ICC International Residential Code for One- and Two-Family Dwelling (IRC) at the time of the Newcastle-Moore tornado.

- Tornadoes are not explicitly considered in either the 2009 IBC or 2009 IRC for any types of buildings, except storm shelters. Although design wind speeds required by those codes are in the range of EF-1 tornadoes, the codes do not address potentially greater lateral and roof uplift pressures in tornadoes compared to other types of windstorms, and do not address windborne debris, which is a significant contributor to building damage in tornadoes.

- There were no public or community shelters in Moore at the time of the NewcastleMoore tornado. The City's strategy was to recommend shelter-in-place, except for occupants in mobile homes or portable buildings, who were advised go to a substantial structure. The City's stated rationale was twofold: there were no public buildings having a suitable location for a shelter; and the overall risk was less to shelter-in-place in a reasonably well-constructed residence (considering available warning time, travel time to a shelter, traffic, and other factors).

\footnotetext{
3 The National Weather Service (NWS) switched from rating tornado intensity using the Fujita Scale to the Enhanced Fujita Scale in 2007 (see Section 2.3 for more information).
} 
- Over 3,000 residential shelters have been constructed in Moore and were registered with the city at the time of the Newcastle-Moore tornado, perhaps the highest number of residential shelters per capita in the U.S.

- Installation of storm shelters in homes or other buildings is strictly voluntary; neither the national model building codes adopted by Moore nor local amendments require storm shelters.

Events Immediately Prior to the Tornado

- The threat of severe weather for the Moore area on May 20, 2013, was identified as early as May 15 by the NWS Storm Prediction Center (SPC). The Hazardous Weather Outlook on May 15 indicated the possibility of severe storms on May 19-20, which was expanded to include possible destructive hail and tornadoes in the May 16 Outlook. The Convective Outlook issued at 1:00 am CDT on May 20 indicated a 10\% or greater probability of EF2-EF5 tornadoes occurring within 25 miles of a point for the central Oklahoma region on the afternoon of May 20.

- The tornado touched down while Moore schools were still in session. However, many parents had picked up their children earlier in the day in response to increasing concerns about the weather, significantly reducing the number of students at the schools when the tornado struck. Due to the threat of severe weather that afternoon, Moore Public Schools made the decision by 9:00 am CDT to cancel all afterschool activities on May 20. By $1: 30 \mathrm{pm}$, the decision was made to shelter-in-place (i.e., not run the buses or release the students at the normal 3:00 pm dismissal time).

\section{Observations on Objective 1: Performance of the emergency communications systems immediately prior to and during the tornado}

- The NWS Weather Forecast Office (WFO) in Norman made extensive use of nontraditional communications on May 20 to provide more frequently updated information about the possibility of severe weather and about the tornado warnings. These new communication methods included recorded severe weather briefings on YouTube, direct emails to stakeholders (e.g., emergency managers, school administrators), and Twitter and Facebook posts.

- The first official tornado warning for the Moore area was issued at 2:40 pm CDT, and the tornado touched down at 2:56 pm, for a lead time of 16 minutes. The 2010 national average tornado warning lead time is 14 minutes (latest available data). The leading edge of the tornado reached Briarwood Elementary School at approximately 3:15 pm, Plaza Towers Elementary School a few minutes later, and the Moore Medical Center at approximately 3:20 pm. 
- An official Tornado Emergency warning, the most urgent official warning type, was issued by NWS at 3:01 pm CDT. This terminology, reserved by NWS for "exceedingly rare situations," had only been used twice previously by the Norman WFO, for the 1999 F5 and the 2003 F4 tornadoes, both of which struck Moore and surrounding areas.

- The tornado sirens in Moore were sounded six times. The initial siren was sounded shortly following the first NWS tornado warning at 2:40 pm CDT, and the last at approximately 3:20 pm. The sirens in Moore are only meant to alert/warn those located outdoors and are used to indicate the urgent need to take shelter. Moore's outdoor warning system is also capable of transmitting pre-recorded messages from its sirens. This feature was used only once, for the $3: 11 \mathrm{pm}$ activation, informing the Moore community that the tornado warning was still in effect.

Observations on Objective 2: Response of critical and educational facilities (specifically, the Moore Medical Center and Briarwood and Plaza Towers Elementary Schools) to the tornado, including emergency operations, the physical performance of the buildings and designated safe areas, and life safety outcomes.

- At both Briarwood and Plaza Towers Elementary Schools, most designated tornado safe areas were severely damaged or destroyed. Some of the designated safe areas at the Moore Medical Center had significant damage due to collapse of interior walls and ceilings on the second floor and due to infiltration of windborne debris in hallways on the first floor. None of these buildings had facilities specifically designed for use as storm shelters ${ }^{4}$ or safe rooms, ${ }^{5}$ and none had basements.

- The designated safe areas in the new main classroom building at Plaza Towers Elementary School did not provide life safety. Seven schoolchildren died when part of the building's designated safe area, in which they were located, collapsed. Two adults and one student were also significantly injured in the new main classroom building. No fatalities occurred in the original main classroom building at Plaza Towers Elementary School; however, two teachers and one child suffered significant injuries.

- Extensive damage to the building envelope of the Moore Medical Center allowed wind, debris, and water inside the building, causing severe damage to the interior and rendering the hospital and medical office buildings completely nonfunctional. Damage to the structural systems (pre-cast concrete and steel framing) was negligible.

- There were no reported fatalities at Briarwood Elementary School or Moore Medical Center. Two teacher's assistants suffered significant injuries at Briarwood Elementary School (in the 100 Building) and no significant injuries were reported at Moore Medical Center.

\footnotetext{
${ }^{4}$ As defined by the ICC 500 Standard for the Design and Construction of Storm Shelters (ICC, 2008).

${ }^{5}$ As defined by FEMA 361, Design and Construction Guidance for Community Safe Rooms (FEMA, 2012)
} 
- For the most part, designated safe areas as identified in emergency plans were used at the three facilities surveyed by NIST. In some cases, last-minute decisions were made to use smaller interior spaces or rooms, which were not previously identified in the building's emergency plans as designated safe areas, such as bathrooms and closets in the two elementary schools and a walk-in freezer in the Moore Medical Center.

- Smaller interior spaces (e.g., bathrooms) surrounded by reinforced masonry (CMU) walls at both schools performed better when compared with adjacent hallways and classrooms. The CMU walls that surrounded these interior spaces were found to more often remain standing and thereby provide some protection against wind-borne debris.

- Multiple buildings at both elementary schools suffered complete collapse or severe damage. The elementary school buildings with box-type construction typically sustained loss of the roof system and diaphragm, leading to partial or total collapse of the supporting walls. Pre-engineered metal gymnasium and multipurpose buildings sustained total structural failure. 


\section{CHAPTER 1. INTRODUCTION}

\section{$1.1 \quad$ Event Overview}

The possibility of severe weather on Monday, May 20, 2013, in the area of Moore, Oklahoma was identified by the NWS as early as May 15, 2013, as part of an outbreak of severe weather that did occur across the central United States on May 18-20, 2013. At 1:00 am CDT on May 20, the NWS/Storm Prediction Center (SPC) issued a probabilistic tornado outlook indicating a $10 \%$ or greater probability of Enhanced Fujita Scale EF2-EF5 tornadoes occurring within 25 miles of a point for central Oklahoma, including the City of Moore. At 8:00 am CDT, the Warning Coordination Meteorologist (WCM) at the NWS Weather Forecast Office (WFO) in Norman, Oklahoma sent an email to his network of leaders (e.g., emergency managers and school administrators) warning them about the possibility of severe weather later in the day, and the potential for serious issues if tornadic storms occurred during school dismissal time. The WCM was also sending out information by other nontraditional channels, such as recorded briefings on YouTube and via social media (Twitter and Facebook). By 9:00 am CDT, the decision was made by Moore Public School District to cancel all after-school activities. The 10:00 am CDT SPC Convective Outlook predicted the peak hours for severe weather, including tornadoes, would be between $3 \mathrm{pm}$ and $8 \mathrm{pm}$.

The first tornado watch including the City of Moore was issued by the WFO in Norman, Oklahoma at 1:10 pm. A tornado warning, based on Doppler radar indications of a severe storm, was issued at 2:40 pm CDT, which included the cities of Newcastle and Moore, and parts of Oklahoma City. The City of Moore sounded its siren system moments later; the first of six times the sirens would be activated that afternoon. A small, short-lived EF-0 tornado touched down west of the City of Newcastle at 2:45 pm, but primarily caused damage to trees.

At 2:56 pm CDT, a second tornado touched down in the rural northwest area of the City of Newcastle. It rapidly increased in size and intensity after crossing the Canadian River and moved through rural southwest Oklahoma City. The NWS issued a Tornado Emergency Warning, its most urgent warning, at 3:01 pm CDT. The tornado had grown to EF-5 intensity on the Enhanced Fujita Scale, with estimated 200+ mph winds, by the time it reached the more densely populated City of Moore, around 3:15 pm. The mile-wide tornado moved to the eastnortheast across Moore at a little more than $20 \mathrm{mph}$, destroying neighborhoods, schools, and the only hospital in this city of 57,810 people. The tornado finally dissipated 4.8 miles east of Moore around 3:35 pm, for a total path length of 14 miles and time on the ground of approximately 39 minutes. 


\subsection{Overview of Damage and Impacts}

The Oklahoma Department of Emergency Management reported a total of 24 fatalities caused by the Newcastle-Moore tornado and 387 injuries treated at local hospitals, as of May 24, $2013 .{ }^{6}$ FEMA (2013) estimated that 2,393 structures were impacted by the Newcastle-Moore tornado, including 1,128 structures that were destroyed, 335 that sustained major damage, 629 that sustained minor damage, and another 301 structures were 'generally affected.' This damage occurred primarily to residential buildings; non-residential buildings accounted for $4 \%$ (85 out of 2,393) of the damaged structures. The Oklahoma Department of Insurance reported that the total number of tornado-related insurance claims from the May 19-20, 2013 tornado outbreak submitted as of June 4, 2013 was 32,433, including 13,938 homeowners claims, 742 commercial property claims, and 17,492 automobile claims (claims were not tracked by individual tornado, but the Newcastle-Moore tornado was by far the most destructive). ${ }^{7}$

Power outages from the May 19-20, 2013 outbreak in the region peaked at 61,500 customers without power. Oklahoma Gas and Electric (OGE) reported a maximum of 18,432 outages in Moore, which were reduced to 4,225 by May 24, 2013. OGE reported that it expected to have all customers capable of receiving power restored by May 26, 2013. The McClain Power Plant in Newcastle, located just outside of the tornado damage path, was knocked offline due to damaged transmission lines to the plant. However, OGE identified that it had sufficient capacity from other generation assets to meet customer demand. Low water pressure was experienced during the first two days after the tornado, but water quality was not affected. ${ }^{8}$

The Moore Medical Center, consisting of a hospital and adjoining medical office buildings, was heavily damaged and rendered completely nonfunctional, although no lives were lost. Thirteen patients located in the hospital when the tornado hit were transferred to other area hospitals. The entire facility was ultimately demolished, leaving the City of Moore without a hospital. Two elementary schools in the Moore Public School District were destroyed and several other schools were damaged, including the district administration building. Seven students were killed in one of the buildings that collapsed at Plaza Towers Elementary School. The school district canceled classes through the end of the school year (which had been scheduled to end on May 23, 2013).

\subsection{Overview and Scope of NIST Preliminary Reconnaissance}

NIST is working to reduce the risk to buildings and communities posed by tornadoes through improvements to building, fire, and emergency communications standards, codes, and practices based upon findings from studies of these events. NIST has statutory authority to deploy teams of technical experts to conduct disaster studies under the NIST Organic Act (15 U.S.C. $\S 271$ et seq., as amended) and the National Windstorm Impact Reduction Act of 2004 (Pub. Law 108360; 118 Stat. 1668). NIST conducts two types of disaster studies: a Preliminary

\footnotetext{
${ }^{6}$ Oklahoma Department of Emergency Management (http://www.ok.gov/OEM/Emergencies_\&_Disasters/2013/20130518_Severe_Weather_Event/20130524_Situation_ Update_7.html).

${ }^{7}$ Oklahoma Insurance Department (http://www.ok.gov/triton/modules/newsroom/newsroom_article.php?id=157\&article id=11981).

8 City of Moore (http://www.cityofmoore.com/city-moore-assures-residents-water-safe).
} 
Reconnaissance, which is a field study at the disaster or failure site to gather information and to help determine if a technical investigation is warranted; and a Technical Investigation, which is a fact-finding study that may include an assessment of the safety and performance of buildings and infrastructure, associated hazard(s), and/or emergency response and evacuation procedures and will likely result in recommendations for improvements to standards, codes, and practices and/or new knowledge. ${ }^{9}$

At the time of the May 20, 2013, Newcastle-Moore tornado, NIST was nearing completion of its technical investigation ${ }^{10}$ of the EF-5 tornado that struck Joplin, Missouri on May 22, 2011. The decision was made by NIST to conduct a Preliminary Reconnaissance of the Newcastle-Moore tornado, to identify any information that might be relevant to certain aspects of the ongoing Joplin tornado investigation. NIST, in cooperation with the NOAA's National Severe Storms Laboratory (NSSL), deployed a team to conduct a Preliminary Reconnaissance of the tornado that struck Moore and parts of Newcastle and southern Oklahoma City, Oklahoma on May 20, 2013.

The Preliminary Reconnaissance team consisted of three researchers from NIST's Engineering Laboratory (EL), with expertise in disaster sociology and structural, wind, and fire protection engineering, and a researcher from NOAA's NSSL, with expertise in severe storm predictions and warnings. All team members were experienced in conducting post-disaster studies following tornadoes and other hazards. The team collected data in Moore from May 22 through May 24, 2013.

The objectives of the Preliminary Reconnaissance were to:

1. Collect data and information on the performance of the emergency communications systems immediately prior to and during the tornado; and

2. Collect data and information on the response of critical and educational facilities (specifically, the Moore Medical Center and Briarwood and Plaza Towers Elementary Schools) to the tornado, including emergency operations, the physical performance of the buildings and designated safe areas, and life safety outcomes.

The scope of the reconnaissance was limited, defined to support the nearly completed NIST technical investigation of the Joplin tornado. Data collected during the Moore reconnaissance support two of the five objectives of the Joplin study.

The reconnaissance team documented the physical damage to understand the physical performance of building and designated safe areas, as well as life safety outcomes. In addition, NIST interviewed staff at each facility to collect information on the emergency response. Officials from the City of Moore, NWS, the Moore Public School District, and the Moore Medical Center were also interviewed to gather information and data on emergency plans, warnings, and emergency response. The team interviewed first responders from the City of Moore and other communities (deployed to Moore for mutual aid) to collect information on

\footnotetext{
${ }^{9}$ NIST (http://www.nist.gov/el/disasterstudies/about.cfm).

${ }^{10}$ See http://www.nist.gov/el/disasterstudies/weather/joplin tornado_2011.cfm for information on the NIST investigation of the Joplin tornado.
} 
fatalities, injuries and rescues at the schools. Meetings were also held with NWS and NSSL to collect meteorological information and data on tornado damage and to document warning dissemination methodology.

NIST received considerable cooperation and information from Federal, State, and local authorities and the private sector. Local authorities providing information include Moore Emergency Management, Moore Community Development Department, Moore Fire Department, Moore Police Department, Moore Public School District, Oklahoma City Clerk, Oklahoma City Fire Department, and mutual aid first responders from the Tulsa Fire Department and the Weatherford Fire Department. State authorities providing information include the Oklahoma Department of Insurance. Federal authorities providing information include NOAA, NSSL and NWS WFO in Norman, Oklahoma. Private sector organizations providing information include the Norman Regional Health System, JHBR Architecture, and Bearing Tree Land Surveying.

Collected data include: 1) meteorological information; 2) warning information; 3) emergency communications procedures for the City of Moore and actions on May 20, 2013; 4) emergency communications and response plans for the specific facilities studied, including identified refuge locations within buildings; 5) ground and aerial photographs of buildings damaged by the tornado; 6) building plans; and 7) interviews with emergency management officials, building officials, first responders, school teachers and administrators, and hospital officials.

\subsection{Organization of Report}

This report presents information and observations from the NIST Preliminary Reconnaissance of the May 20, 2013, Newcastle-Moore tornado. Chapter 2 provides a description of the tornado and wind field. Chapter 3 presents information on the City of Moore's emergency communications systems and procedures, and warning information transmitted to the public by NWS and the City of Moore in the time leading up to and during the tornado. For the surveyed facilities, Chapter 4 first describes each facility and its pre-event emergency plans and procedures, and then recounts the specific actions taken by building occupants in response to the tornado, the damage caused by the tornado, and life safety outcomes. Chapter 5 presents observations on the performance of the emergency communications system during the Newcastle-Moore tornado, and observations on the emergency operations, the physical performance of buildings and their designated safe areas, and life safety outcomes at the three surveyed facilities. 


\section{CHAPTER 2. THE TORNADO}

\subsection{Moore Tornado History and Preparedness}

The City of Moore (population 57,810) has experienced several strong tornadoes in the last 15 years that traversed similar tracks through the central parts of the city. On October 4, 1998, an F-2 tornado ${ }^{11}$ briefly touched down in central Moore, traversing 3 miles. ${ }^{12}$ That tornado was part of the largest autumnal outbreak of tornadoes ever recorded in Oklahoma. On May 3, 1999, a long-track tornado touched down at $6: 23 \mathrm{pm}$ in the Bridge Creek, Oklahoma area. ${ }^{13}$ That tornado quickly strengthened into an F-4 storm, and gradually reached F-5 intensity after traveling 6.5 miles. Throughout its one hour and 25 minutes on the ground, the tornado covered 38 miles and caused \$1 billion (1999 USD) in damage. The 1999 tornado was responsible for 36 fatalities and 583 injuries.

Another strong tornado (F-4) touched down at 5:00 pm on May 8, 2003, on the west side of Moore. This storm was part of a large-scale outbreak that included 401 tornado reports in 19 states and 1 Canadian province. More severe weather broke out that week than any other week in U.S. history. In Moore, the May 8 storm crossed Interstate 35 and continued east to near Tinker Air Force Base, and also affected the cities of Midwest City and Choctaw, Oklahoma. ${ }^{14}$ That tornado caused $\$ 160$ million worth of damage (2003 USD), 89 injuries, but no fatalities. On May 10, 2010, an EF-4 tornado crossed the southern part of Moore, killing 2 and injuring 49 along its 24 -mile path from north Norman, Oklahoma to Harrah, Oklahoma. ${ }^{15}$

While research has shown that high false alarm rates can contribute to complacency by the public in response to warnings (Simmons and Sutter 2011), the false alarm rate for official tornado warnings in Moore in recent years was considerably lower than the national average. During the era of storm-based warning polygons (as opposed to earlier county-wide warnings), between October 2007 and May 19, 2013, 16 official tornado warnings were issued for all or some parts of Moore. Twelve of the 16 official tornado warnings were followed by verified tornadoes. This yielded a false alarm rate for the Moore area of 25 percent ( 4 false alarms out of 16 warnings), compared to the national average false alarm rate of 74 percent for 2010 .

Following the 1999 F-5 tornado, the State of Oklahoma and the Federal Emergency Management Agency (FEMA) developed an incentive program to assist homeowners with construction of storm shelters in houses that were being built or rebuilt after the tornado, using recently published FEMA design guidance. ${ }^{16}$ Over 3,000 residential shelters have been constructed in Moore and were registered with the City at the time of the tornado, perhaps the highest number

\footnotetext{
${ }^{11}$ The NWS used the Fujita Scale (F Scale) to rate tornado intensity until 2007, when the Enhanced Fujita Scale (EF Scale) was adopted. See section 2.3 of this report for more information.

${ }^{12}$ NWS (http://www.srh.noaa.gov/oun/?n=events-19981004).

${ }^{13}$ NWS (http://www.srh.noaa.gov/oun/?n=events-19990503).

${ }^{14}$ NWS (http://www.srh.noaa.gov/oun/?n=events-20030508).

${ }_{15}$ NWS (http://www.srh.noaa.gov/oun/?n=tornadodata-city-moore).

${ }^{16}$ National Storm Shelter Association (http://aln.coe.ttu.edu/nssa-new/Origins.php).
} 
of residential shelters per capita in the U.S. ${ }^{17}$ In contrast, the City of Moore has no public or community tornado shelters; its strategy is to recommend shelter-in-place, except for occupants in mobile homes, ${ }^{18}$ who are advised go to a substantial structure. ${ }^{19}$ The City's stated rationale is twofold: there is no public building in Moore which has a suitable location for a shelter; and there is less overall risk to shelter-in-place in a reasonably well-constructed residence (considering available warning time, travel time to a shelter, traffic, and other factors).

As part of its public preparedness information, the City of Moore has a list of frequently asked questions and answers concerning sheltering from storms on its webpage. An individual is advised to seek shelter where he/she is already located, as close to or as far below ground level as possible. Also, Moore recommends that individuals go to the center of the building away from windows and to place as many barriers as possible between the outside windows and the individual, using such items as blankets, mattresses, coats, bicycle/motorcycle helmets, etc. Those in mobile homes or motor vehicles are advised to find the nearest building that can provide shelter and remain there until the tornado passes. $^{20}$

At the time of the Newcastle-Moore tornado, Moore had adopted the 2009 International Code Council (ICC) International Building Code or IBC (ICC, 2009a) and the 2009 International Residential Code for One- and Two-Family Dwelling or IRC (ICC 2009b). Installation of storm shelters in homes or other buildings is strictly voluntary; neither the national model building codes adopted by Moore nor local amendments require storm shelters. Tornadoes are not explicitly considered in either the 2009 IBC or 2009 IRC for any types of buildings, except storm shelters. Although design wind speeds required by those codes are in the range of EF-1 tornadoes, the codes do not address potentially greater lateral forces and uplift forces on the roof in tornadoes compared to other types of windstorms (Haan et al. 2010), and do not address windborne debris, which is a significant contributor to building damage in tornadoes (FEMA 2012).

\subsection{Meteorological Description}

The May 20, 2013, Newcastle-Moore tornado was part of a larger outbreak of severe weather that affected the central United States on May 18-20, 2013. A shift in the synoptic weather pattern over the Midwest U.S. beginning May 18 brought a strong jet stream at mid levels superimposed on a near surface southerly flow of warm, moist air from the Gulf of Mexico. Severe convective storms, many with embedded tornadoes, developed during the late afternoon of May 18, producing 16 tornadoes in Kansas and Nebraska. On May 19, storms again developed in the late afternoon producing 29 tornadoes in the Midwest U.S. (8 in Oklahoma, including a strong EF-3 near Shawnee, Oklahoma, just east of Oklahoma City). Another outbreak of strong storms on May 20 produced 32 tornadoes in the Midwest U.S., including 8 in Oklahoma, the most intense of which was the Newcastle-Moore tornado.

\footnotetext{
17 Tulsa World

(http://www.tulsaworld.com/article.aspx/Moore_residents_learn_from_past_regarding_tornadoes/20130525_11_A1 CUTLIN869479?subj=1).

${ }_{18}$ City of Moore (http://www.cityofmoore.com/storm-shelters).

${ }^{19}$ City of Moore (http://www.cityofmoore.com/severe-weather-safety).

${ }^{20}$ City of Moore (http://www.cityofmoore.com/uploaded/File/ShelteringFAQ(FINAL).pdf ).
} 
The initial indication that central Oklahoma was at risk for severe storms and possible strong tornadoes on Monday, May 20 was NOAA/NWS/SPC's Convective Outlook that was issued on Wednesday May 15, at 5:00 AM CDT, based on a forecast of greater instability and wind shear for Sunday and Monday over central and eastern Oklahoma. SPC issued a probabilistic tornado outlook at 1:17 AM CDT on May 20 that narrowed the precise location of highest risk to central Oklahoma (Figure 2-1). The Convective Outlook issued at 10:00 AM CDT on May 20 pinned the timing down further, indicating peak hours for severe weather, including tornadoes, would be between $3 \mathrm{pm}$ and $8 \mathrm{pm}$.

In response to these outlooks, and further monitoring of the evolution of the large-scale environment, particular morning soundings of convective instability and wind shear, forecasters from NWS Norman forecast office issued a tornado watch (\#191) at 1:10 PM CDT on Monday May 20 for a large swath of central Oklahoma until 10:00 PM CDT, including Cleveland and $\mathrm{McClain}$ counties that were eventually affected by the tornado. Development of convective storms, which began around 2:00 PM CDT, was detected by the NWS Doppler radar in central Oklahoma (called "KTLX") along a weak cold front and dryline just west of the Oklahoma City metro area, and extending southwest to extreme southwest Oklahoma. As those convective storms developed further, NWS Norman forecast office issued a severe thunderstorm warning at 2:12 PM CDT. A strong circulation signature was seen in the radial velocity data (a cyclonic or counterclockwise rotation indicative of a mesocyclone at low levels) at about 2:35 PM CDT, and a tornado warning was issued (Figure 2-2) at 2:40 PM CDT. The warning polygon included Moore, Newcastle, southern Oklahoma City and northern Norman.

Based on the sudden strengthening of the radar-observed mesocyclone circulation seen in the radar radial velocity data (a "debris ball" or high reflectivity zone near the tip of the hook echo; Figure 2-2) as well as storm spotter reports indicating a funnel cloud reaching the ground at 2:56 PM CDT, NWS Norman forecast office issued a tornado emergency warning, indicating an extremely strong tornado hazard from this storm, at 3:01 PM CDT.

The first real-time confirmation of a tornado on the ground came at 2:56 PM CDT, just west of the Canadian River in the rural northwest area of the City of Newcastle, from spotter reports and observations from a television station helicopter. ${ }^{21}$ The storm crossed the Canadian River around 3:00 PM CDT, and then began to affect the more heavily populated area of Moore. The area of western Moore (where Briarwood and Plaza Towers Elementary Schools and the Moore Medical Center are located) was affected by the tornado starting about 3:15-3:20 PM CDT (see Figure 23). The tornado's path followed a general east-northeast direction, but veered sharply to the north as it approached Interstate Highway 35 (I-35) and struck the Moore Medical Center. It briefly turned east-southeast as it crossed I-35, then resumed its general east-northeast path, passing through mostly residential neighborhoods. It then struck the Highland East Junior High School, located a mile and a half due east of the Moore Medical Center, where it destroyed the

\footnotetext{
${ }^{21}$ Damage survey teams sent out the next day, a joint effort by NOAA's NWS and NSSL, documented evidence of damage farther west than the position determined by radar at 2:56 PM. The NWS later identified this damage being caused by a separate, short-lived EF-0 tornado, which touched down near 2:45 PM CDT about 4.4 miles west of the small City of Newcastle, Oklahoma.
} 


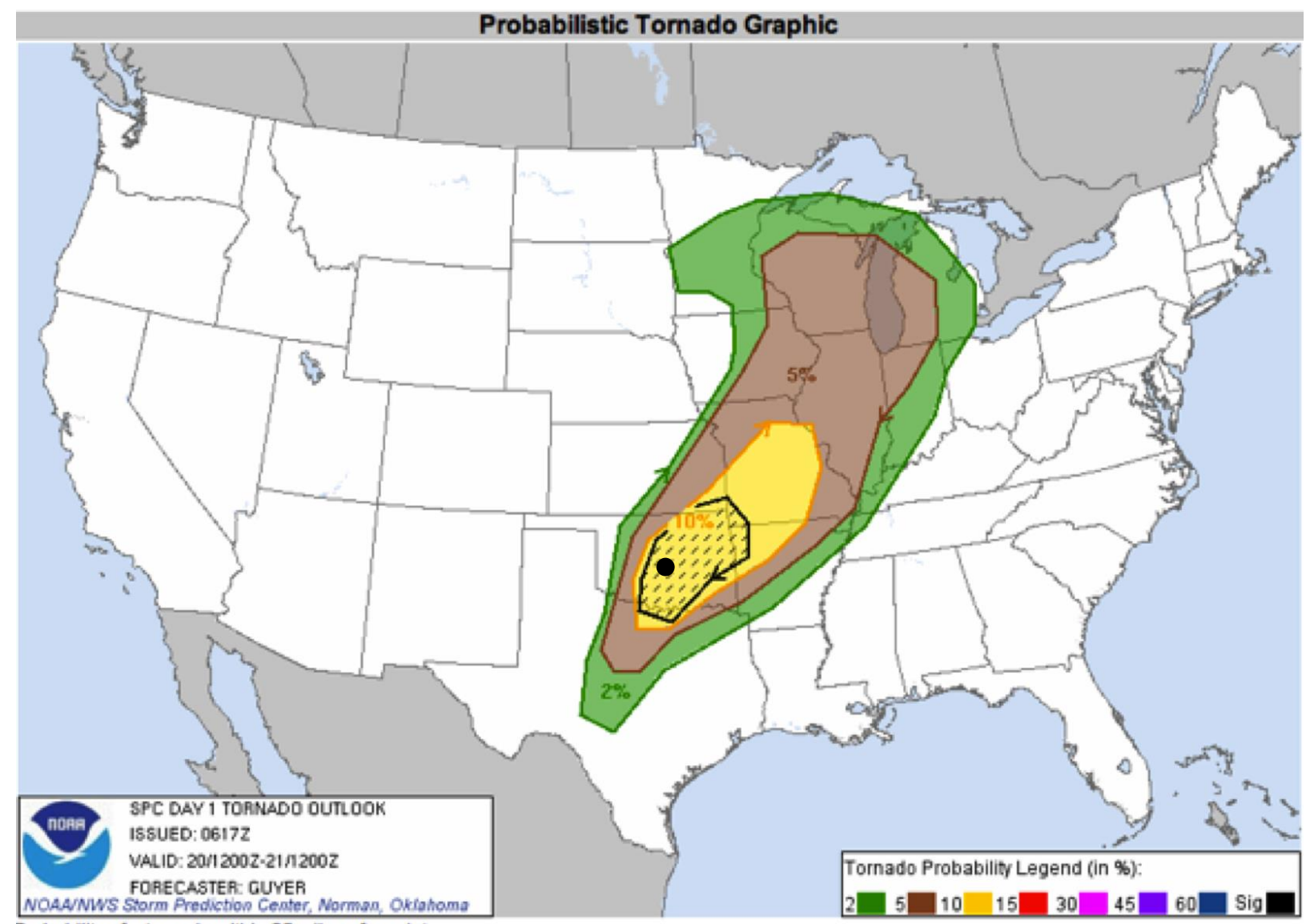

Probability of a tornado within 25 miles of a point.

Hatched Area: $10 \%$ or greater probability of EF2 - EF5 tornadoes within 25 miles of a point.

Source: NOAA/NWS. Enhancements by NIST.

Figure 2-1. NOAA/NWS/SPC Convective outlook for Monday May 20, 2013 issued at 1:17 AM CDT May 20, 2013, showing highest risk for EF-2 - EF-5 tornadoes to be central Oklahoma. The black dot indicates the approximate location of Moore, OK.

gymnasium building, damaged the school building, and damaged the nearby Moore School Board's Administration Service Center Building. The tornado eventually dissipated 4.8 miles east of Moore at about 3:35 PM CDT, for a total path length of about14 miles. ${ }^{22}$ The average forward speed of the tornado during its 39 minutes on the ground was approximately $21.5 \mathrm{mph}$.

Times associated with passage of the center of the tornado at several locations along the track were estimated using data from the NWS radar located approximately 12 miles east of Moore (call letters KTLX) and shown in Figure 2-3. Given the size of the tornado and its forward speed, EF-0 and greater winds would typically have begun at these locations 1 to 2 minutes prior to the indicated time and lasted 1 to 2 minutes after the indicated time. Therefore, the duration of EF-0 or greater winds at any point along the centerline of the track would have typically been 2 to 4 minutes. The tornado was relatively close to the radar (19 miles to 6 miles as it tracked west to

${ }^{22}$ NWS (http://www.srh.noaa.gov/oun/?n=events-20130520). 

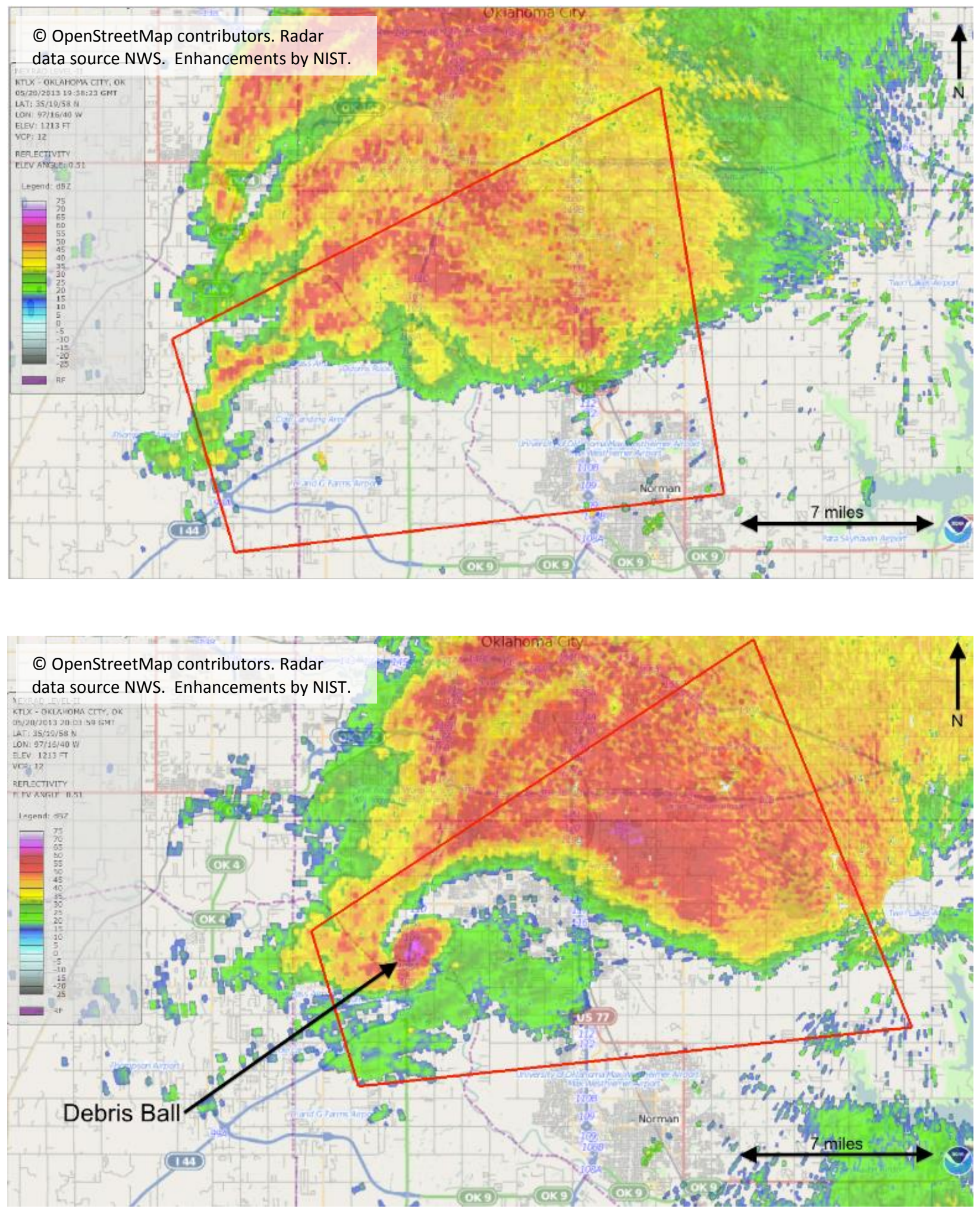

Figure 2-2. Storm-based tornado warning polygon (red lines) issued at 2:40 PM CDT Monday May 20, 2013 (top) and tornado emergency polygon issued at 3:01 PM CDT (bottom). Background colors are radar reflectivity from the KTLX radar. 


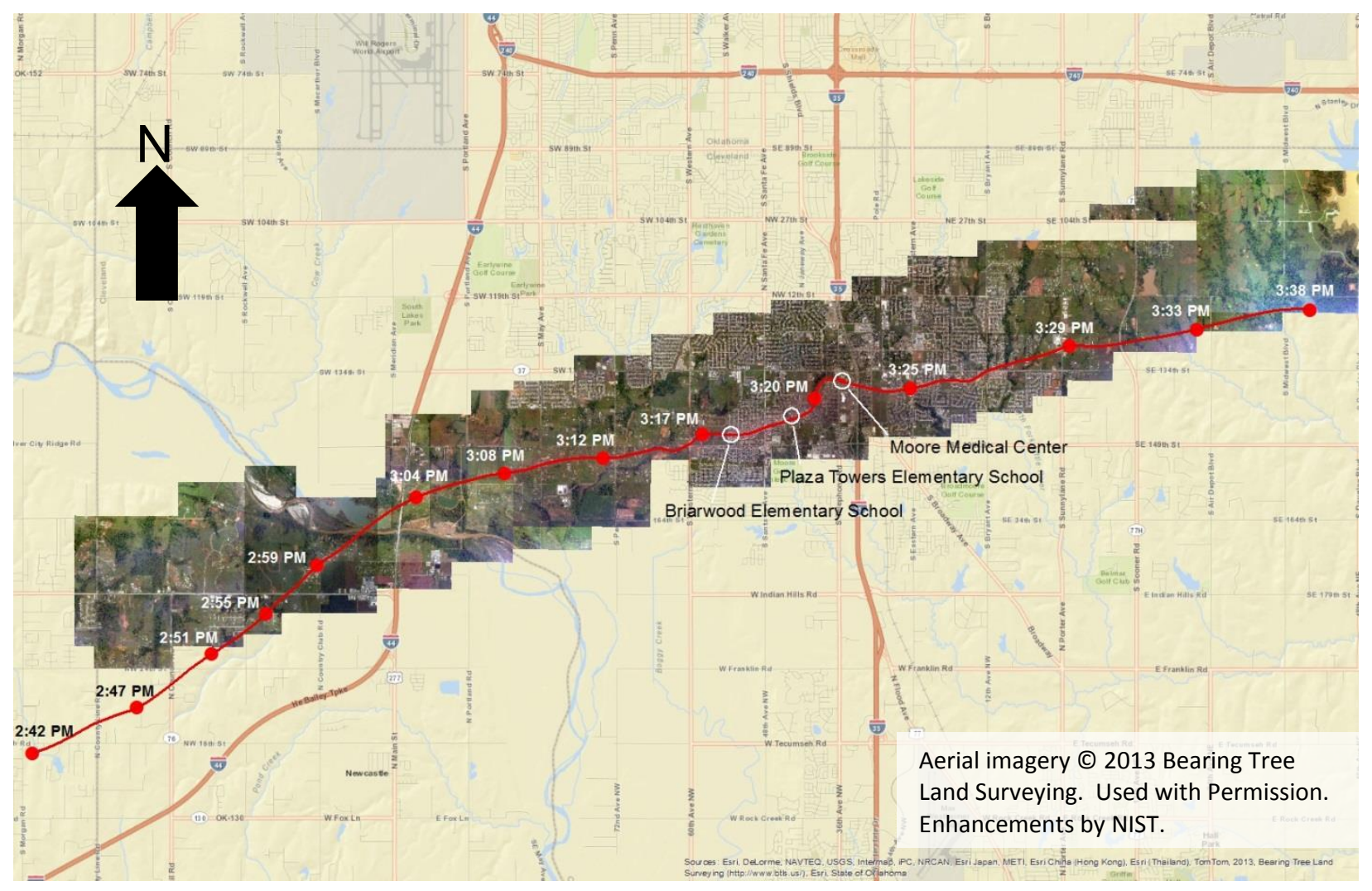

Figure 2-3. Estimated centerline of tornado damage path (in red) and locations of three critical and educational facilities surveyed. Tornado locations and times estimated from NWS radar data are also shown (red dots; every 5 minutes).

about $1500 \mathrm{ft}$ to about $300 \mathrm{ft}$ above the ground. This relatively low beam height, combined with the predominantly vertical orientation of the funnel visible in the news helicopter video of the storm, provides considerable support for the reliability of the timings, since the radar track closely matched the tornado ground track.

\subsection{Estimated Wind Speeds and Observed Damage}

There were no known direct measurements of near-surface wind speeds in the Newcastle-Moore tornado. Wind speeds were however, estimated indirectly by the NWS using the EF Scale, ${ }^{23}$ which provides a correlation between observed damage and wind speed. Wind speed ranges associated with EF numbers are shown in Table 2-1, and are defined as three-second peak gust wind speeds at a height of $33 \mathrm{ft}$ above the ground over open terrain.

\footnotetext{
${ }^{23}$ Enhanced-Fujita Scale, used by the NWS to assign ratings of EF0-EF5 to tornadoes (see http://www.spc.noaa.gov/efscale/).
} 
Table 2-1. Enhanced Fujita (EF) Scale

\begin{tabular}{|c|c|}
\hline EF Number & Wind Speed (mph) \\
\hline 0 & $65-85$ \\
\hline 1 & $86-110$ \\
\hline 2 & $111-135$ \\
\hline 3 & $136-165$ \\
\hline 4 & $166-200$ \\
\hline 5 & $200+$ \\
\hline
\end{tabular}

The damage path of the tornado is shown Figure 2-4, which also shows observed damage to different buildings, trees, and other damage indicators (shown as color coded triangles on the map, where the color indicates an EF-number based on a range of wind speeds derived from observed damage). The NWS/NSSL survey team documented damage at several hundred locations to determine the tornado track and intensity at different locations within the track. Figure 2-4 also shows estimates of overall damage swaths, including small pockets of EF-4 damage just west and just east of the Canadian River. The maximum damage path width was estimated as 1.1 miles. ${ }^{24}$ The main swath of EF-4 and above damage runs over three miles from about South Pennsylvania Avenue east-northeast to Interstate 35 (including Briarwood and Plaza Towers Elementary Schools and the Moore Medical Center), and then continues another two miles farther east.

As the tornado passed through Newcastle, southern parts of Oklahoma City, and Moore, it struck mainly residential buildings and neighborhoods. The initial touchdown location in northwest Newcastle is very rural; damage over the first few miles of the track was primarily to trees. Approaching the Canadian River, the tornado intensified and damaged homes and farm buildings, and destroyed two spans of the historic 1923 trestle bridge over the Canadian River (Figure 2-5). The damage to isolated residential buildings continued for several miles until crossing South Western Avenue, east of which the land use is more suburban, consisting primarily of single family residential subdivisions with neighborhood schools. At this point, the width of the tornado damage path was approximately one mile as defined by the width of the radar observed debris ball, with an estimated maximum intensity of EF-4 winds near the center.

Continuing east, the tornado then struck the Briarwood and Plaza Towers Elementary Schools, and destroyed the surrounding single family residential neighborhoods. Just west of Interstate 35, the tornado passed through a narrow commercial area, including the Moore Medical Center. Figure 2-6 shows an aerial view of the damage to the Moore Medical Center and adjacent residential neighborhood. The Warren Theater, located immediately south of the Moore Medical Center, experienced only minor damage. The tornado track width narrowed to approximately a

\footnotetext{
${ }^{24}$ NWS (http://www.srh.noaa.gov/oun/?n=events-20130520).
} 


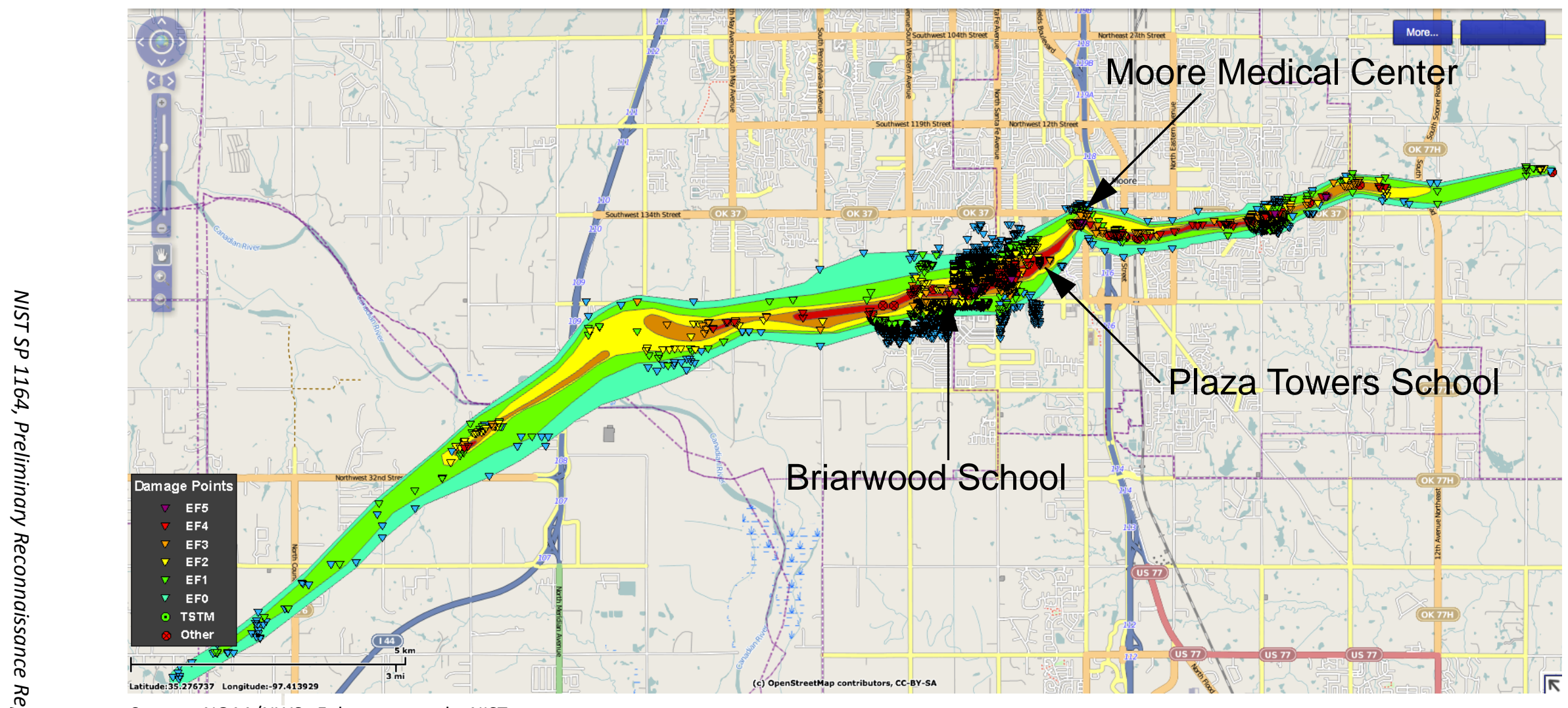

Source: NOAA/NWS. Enhancements by NIST.

Figure 2-4. Tornado damage path map showing point estimates of EF damage at specific locations (triangles) and swaths for EF-0 (turquoise), EF-1 (green), EF-2 (yellow), EF-3 (brown), EF-4 (red) and EF-5 (purple) intensity damage (data source NOAA/NWS). The locations where damage was evaluated represents only a small percentage of the number of buildings damaged or destroyed by the tornado. 


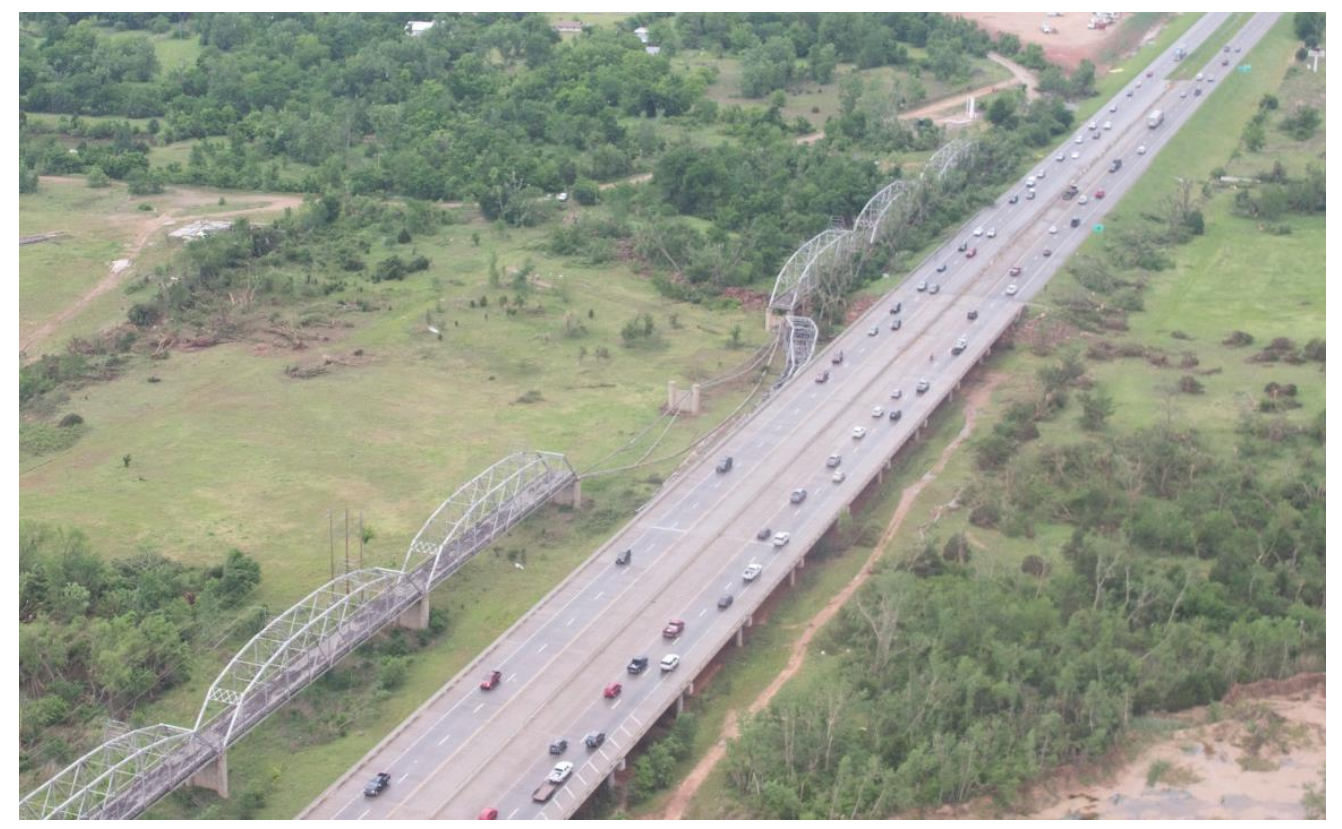

Source: NOAA.

Figure 2-5. Two spans of the historic trestle bridge on US 62 running parallel to I-44 were destroyed. The bridge had been closed to traffic since 1963 but carried water pipes across the Canadian River.

half mile after crossing Interstate 35, while retaining EF-4 winds. It continued on for six miles east of Interstate 35, as it slowly shrank and weakened while impacting primarily residential neighborhoods.

Figure 2-7 shows EF-rated damage by the NWS/NSSL survey teams in the vicinity of Briarwood and Plaza Towers Elementary Schools and the Moore Medical Center. NWS rated the Newcastle-Moore Tornado as an EF-5, with maximum wind speeds of 200-210 mph based on the damage observed at the Briarwood Elementary School. ${ }^{25}$ A multi-university team, comprised of researchers from the University of Alabama, Mississippi State University, and the University of Florida, estimated EF-4 damage at Briarwood Elementary School. ${ }^{26}$ Figure 2-7 shows EF-4 ratings assigned by NWS to numerous residences immediately east of Briarwood, and around the Plaza Towers Elementary School. EF-5 damage was observed at several single family residences immediately west of the Moore Medical Center (purple triangles in Fig. 2-7).

\footnotetext{
${ }^{25}$ NWS (http://www.srh.noaa.gov/oun/?n=events-20130520).

${ }^{26}$ University of Alabama (http://esridev.caps.ua.edu/MooreTornado/MooreTornado.html).
} 


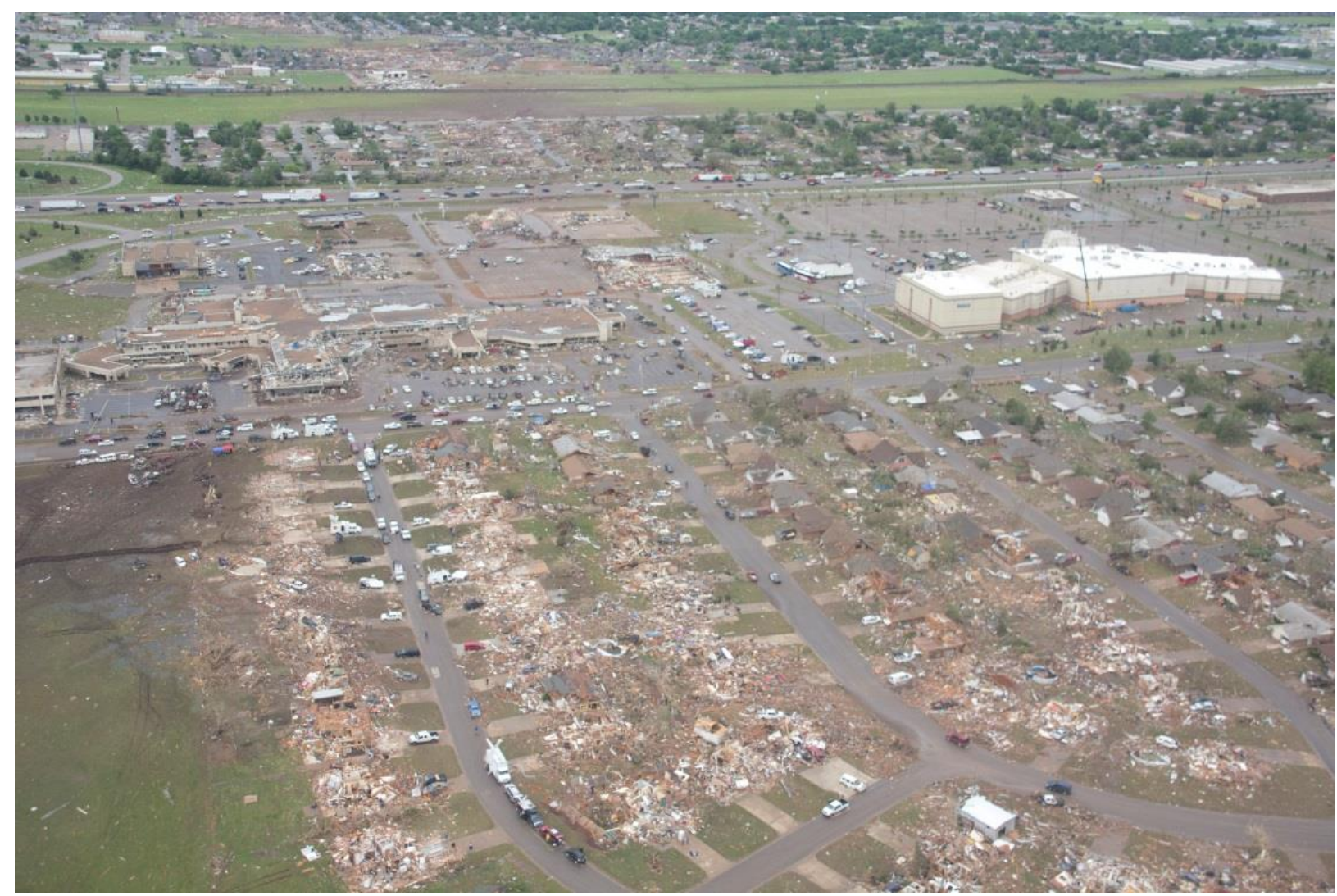

Source: NOAA.

Figure 2-6. Aerial view (facing east) of damage to the Moore Medical Center (upper left), with heavily damaged residential neighborhood immediately west of the Medical Center in the foreground. 


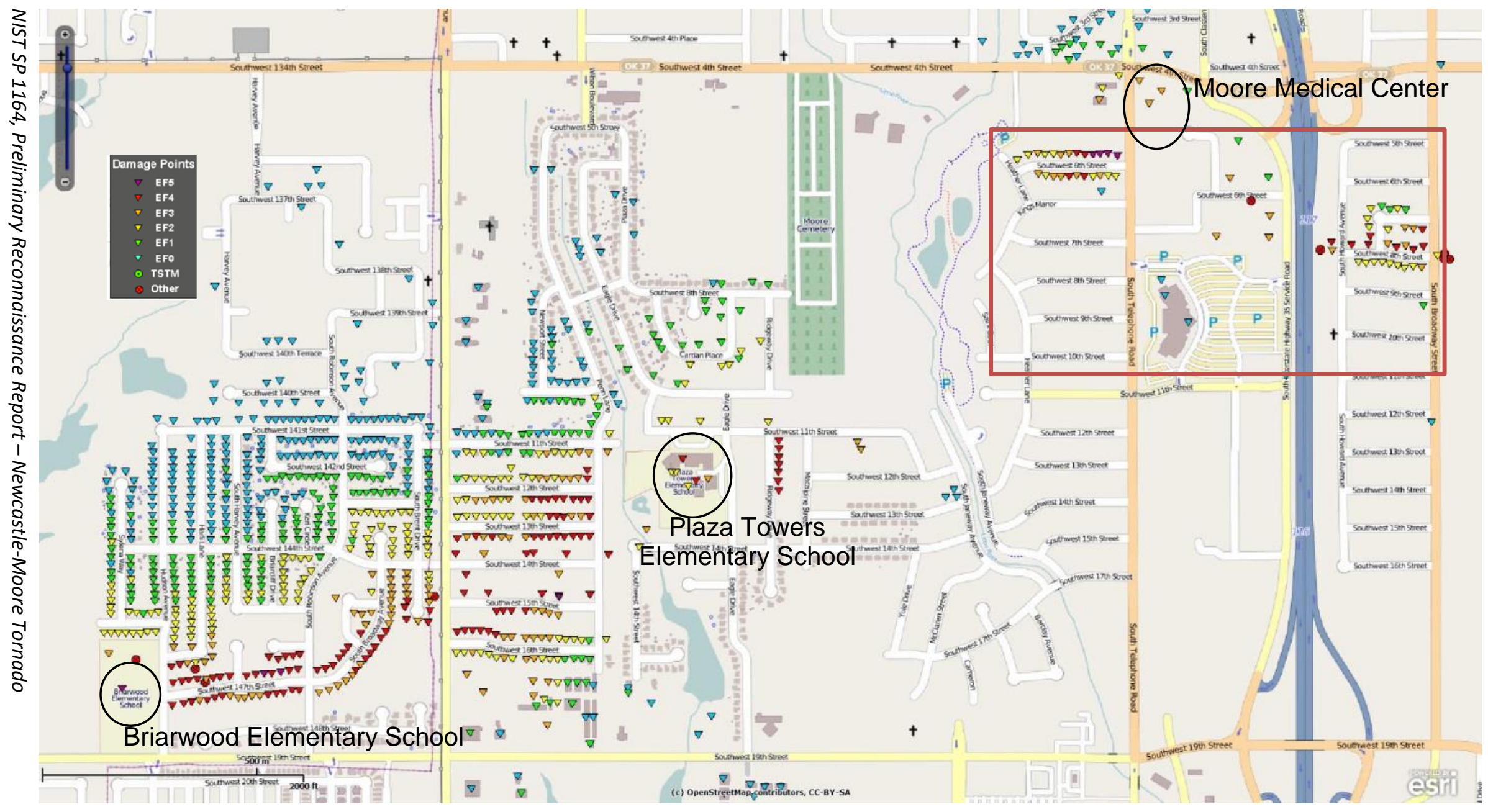

Source: NOAA/NWS. Enhancements by NIST.

Figure 2-7. EF-rated damage by NWS west of Interstate 35 in the vicinity of Briarwood and Plaza Tower Elementary Schools and the Moore Medical Center. The triangles indicate locations where damage was assessed and the triangle color indicates the EF number assigned to each assessment. The red rectangle shows the approximate field of view of the aerial photo in Figure 2-6. 
The page intentionally left blank. 


\section{CHAPTER 3. EMERGENCY COMMUNICATIONS IN MOORE, OKLAHOMA}

\subsection{Emergency Communications System}

\section{Outdoor Warning System}

The City of Moore's outdoor warning system is comprised of 36 sirens which are capable of producing alerting tones as well as both pre-recorded and live voice announcements. The locations of these sirens are shown in Figure 3-1. According to the City of Moore Emergency Manager, ${ }^{27}$ the sirens may be sounded for other impending dangers but their activation is usually reserved for tornadoes. The sirens in Moore are only meant to alert/warn those located outdoors and are used to indicate the urgent need to take shelter.

\section{Emergency Communications}

The City of Moore also has a "Code Red" Mass Notification System that sends emails, text messages, and pre-recorded messages to phone numbers within a specified area. Additionally, many websites, such as the Homeland Security Alerting System, provide warning notifications, and a number of government and privately run applications will email crucial alerts to their subscribers (City of Moore, 2012).

Furthermore, NOAA Weather Radio and Commercial Television will interrupt regular programming to inform the Moore community about exigent emergencies, such as an approaching tornado (City of Moore, 2012). Although television and radio broadcasts are heavily relied upon, Smartphone Apps are often used as an auxiliary source for weather alerts (Sistek, 2013).

\section{Warning Initiation}

The Emergency Management Director, either alone or with the Police Chief, Fire Chief, City Manager, and/or scene Incident Commander, ascertains any intelligence acquired by the Emergency Operations Center (EOC) regarding impending danger to the City of Moore. If the threat is determined to be real and imminent, the appropriate emergency communication system is activated.

The Emergency Management Director has the final decision regarding the operation of the City's emergency warning systems. If the Emergency Management Director is unavailable, that responsibility is devolved as follows:

- Police Chief or acting Chief

- Fire Chief or acting Chief

- Senior on-duty Police Supervisor

- Senior on-duty Fire Assistant Chief

- Senior on-duty Communications Dispatcher (City of Moore, 2012)

\footnotetext{
${ }^{27}$ NIST Interview \#1 (City of Moore Director of Emergency Management).
} 


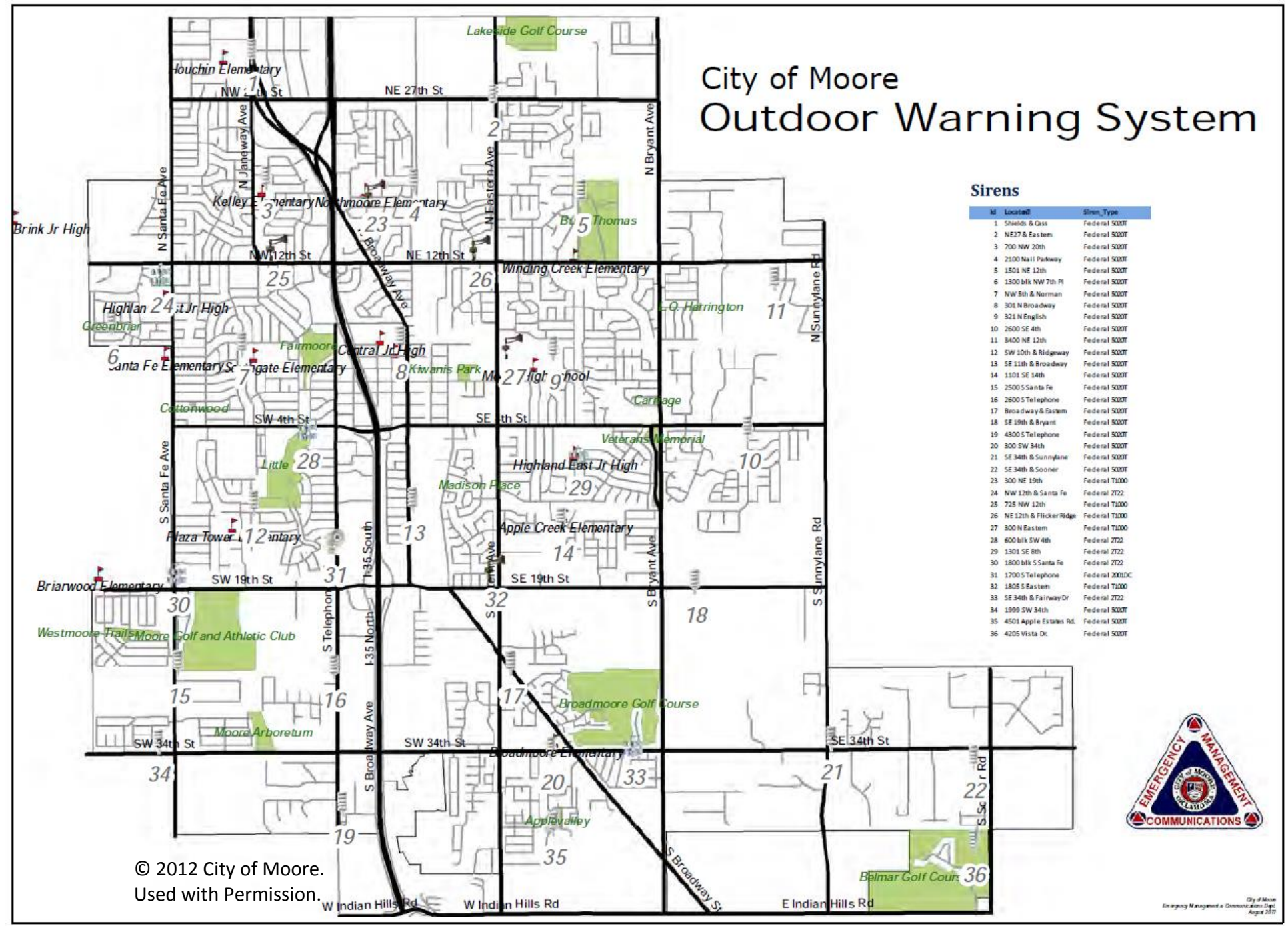

Figure 3-1. Map showing location of sirens in Moore. 


\section{Emergency Detection and Preparation}

Well-experienced in tornadic disasters, Moore has established an emergency operations plan and a weather-monitoring program. ${ }^{28}$ The NWS certified Moore as "StormReady" in 2001, and the City was most recently re-certified in $2012 .{ }^{29}$ Requirements of the program included maintaining a 24-hour EOC; having multiple methods to receive severe weather warnings and forecasts and to alert the public; promoting the importance of public readiness through community seminars; and maintaining a formal hazardous weather plan, which includes training severe weather spotters and holding emergency exercises. As a result of the tornado that occurred on May 3, 1999, Moore installed an additional 22 sirens and upgraded its 1970's-era outdoor warning system to new state-of-the-art sirens (Hauser 2013). Then, in 2011, additions were made resulting in the outdoor warning system used on May 20, 2013, which consisted of 36 sirens in total (CBS News 2013).

\section{Official Warnings}

The City of Moore also receives official or NWS-issued warning information. These official warnings are primarily disseminated to the population via NOAA Weather Radios, the Emergency Alert System, television and radio broadcasts (and associated mobile-based opt-in services), social media, and Internet-based sites, including the NWS website for the Norman WFO.

\subsection{Emergency Communications on May 20, 2013}

According to the NWS's Warning Coordination Meteorologist (WCM) in the Norman WFO, forecasters had been speaking about the possibility of severe weather for May 20, 2013 as early as May 15, 2013. Figure 3-2 displays the seven-day forecast provided by the Norman forecast office on Thursday, May 16, showing the potential for significant severe storms from Sunday (May 19) to Monday (May 20). A similar forecast was also issued on Friday, May 17.

NWS also issued Hazardous Weather Outlooks as early as 5:00 am CDT on Wednesday, May 15, 2013, that mentioned the possibility of severe weather for Monday, May 20, 2013 in the following way:

"Greater instability and wind shear will support severe storms on Sunday and Monday...mainly over the central and eastern portions of Oklahoma."

The Hazardous Weather Outlook issued on Thursday morning (May16, 2013) at 5:00 am CDT provided more detailed information...

"Greater instability and wind shear will support severe storms on Sunday through Tuesday...mainly over the central and eastern portions of Oklahoma. The latest forecast data indicates that significant severe weather will be possible...including destructive hail and tornadoes."

\footnotetext{
${ }^{28}$ NIST Interview \#1 (City of Moore Director of Emergency Management).

${ }^{29}$ City of Moore (http://www.cityofmoore.com/we-are-stormready).
} 


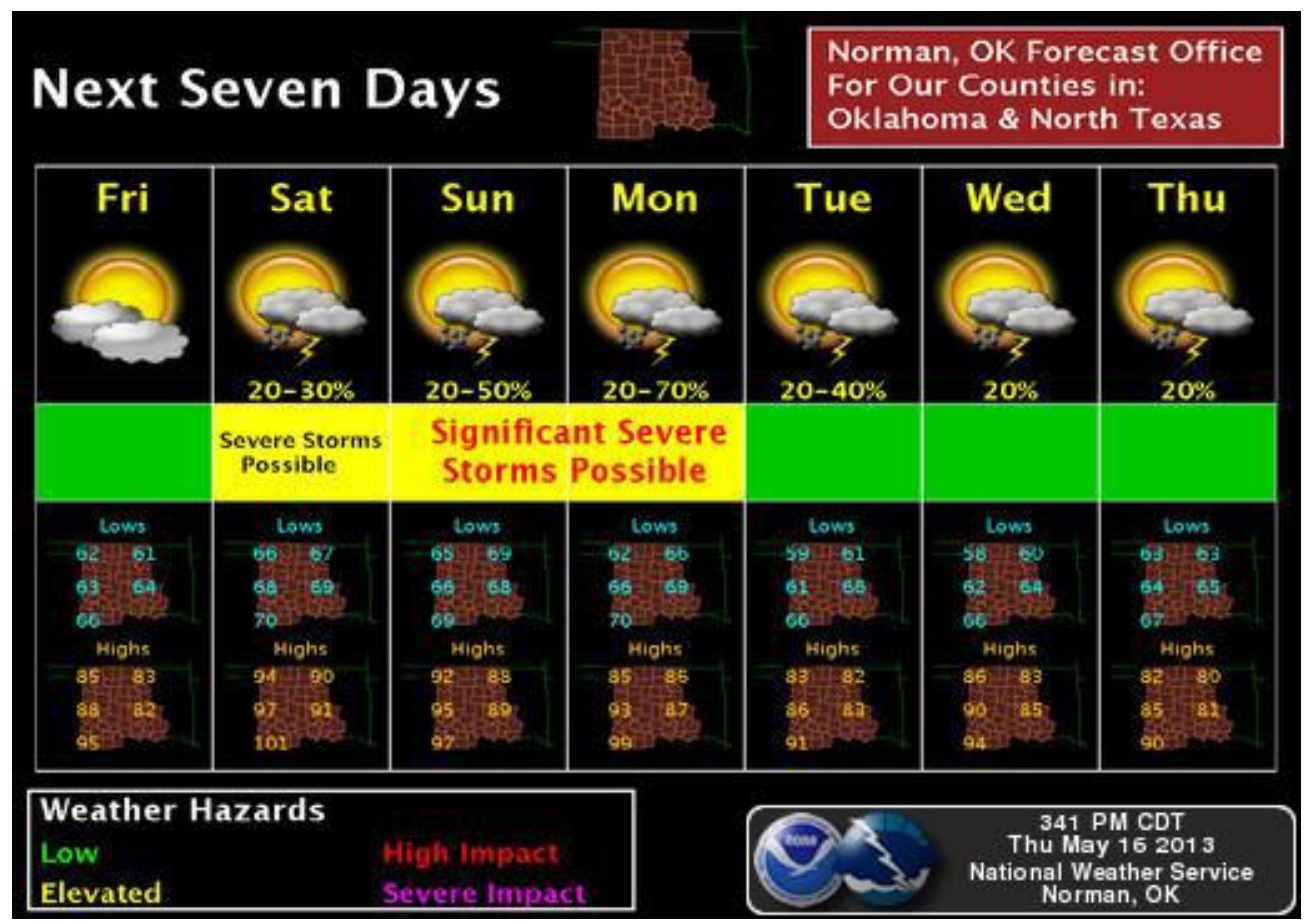

Source: NOAA/NWS.

Figure 3-2. Seven-day forecast published on Thursday, May 16, 2013, indicating 'Significant Severe Storms Possible' for May 19-20.

At 8:00 am CDT on May 20, 2013, in addition to disseminating Hazardous Weather Outlooks that day, the Norman WCM sent an email to his network of leaders inside and outside of Moore (i.e., approximately 400 people from 56 counties and 2 states, including emergency managers, school administrators and others) warning them about the possibility of severe weather later in the day, and the potential for serious issues if tornadic storms occurred during school dismissal time. An excerpt from the email reads as follows:

"We are going to be dealing with more significant storms today, including the potential for tornadoes and giant hail. The risk for tornadoes will be highest along and south of I-44, including the OKC metro area. We expect storms to develop a little earlier than yesterday, maybe as soon as 1-2 pm.

This is going to create serious issues if we have tornadic storms in the area at school dismissal time, and certainly during the afternoon drive time. Please be sure that schools in your area are aware of this risk and that they start thinking about what they will do if there are warnings at those critical times today."

Additionally, at 10:00 am CDT, the Norman WCM held a weather briefing, via an online webinar attended by over 100 emergency officials, school officials, and other community leaders. During this webinar, he reiterated statements made in his earlier email and noted that 
they were expecting storms earlier than usual (i.e., during the 2 to $4 \mathrm{pm}$ time-frame), which made him concerned about school dismissal and the potential risks to safety during this time period.

However, it was not until the afternoon that severe weather watches and warnings were issued by the WFO in Norman. The first official tornado-related emergency message was provided for Moore on May 20, 2013 at 1:10 pm CDT in the form of a Tornado Watch. Tornado Watch 191 was valid from 1:10 pm until 10:00 pm CDT for 30 counties in Oklahoma. One of those counties was Cleveland County, in which Moore is located.

At 2:12 pm CDT, the Norman WFO issued a severe thunderstorm warning for Northern Cleveland County in central Oklahoma, among other areas. As shown in Figure 3-3, Moore was almost directly in the center of that severe thunderstorm warning polygon.

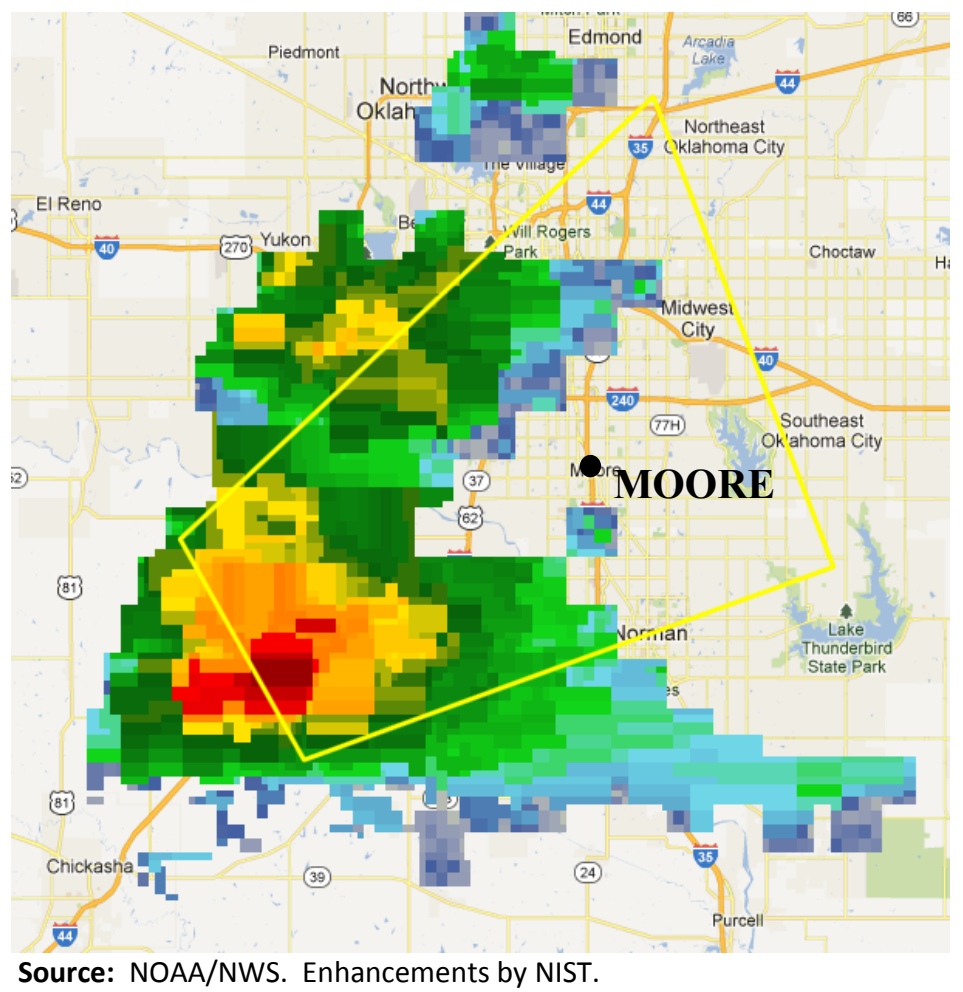

Figure 3-3. Severe thunderstorm warning polygon issued at 2:12 pm CDT, including Moore.

Approximately 30 minutes later, using radar data, a tornado warning was issued by the Norman WFO (at 2:40 pm CDT) that included Moore (see Figure 3-4). The warning was issued until 3:15 pm CDT, and the text provided in the warning was as follows:

* AT 238 PM CDT...NATIONAL WEATHER SERVICE METEOROLOGISTS DETECTED A SEVERE THUNDERSTORM CAPABLE OF PRODUCING A TORNADO. THIS DANGEROUS STORM WAS LOCATED NEAR NEWCASTLE...AND MOVING EAST AT 20 MPH. 


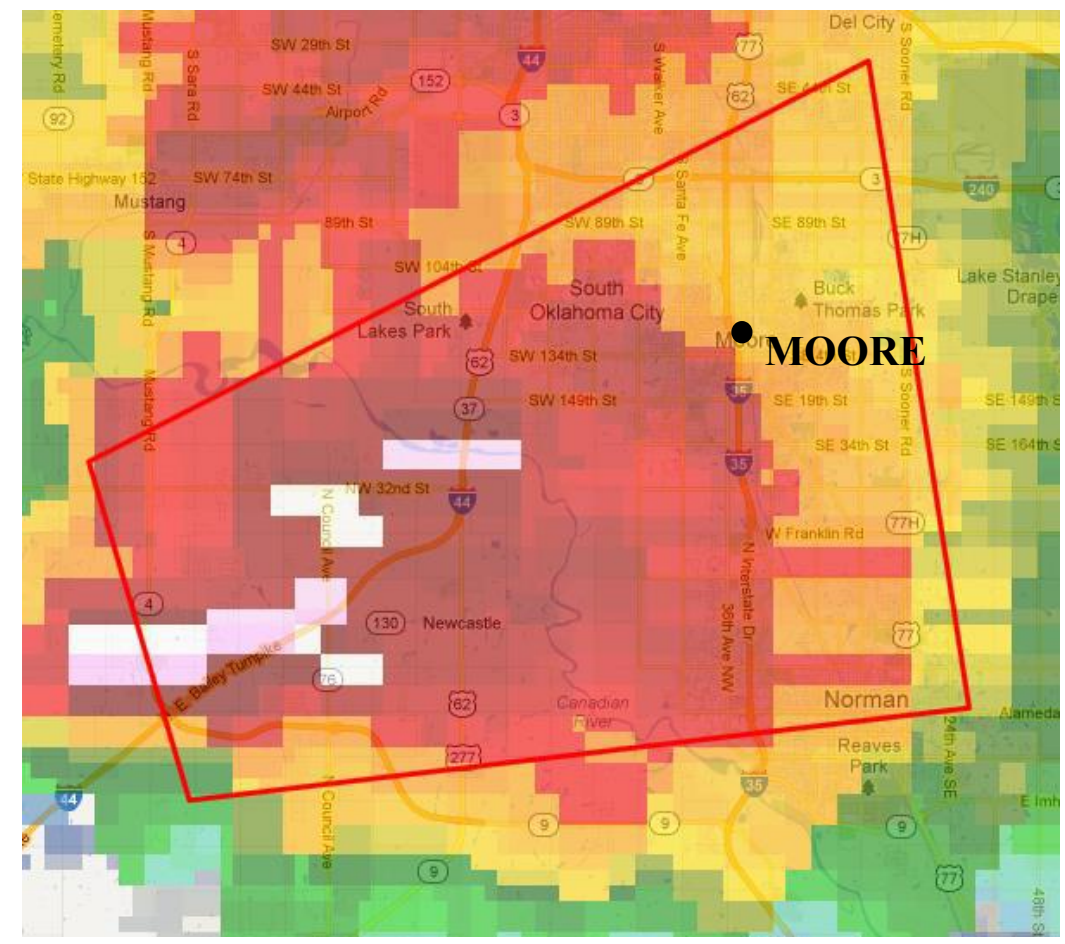

Source: NOAA/NWS. Enhancements by NIST.

Figure 3-4. Tornado warning polygon issued at 2:40 pm CDT, including Moore.

\section{IN ADDITION TO A TORNADO...LARGE DAMAGING HAIL UP TO GOLF BALL SIZE IS EXPECTED WITH THIS STORM. * LOCATIONS IMPACTED INCLUDE... NORMAN...MOORE...NEWCASTLE...BRIDGE CREEK AND VALLEY BROOK.}

The 2:40 pm CDT tornado warning prompted the Emergency Management (EM) Director from Moore to activate the outdoor siren (or alarm) system at 2:42:34 pm. The apparent two-minute time delay in communication of the first alarm following the WFO's warning, however, is not accurate. Rather, this difference is due to a lack of synchrony between the clock used to track the weather and the clock on the computer in the Moore EOC that activates the siren. The EM Director activated the sirens immediately following the 2:40 pm NWS tornado warning in the presence of and with approval from the City Manager. ${ }^{30}$

The Norman WFO identified the time of tornado formation to be 2:56 pm, based upon reports from ground chasers, helicopters, and additional observation from the damage survey team. At the same time, the outdoor siren system in Moore was activated again by the EM Director at 2:56:56 pm CDT.

\footnotetext{
30 NIST Interview \#1 (City of Moore Director of Emergency Management). Times shown in this report for all Moore siren soundings are as reported to NIST, but in actuality would have been slightly earlier due to the difference in computer clock timings.
} 
Approximately 5 minutes later, at 3:01 pm CDT, the Norman WFO issued a Tornado Emergency statement. ${ }^{31}$ The Tornado Emergency was in effect until 3:45 pm and contained the following information:

* AT 259 PM CDT...NATIONAL WEATHER SERVICE METEOROLOGISTS
AND STORM SPOTTERS WERE TRACKING A LARGE AND EXTREMELY
DANGEROUS TORNADO NEAR NEWCASTLE. DOPPLER RADAR
SHOWED THIS TORNADO MOVING NORTHEAST AT 20 MPH.
THIS IS A TORNADO EMERGENCY FOR MOORE AND SOUTH
OKLAHOMA CITY.
PRECAUTIONARY/PREPAREDNESS ACTIONS...
THIS IS AN EXTREMELY DANGEROUS AND LIFE THREATENING
SITUATION. IF YOU CANNOT GET UNDERGROUND GO TO A STORM
SHELTER OR AN INTERIOR ROOM OF A STURDY BUILDING NOW.

Subsequently, the sirens sounded in Moore four additional times, at 3:05:35 pm, 3:10:58 pm, 3:13:10 pm, and 3:20:18 pm CDT. Siren activation was based on Doppler radar images available in the EOC, reports of visual confirmation of the tornado from spotters and three local television broadcasts, and direct radio communications with the NWS. Each of the sirens produced a steady tone for a duration of three minutes. Moore's outdoor warning system is also capable of transmitting pre-recorded messages from its sirens. This feature was used only once, for the 3:10:58 pm activation, informing the Moore community that the tornado warning was still in effect. ${ }^{32}$ Also, the Norman WFO issued two additional tornado emergency statements at 3:16 $\mathrm{pm}$ and 3:23 pm CDT. According to the Norman WCM, the tornado actually moved into Moore at 3:16 pm CDT.

Based upon the tornado timeline and emergency communications timeline, outlined above, the time between the first official NWS warning and the tornado's contact with the ground, just west of the Canadian River in rural northwestern Newcastle was 16 minutes. For reference, the national average warning lead time for 2010 was 13 minutes. ${ }^{33}$ The time from the first tornado warning until the tornado entered the City of Moore was 36 minutes.

The NWS and Moore Emergency Management Department used social networking sites such as Twitter and Facebook to disseminate emergency information about the tornado (Bender 2013). The City of Moore can send messages to those that have "followed" any of the City's social media accounts (City of Moore 2012). Additionally, the WCM in Norman mentioned his aggressive use of social media to get word out about the Newcastle-Moore tornado. The development of the tweets and Facebook messages was completely freeform, as there was no specific guidance or templates available to use for emergencies, generally, or for tornadoes,

\footnotetext{
31 The warning terminology "Tornado Emergency" is reserved by the NWS for "exceedingly rare situations," and only where all of the following three conditions are met: (1) severe threat to human life is imminent or ongoing; (2) catastrophic damage is imminent or ongoing; and (3) reliable sources confirm tornado, either visual confirmation or radar imagery that strongly suggests the existence of a damaging tornado such as a debris ball signature (http://www.nws.noaa.gov/directives/sym/pd01005011curr.pdf).

${ }^{32}$ NIST Interview \#1 (City of Moore Director of Emergency Management).

${ }^{33}$ NOAA (http://www.noaa.gov/features/protecting/tornados101.html).
} 
specifically. The WCM created Twitter and Facebook messages using phrases such as "this is as bad as it gets" and identifying landmarks (e.g., the Warren Theater) in one of the tweets to ensure that individuals in the direct path of the tornado would take sheltering seriously. Also, to control the concept of retweeting (where any messages can be re-sent by any other member of Twitter), the tweets were manually time-stamped so that individuals would know when the tornado-related status updates had been disseminated.

There were some issues identified by the Norman WCM regarding the use of social media in a tornado emergency. While it is beneficial to provide building landmarks and/or cross streets in emergency messages, it was challenging to pinpoint the tornado's exact path . To capture geographic information, he relied on many information sources, including the television reports and tornado chasers. Also, due to the rapid formation and evolution of the tornado, the WCM rarely had time to respond to any incoming messages immediately before and during the storm.

Although the City of Moore had access to their "code red" mass notification system, it was not used on May 20, 2013. A spokesman for the City said that the sirens were decidedly more efficient means to communicate with the public than the "code red" mass notification system (Hauser 2013). 


\section{CHAPTER 4. BUILDING PERFORMANCE, EMERGENCY OPERATIONS, AND LIFE SAFETY OUTCOMES}

This chapter focuses on the emergency operations and consequences experienced by the two elementary schools and the medical center as a result of the Newcastle-Moore tornado. Details are provided on occupant response, building performance, and injuries and deaths for each of the three facilities.

\subsection{Introduction}

Three facilities were surveyed by the NIST Preliminary Reconnaissance team, two elementary schools (Briarwood and Plaza Towers) and the Moore Medical Center. Figure 4-1 shows an aerial photograph of these facilities and surroundings shortly after the tornado. All three were in close proximity to the estimated center of the tornado damage path (shown by the red line) in Figure 4-1. Briarwood Elementary was located in Oklahoma City, while Plaza Towers Elementary and Moore Medical Center were located in Moore, Oklahoma. Both elementary schools are part of the Moore Public School District. All three facilities were comprised of several individual low-rise buildings. The buildings at the two elementary schools were onestory in height, while the Moore Medical Center was a combination of adjoining one- and twostory structures.

Both the Moore Public School District and the Moore Medical Center have specific emergency action plans for tornadoes, including designated safe areas for each facility and procedures for monitoring and responding to tornadoes. A summary of the general tornado emergency procedures used by schools in the Moore Public School District and by the Moore Medical Center is provided in the Appendix.

On May 20, 2013, administrators in the Moore Public Schools Superintendent's office were paying close attention to the threat of severe weather all day. By 9:00 am CDT, the decision was made to cancel all afterschool activities. Morning kindergarten was released at 11:30 am CDT. Sometime between 1:00 and 1:30 pm CDT, the decision was made to shelter-in-place (i.e., hold all the students and faculty inside the school buildings and not run the busses).

New to the school district's policy, and initiated on May 20, 2013, was the rule that if parents did not have their children picked up by 2:00 pm, the students would be automatically sheltered in the schools where they were located (normal elementary school dismissal time was 3:00 pm). However, parents of children in Moore Public Schools that did arrive after 2:00 pm on May 20, 2013 were allowed to pick up their children, if so desired. ${ }^{34}$ Some family members arrived at schools so late in the storm that they perceived no other option than to shelter with their children at the school.

\footnotetext{
${ }^{34}$ NIST Interview \#20 (Assistant Superintendent, Moore Schools).
} 
According to the Assistant Superintendent of Moore Public Schools, at 2:15 pm CDT, the storms started to hit west of Newcastle. All schools (kindergarten through high school) were told to evacuate all people from the outbuildings (i.e., those buildings in which no designated shelter areas were identified) and move them into other buildings on the school campus. Around 2:40 pm CDT, when the first tornado warning was issued by NWS, the school district instructed all schools that everyone should move to their safety positions.

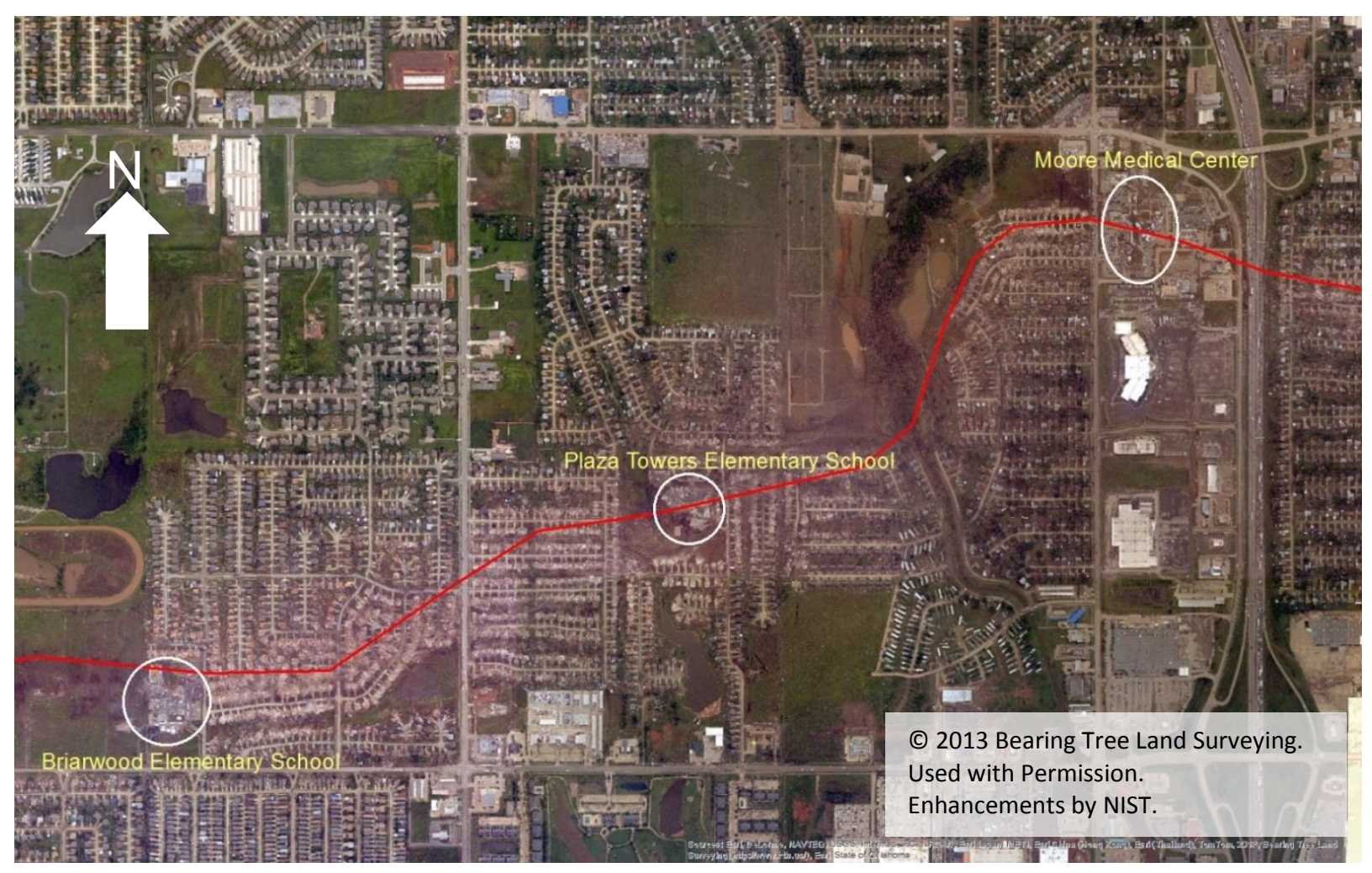

Figure 4-1. Aerial overview, after the tornado, showing NIST-surveyed facilities relative to the estimated center of the tornado damage path (red line).

\subsection{Plaza Towers Elementary School}

\section{Facility and Tornado Sheltering Plan Description}

Plaza Towers Elementary School was constructed in the 1970s with one original main classroom building. Later additions included a Gymnasium building, a new main classroom building (stand-alone), a Media building (connected to the original main classroom building), and four portable classroom buildings (see Figure 4-2). All Plaza Towers' buildings were one-story structures. Despite media reports to the contrary, none had a basement or below-ground level. The buildings were one of the following common structural systems:

- Box-type system (BTS) with reinforced concrete masonry unit (CMU) perimeter walls laterally braced by a metal roof system that consisted of wide-rib metal roof decks 
covered with rigid thermal insulation and supported by open-web steel roof joists (new main classroom building).

- Light steel frame (bolted W-shape beams and circular columns) supporting a metal roof system with perimeter reinforced CMU walls (original main classroom and Media buildings).

- Pre-engineered rigid steel frame cladded with perimeter reinforced CMU walls (Gymnasium building).

The school's tornado emergency procedures designate areas of safety in the original and new main classroom buildings (locations shown in Figure 4-3). Within the original main classroom building, students were primarily instructed to move from external classrooms into the interior hallway areas. Each classroom had a specific location within the main interior hallways where shelter should have been taken. Additionally, occupants of the Gymnasium building were instructed to travel to the original main classroom building for shelter (in the interior hallway). Occupants of the portable classroom buildings were also directed to move into the original main classroom building for shelter in the interior hallway. In the new main classroom building, individuals were instructed to shelter in the interior hallway and the girls and boys bathrooms.

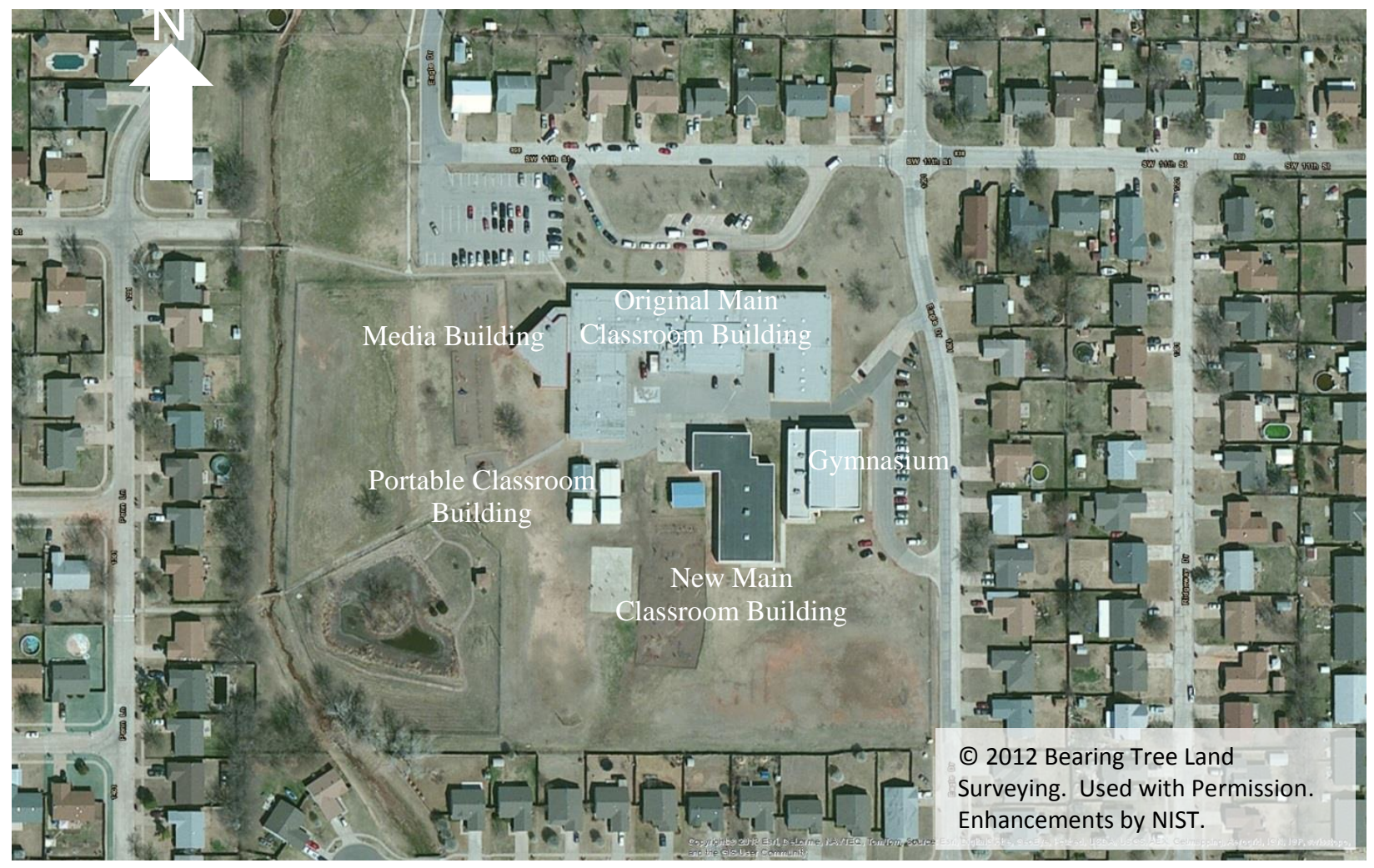

Figure 4-2. Aerial photograph of Plaza Towers Elementary School prior to the tornado. 


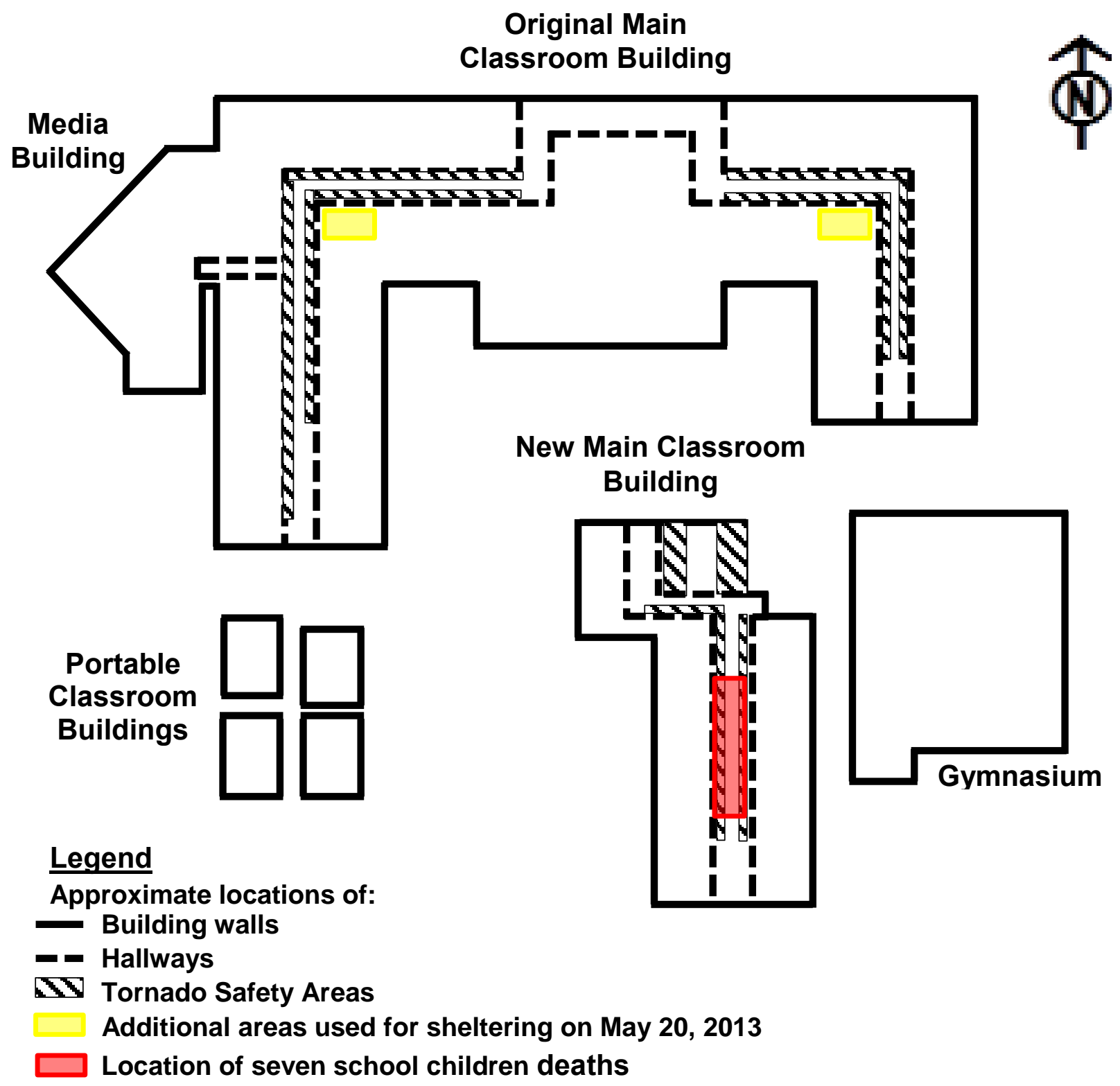

Figure 4-3. Designated areas of safety for tornadoes for the Plaza Towers Elementary School. The yellow shaded areas indicate the locations of bathrooms also used for shelter on May 20, 2013. The area shaded in red indicates where seven school children died.

Emergency Operations, Facility Performance, and Life Safety Outcomes

At Plaza Towers Elementary School, NIST obtained first-hand accounts of the emergency response from three teachers who were located on the northeast side of the original main classroom building. Before the tornado hit, teachers, school staff, and students received instructions to take cover, i.e., to initiate their tornado procedures, via the school-wide public address announcement system. Teachers then led their students to shelter in the designated locations, which included both internal hallways of the building (i.e., the north-to-south hallways and the east-to-west hallway as shown in Figure 4-3). The number of students within the Original 
Main Classroom Building was reduced, since many students had been picked up by family members earlier that day. ${ }^{35}$

Whereas media articles claimed that some students were bused from Plaza Towers before the tornado hit, teachers interviewed for this study disputed those claims. ${ }^{36}$ Some students were picked up by their families prior to the tornado strike, and all remaining students took shelter inside the elementary school. It was only after the tornado was over that students, teachers, and school staff walked to a nearby church.

As students and teachers in the original main classroom building remained in their shelter locations, another teacher was observing the tornado approaching from an exterior window of the school. ${ }^{37}$ As the skylights in this teacher's hallway (on the northeast corner of the original main classroom building) where the students were taking refuge began getting sucked up into the tornadic winds, this teacher instructed students and school staff to take refuge in the nearby bathrooms immediately. The teacher made this decision because the teacher felt that the hallways would not be safe enough for the children. The students and teachers in this group dispersed among the two main bathrooms and closet in the northeast section of this building, shown in yellow in Figure 4-3 (with 25 to 30 students and teachers in each bathroom, and more in a closet between the bathrooms) moments before the roof was blown off of the school. Overall, in the original main classroom building, staff, teachers and students ended up taking shelter in the hallways that ran east-west only (and not in the hallways that ran north-south) as well as the restrooms off of the east-west hallways. Minimal debris came down in the bathrooms and closet, but adjacent hallways were buried under several feet of debris, high enough that the teacher could stand on the debris and reach over the top of the wall to help extricate students from the bathrooms and closet. The debris in the hallway in the northwest part of the building was only 2 to $3 \mathrm{ft}$ deep, but also included a vehicle.

The buildings of Plaza Towers Elementary School sustained significant structural damage due to strong wind and debris impact loadings. Figures 4-4 and 4-5 show aerial views of Plaza Towers Elementary School shortly after the tornado hit. Following is a summary of the damage observed at this facility and related fatalities and injuries.

\footnotetext{
${ }^{35}$ NIST Interview \#19 (Teacher, Plaza Towers Elementary School).

${ }^{36}$ Ibid.

${ }^{37}$ NIST Interview \#13 (Teacher, Plaza Towers Elementary School).
} 


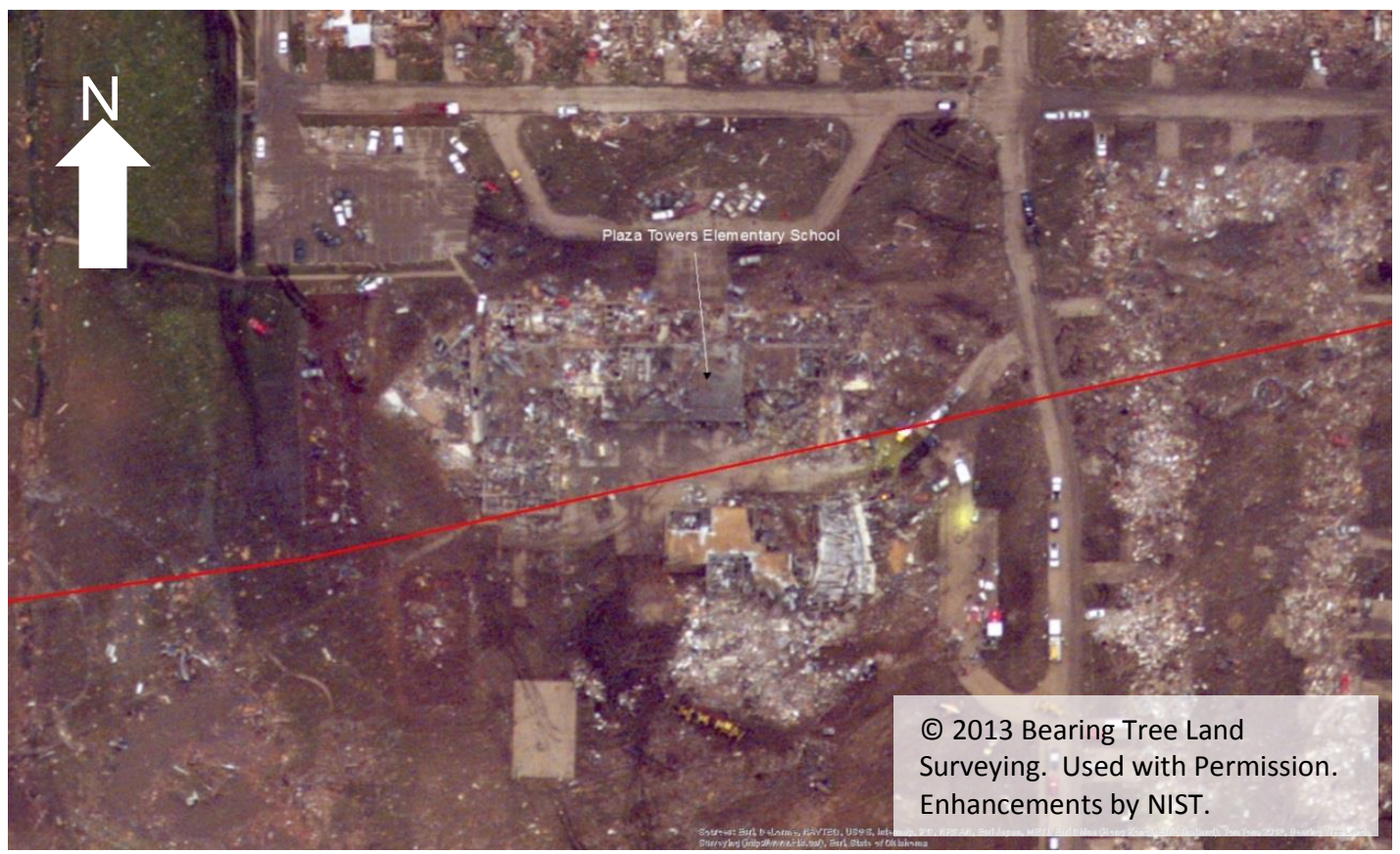

Figure 4-4. Aerial photograph of Plaza Towers Elementary School and proximity to estimated center of tornado damage path.

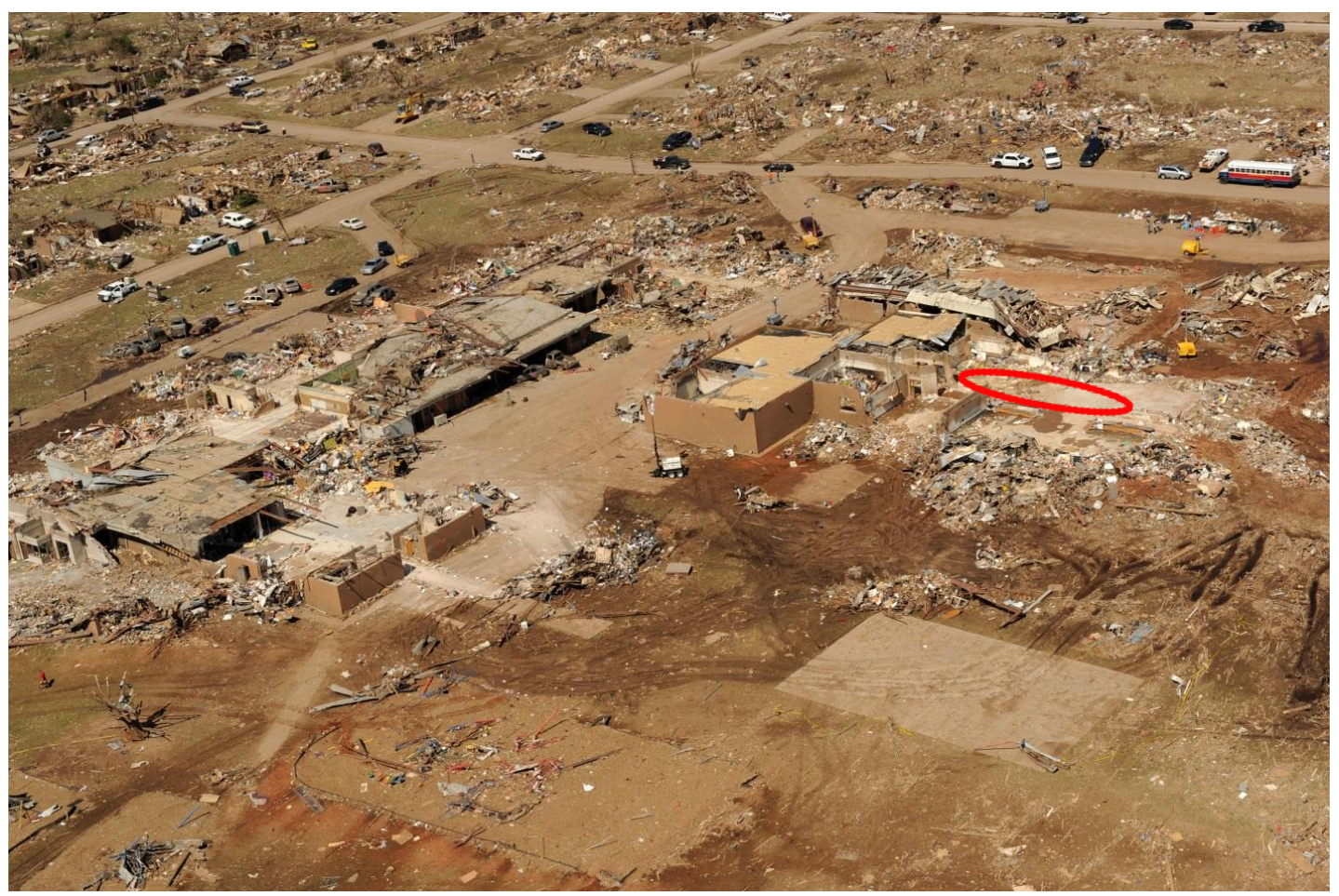

Source: NOAA. Enhancements by NIST.

Figure 4-5. Post-tornado aerial view (looking northeast) of the Plaza Towers Elementary School taken May 21, 2013. Much of the debris had already been moved by the time of this photograph as part of the search and rescue operations. The area circled in red shows the approximate location in the hallway of the new main classroom building where the 7 fatalities occurred. 
- This area was a "designated area of safety" according to the school's tornado emergency procedures (location shown on Figure 4-3). Five of the seven children died after the west masonry hallway wall collapsed on them. The east hallway wall also collapsed into the hall, but in such a manner as to leave an area of void space. Two fatalities occurred along the eastern wall, and seven or eight students and one teacher were rescued from under the rubble in that area as well. ${ }^{38}$ According to the school principal, ${ }^{39}$ injuries suffered in this building included a head injury to a staff person, a sternum fracture to a teacher, and a puncture wound in the back to a student; and at least one of the three injured was reported to be located in the "designated area of safety".

- Original main classroom Building: A portion of the building (southwest wing) sustained complete structural failure with loss of the metal roof system (i.e., failure of joist-to-wall anchors) and collapse of the reinforced CMU perimeter walls (Figure 4-7). Other portions of the building sustained partial roof loss, but the building did not collapse. This was likely due to the redundancy of the steel frame system, which does not rely solely upon lateral bracing by the roof for stability. The un-collapsed portion of the building sustained significant damage to the interior (Figure 4-8) due to damage to the building envelope (i.e., broken windows and missing sections of the roof). An interview with a teacher who sheltered in a bathroom near the northeast corner of the building confirmed that the structural failure sequence first involved the roof system being blown off before the walls started to collapse. ${ }^{40}$ In the front hallway to the west of the Main Office, a toddler suffered a broken leg and a teacher suffered a fractured pelvis and was hospitalized. Additionally, a teacher in one of the restrooms sustained tendon damage to the wrist. $^{41}$

- Gymnasium building: The gymnasium side (west side) of the building was largely demolished, with the collapse of the structural frame and most of the perimeter reinforced CMU walls, as shown in Figure 4-9. The loss of the building envelope resulted in significant damage to the interior of the portions of the building that did not collapse. The interior reinforced CMU walls that surrounded the Gymnasium Office remained intact and offered some protection and safe shelter against debris impact, despite having also lost their roof system. No one took shelter in the gymnasium before or during the tornado. $^{42}$

\footnotetext{
${ }^{38}$ Ibid.

${ }^{39}$ NIST Interview \#21 (Principal, Plaza Towers Elementary School).

${ }^{40}$ NIST Interview \#13 (Teacher, Plaza Towers Elementary School).

${ }^{41}$ NIST Interview \#21 (Principal, Plaza Towers Elementary School).

${ }^{42}$ Ibid.
} 


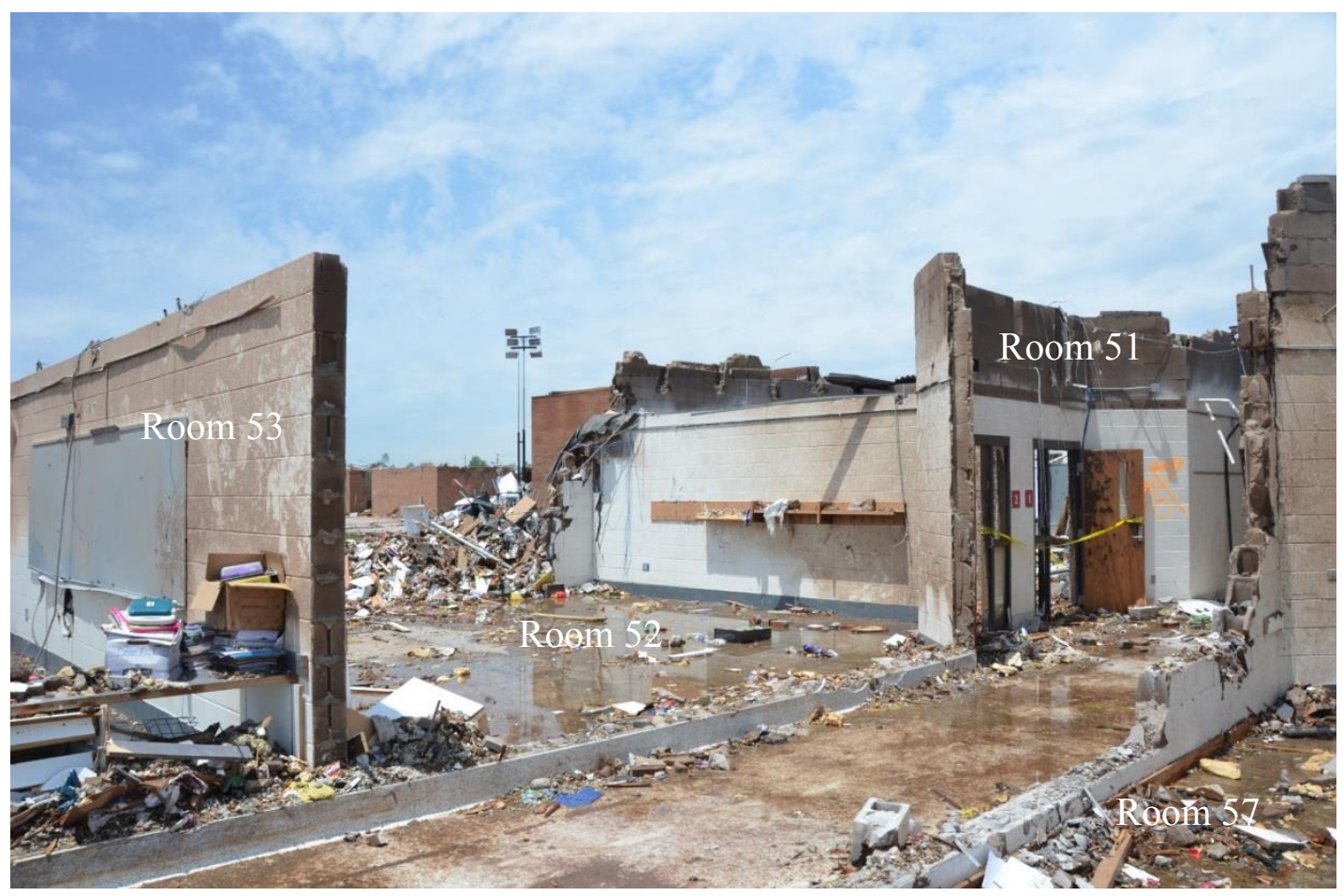

Figure 4-6. Damage to the hallway and classrooms of the new main classroom building (complete loss of roof and many walls) where the 7 fatalities occurred (most of the debris has already been removed). This hallway area was a "designated area of safety."

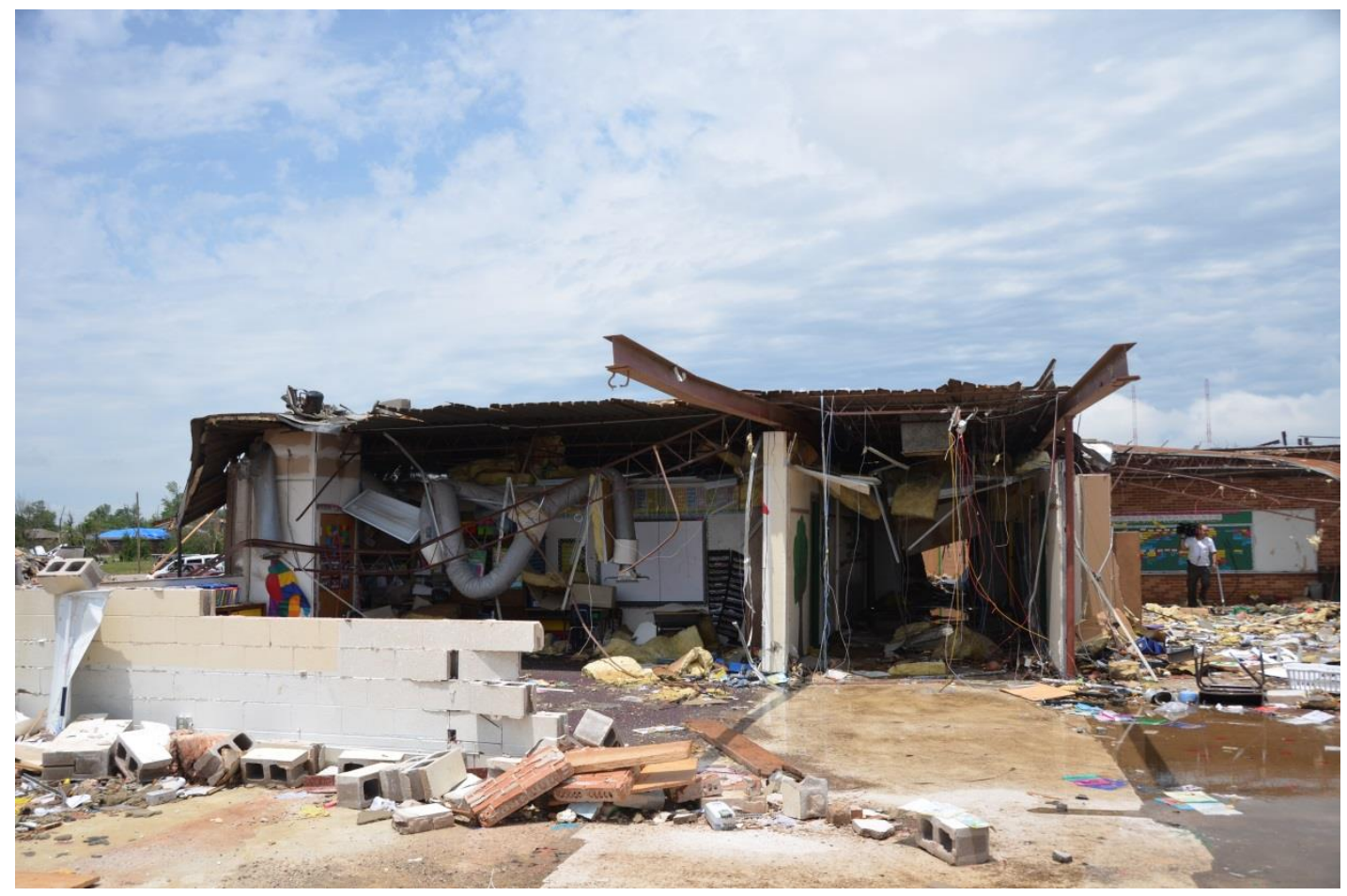

Figure 4-7. Collapsed southwest wing of original main classroom building. 


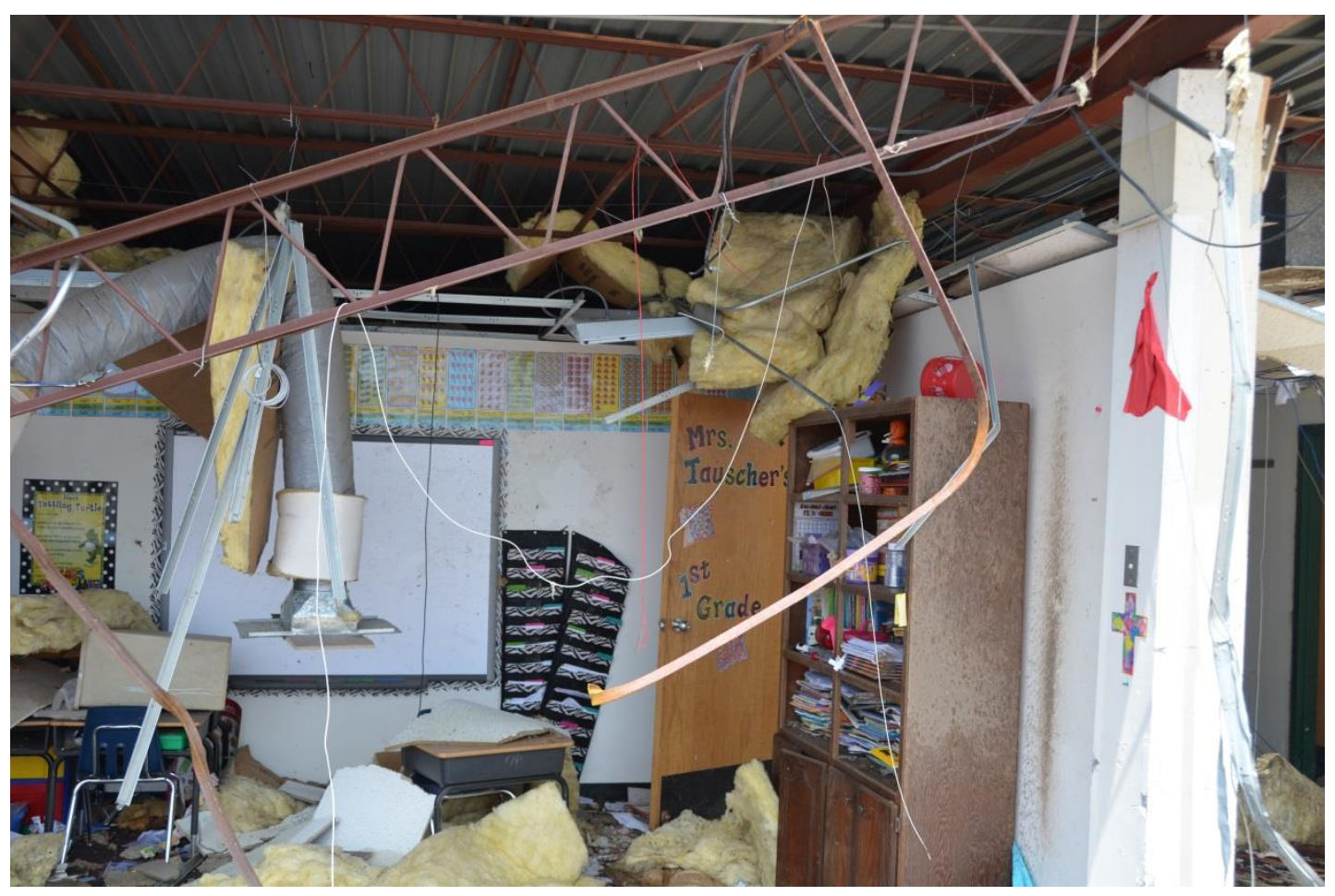

Figure 4-8. Damaged interior of a classroom in the original main classroom building.

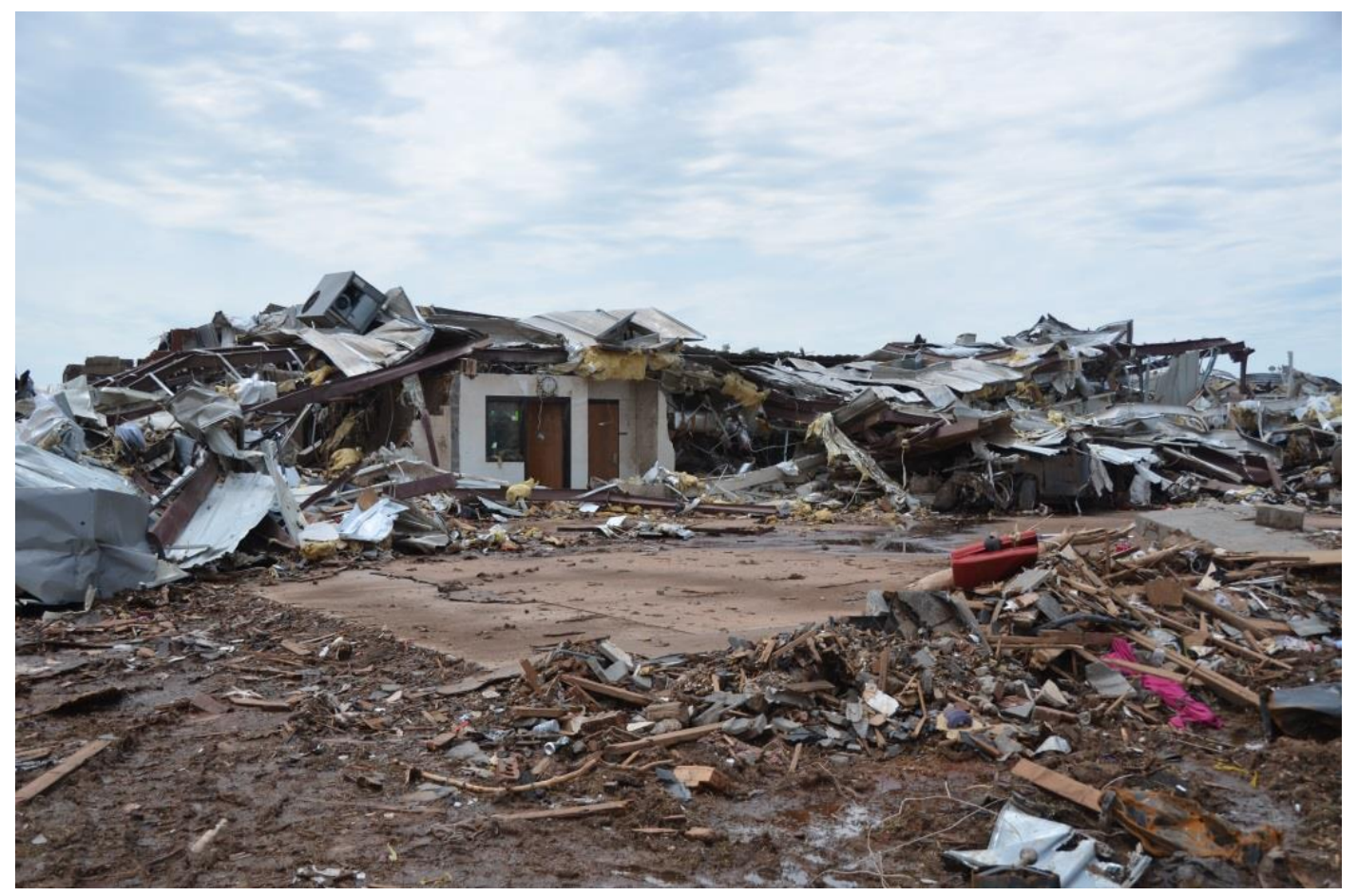

Figure 4-9. Collapsed Gymnasium building (Note the interior Gymnasium Office surrounded by a reinforced $\mathrm{CMU}$ wall remained standing). 


\subsection{Briarwood Elementary School}

\section{Facility and Tornado Sheltering Plan Description}

Figure 4-10 shows an aerial view of the buildings at Briarwood Elementary School before the tornado. The school comprised of four main classroom buildings (designated 100 to 400), six portable classroom buildings (together designated as 500 buildings), a cafeteria building, and a multipurpose building that housed a basketball court, a music classroom, an art classroom, and a set of bathrooms. All were one-story buildings. The structural damage at this school was cited as the reason for the EF-5 rating of this tornado by the NWS/NSSL survey team.

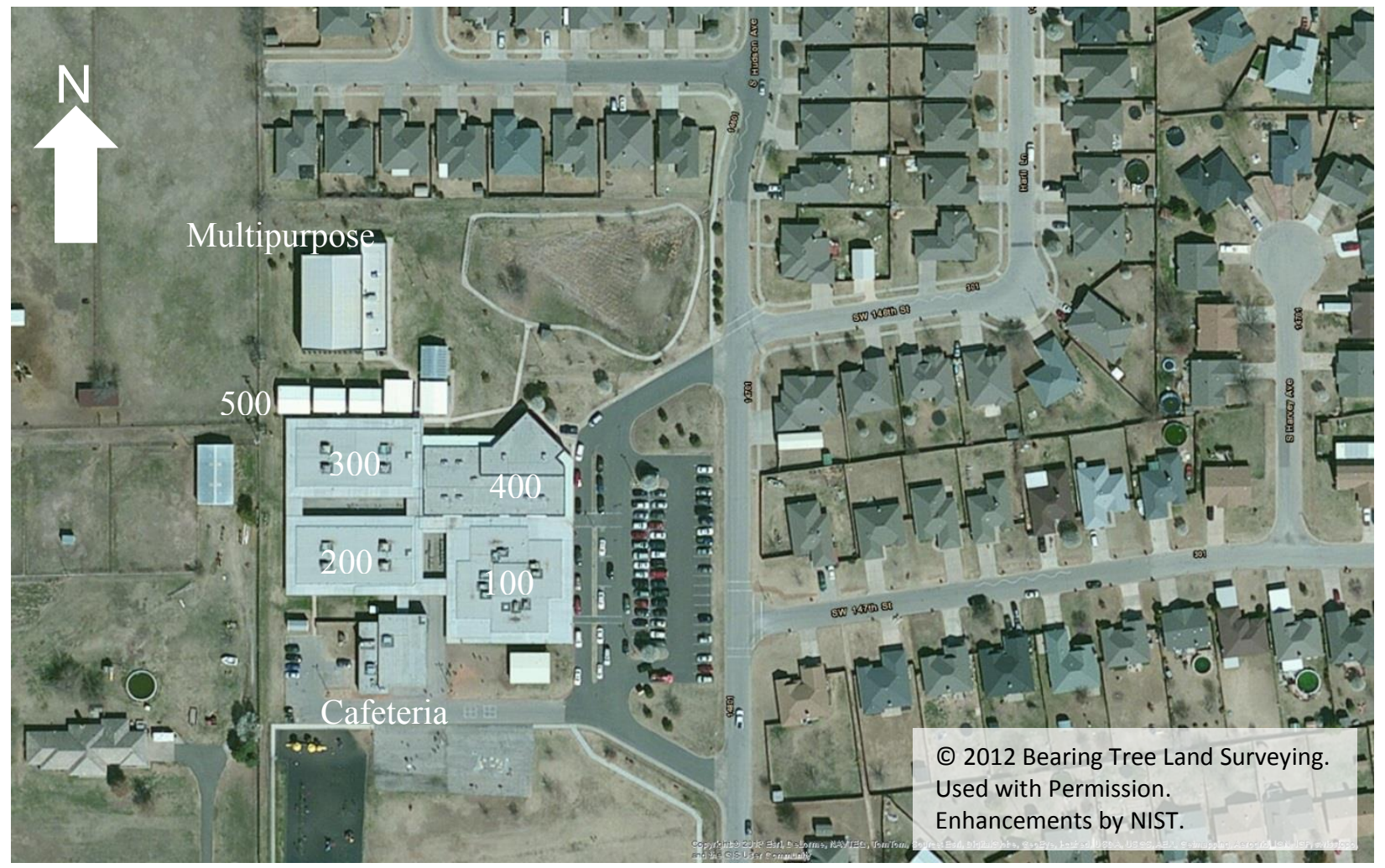

Figure 4-10. Aerial overview of the Briarwood Elementary School before the tornado.

The buildings at Briarwood Elementary School were constructed of two common structural systems. The four main classroom buildings (buildings 100 to 400) and the Cafeteria were BTS with reinforced CMU perimeter walls supporting (and laterally braced by) a metal roof system that consisted of wide-rib steel roof decks connected by puddle welds to open-web steel roof joists. The perimeter reinforced CMU walls were clad with a layer of exterior brick façade. The multipurpose building, built in 2002, employed a combined system of pre-engineered rigid steel frames (tapered built-up plate sections) supporting cold formed " $Z$ "-shaped roof purlins and a metal roof deck, with reinforced CMU perimeter walls.

Figure 4-11 shows the designated tornado safety area locations within each building at Briarwood Elementary school, where students and teachers/staff were to take shelter in a tornado 
event. In most buildings, students and teachers/staff were instructed to leave external classrooms and move to the main interior hallways. In the 100 building, the interior hallways surrounding the central teacher's lounge area were the designated safety areas. The multipurpose building did not contain any designated safety areas, and therefore, occupants were instructed to return to their homerooms in the event of a tornado. Occupants of portable classroom buildings (500) were instructed, by this plan, to enter the nearest building (either the 300 or 400 building) for shelter.

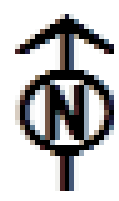

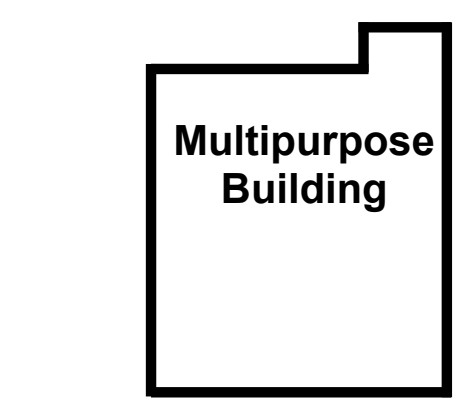
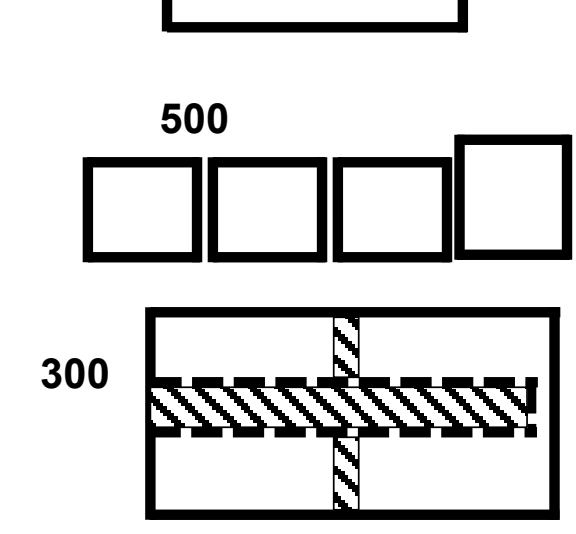

200
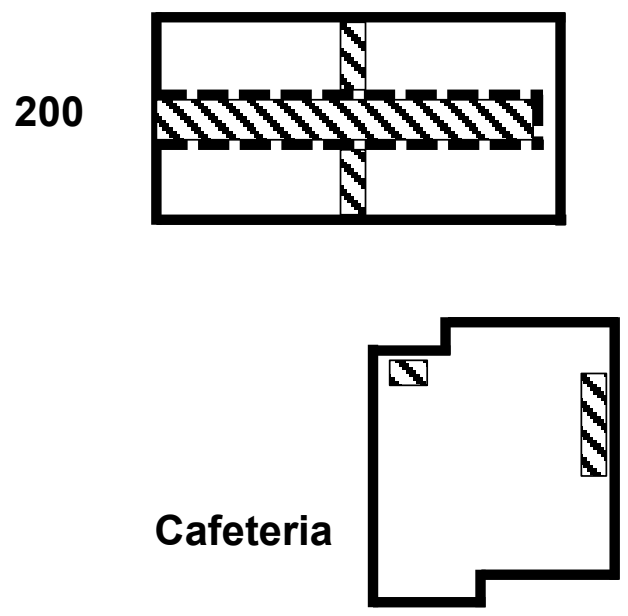

\section{Legend}

Approximate Locations of:

Building walls

- Hallways

WV Tornado Safety Areas

Additional areas used for sheltering on May 20, 2013
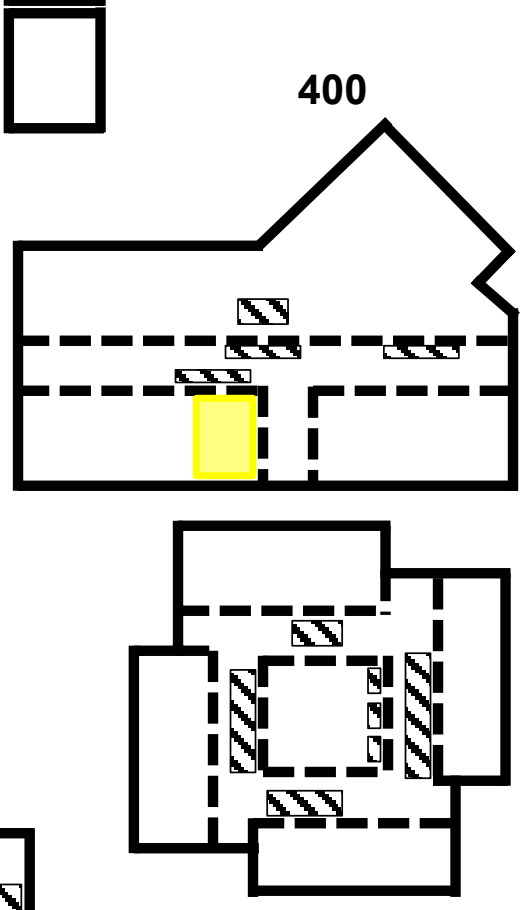

100

Figure 4-11. Tornado safety areas for Briarwood Elementary School. The students and staff generally sheltered according to the tornado plan (hatched areas), but, as described in the text, some used the bathrooms in the 400 building (yellow shaded area). 


\section{Emergency Operations, Facility Performance, and Life Safety Outcomes}

NIST obtained first-hand accounts of the emergency response on May 20, 2013 from the principal and from two teachers who were located in the 400 building before and during the tornado. The teachers indicated about two thirds of the students were picked up early by their parents, leaving around 8 to 10 students per class, compared with a typical class size of 25 .

School staff, teachers, and students received instructions to take shelter over the school's intercom or public address system. According to one teacher, the principal told them to "take your tornado precautions...this is not a drill" 33 . The teachers then instructed their students to get into the designated shelter areas, as shown in Figure 4-11. The $5^{\text {th }}$ and $6^{\text {th }}$ grade students, located in the 400 building, initially took shelter in the main hallway and were told to get down into the safety position. However, after students took refuge in their designated shelter areas, against the newly initiated school policy for shelter-in-place, teachers noted that parents were still arriving at the school to pick up their children. ${ }^{44}$ In other parts of the school campus, shelter spaces identified in Figure 4-11 were used generally according to plan, although three of the $3^{\text {rd }}$ grade classes from the 300 building were moved to the 400 building. In the 200 building, $1^{\text {st }}$ graders moved their desks into the designated hallway and got under the desks. ${ }^{45}$

As the tornado traveled closer, the teachers took notice. One teacher in particular, located in the 400 building, stood at a window and observed the tornado heading directly for Briarwood Elementary. At this moment, the teacher decided that the situation was worse than any of them had originally anticipated and told the other teachers to get their students into the bathrooms (yellow shaded area in Figure 4-11). ${ }^{46}$ Figure 4-12 shows one of the bathrooms used for shelter in the 400 building. According to interviews with teachers in that building, 20 to 30 children were located in each bathroom (the boys' and the girls' bathrooms) in addition to a few parents and the teachers of the students who held class in that building. The ceiling tiles and insulation fell onto the children and adults sheltering in the bathrooms but caused no injuries. Despite extensive damage to or total collapse of most of the buildings at Briarwood Elementary, there were no fatalities at the school. ${ }^{47}$ Two teacher's assistants were injured in the 100 Building, one suffering broken ribs and cheekbone, and another impaled through the leg. ${ }^{48}$

The buildings of Briarwood Elementary School sustained significant structural damage due to strong wind and debris impact loadings. Figure 4-13 show an aerial view from the morning after the tornado struck. Following is a summary of the damage observed at this facility.

\footnotetext{
${ }^{43}$ NIST Interview \#15 (Teacher, Briarwood Elementary School).

${ }^{44}$ NIST Interview \#14 (Teacher, Briarwood Elementary School).

${ }^{45}$ NIST Interview \#22 (Principal, Briarwood Elementary School).

${ }^{46}$ NIST Interview \#15 (Teacher, Briarwood Elementary School).

${ }^{47}$ NIST Interview \#23 (Captain, Oklahoma City Fire Department).

${ }^{48}$ NIST Interview \#22 (Principal, Briarwood Elementary School).
} 


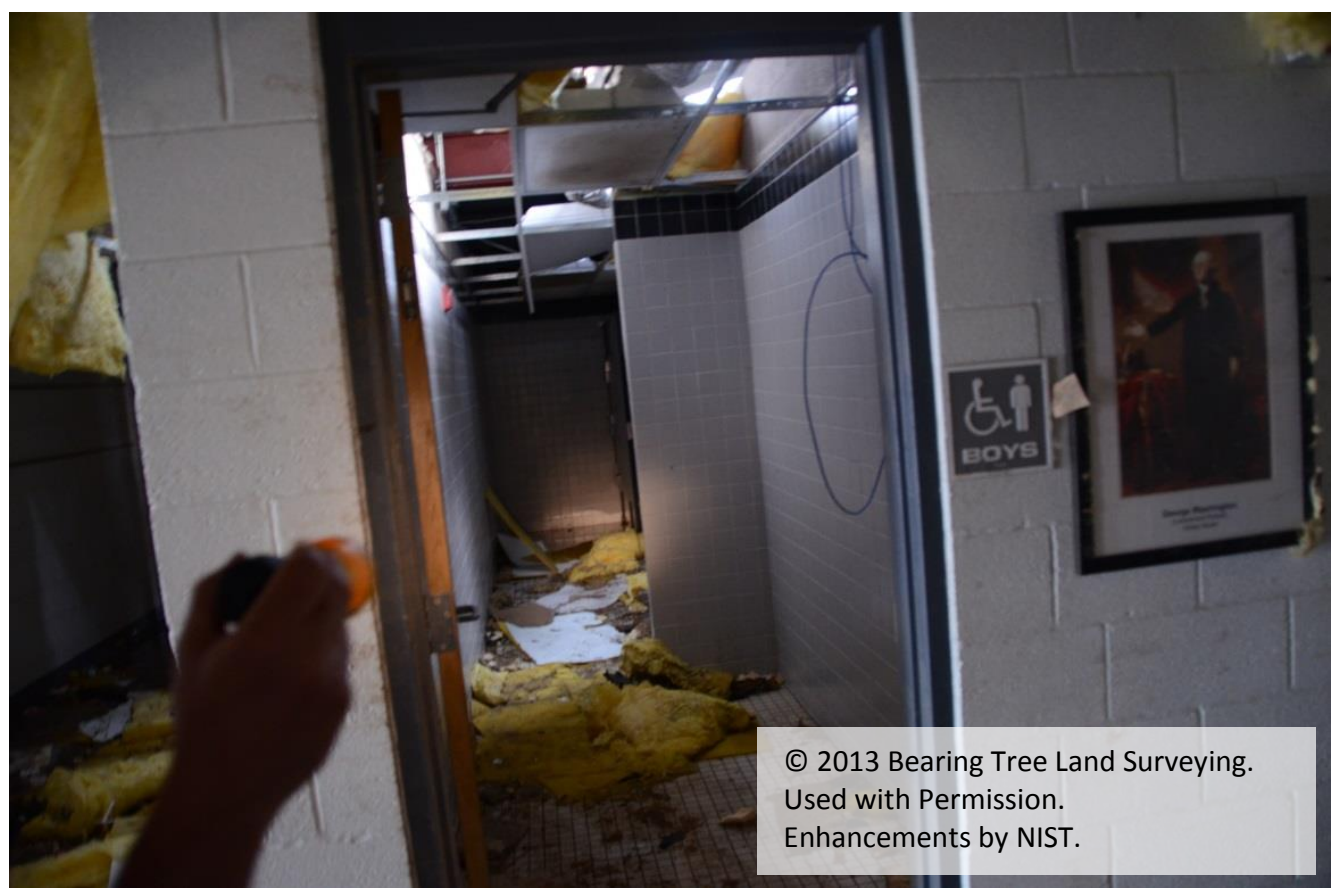

Figure 4-12. Bathrooms used for shelter in the 400 building of Briarwood Elementary School.

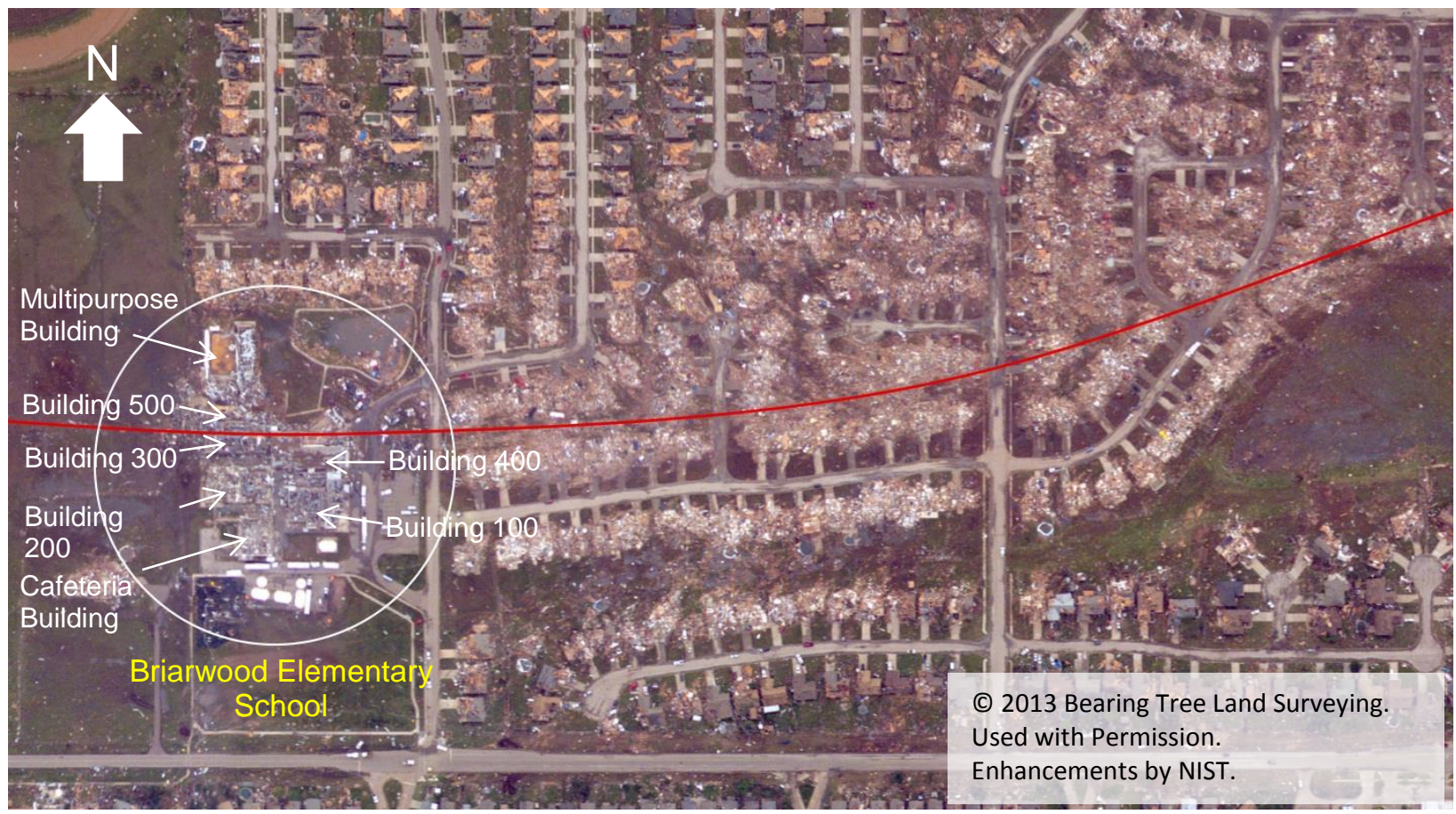

Figure 4- 13. Aerial photograph of Briarwood Elementary School and proximity to estimated center of tornado damage path (red line). 
- Multipurpose Building: This pre-engineered rigid steel frame building sustained complete structural failure, with the collapse of all the steel frames and three of the four perimeter reinforced CMU walls (see Figure 4-14).

- 300 Building: This BTS building sustained complete structural failure with the loss of the metal roof system and partial collapse of perimeter reinforced CMU walls. The building was also impacted by large windborne debris, including automobiles and a large propane tank labeled as belonging to a farm located half a mile west-northwest (see Figure 4-15). The tank was $20 \mathrm{ft}$ long, $7 \mathrm{ft}$ in diameter, with an empty weight of 10 tons (fuel level unknown).

- 200 Building: This BTS building sustained complete structural failure with the loss of the metal roof system and collapse of all perimeter reinforced CMU walls (Figure 4-16). Similar to the 300 Building, this building was also impacted by large windborne debris (automobiles). The only spaces within this building that did not collapse completely were the boys' and girls' bathrooms, which were surrounded by interior reinforced CMU walls. The bathrooms did provide some safe shelter despite complete loss of the roof system.

- Cafeteria: Similar to the 200 Building, the cafeteria building sustained complete structural failure with the loss of the metal roof system and collapse of all perimeter reinforced CMU walls. The only area that remained standing was the boys' and girls' bathroom area (see Figure 4-17).

- 100 Building: This building was a BTS building with a steel roof framing system. Damage included disconnection and displacement of the steel roof framing system and partial collapse of the reinforced CMU perimeter walls.

- 400 Building: This BTS building, shielded to some extent by the 300 and 200 buildings from the west and the 100 building from the south, sustained the least structural damage compared with the rest of the school buildings. Damage included the loss of a small section of the roof, with the perimeter reinforced CMU walls remaining essentially intact. However, the damage to the building envelope (i.e., roof and windows) also led to significant damage to the interior of this building. Figures 4-18 and 4-19 show interior views of a classroom and a hallway in the 400 Building after the tornado.

- 500 Buildings: Portable buildings housing classrooms 501-506 were completely swept away from the site. 


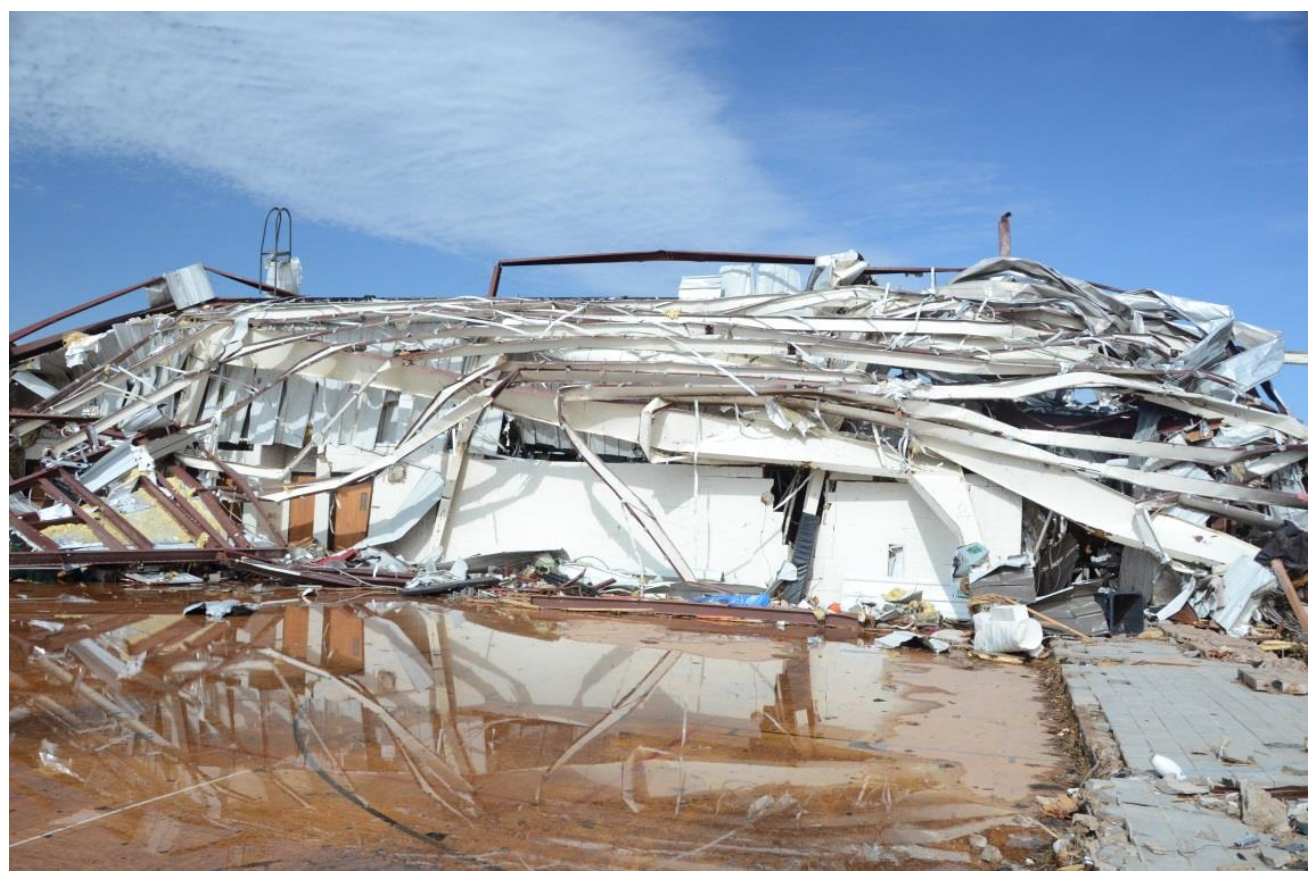

Figure 4-14. Collapsed Multipurpose Building of Briarwood Elementary School.

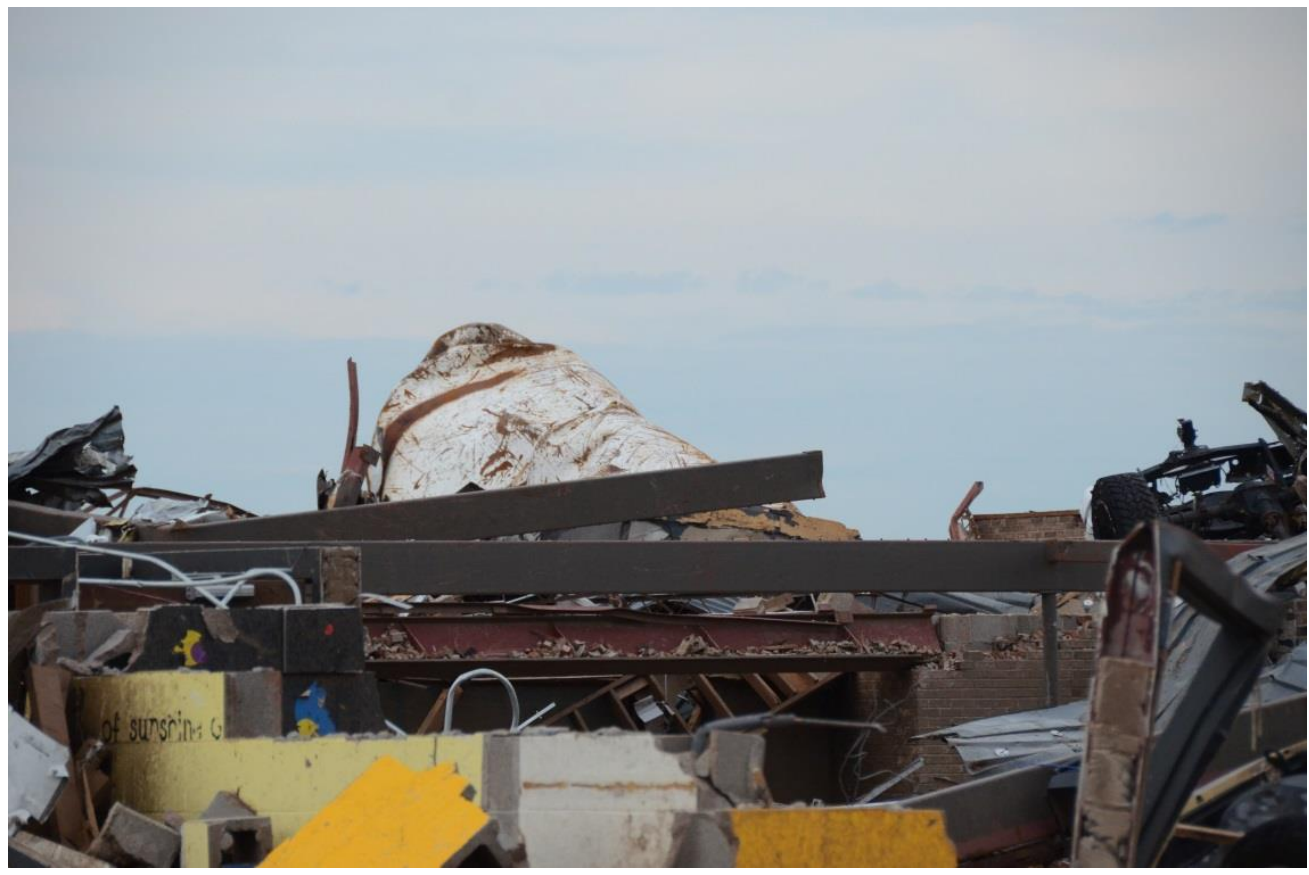

Figure 4-15. Building 300, with propane storage tank (white) that landed on top. 


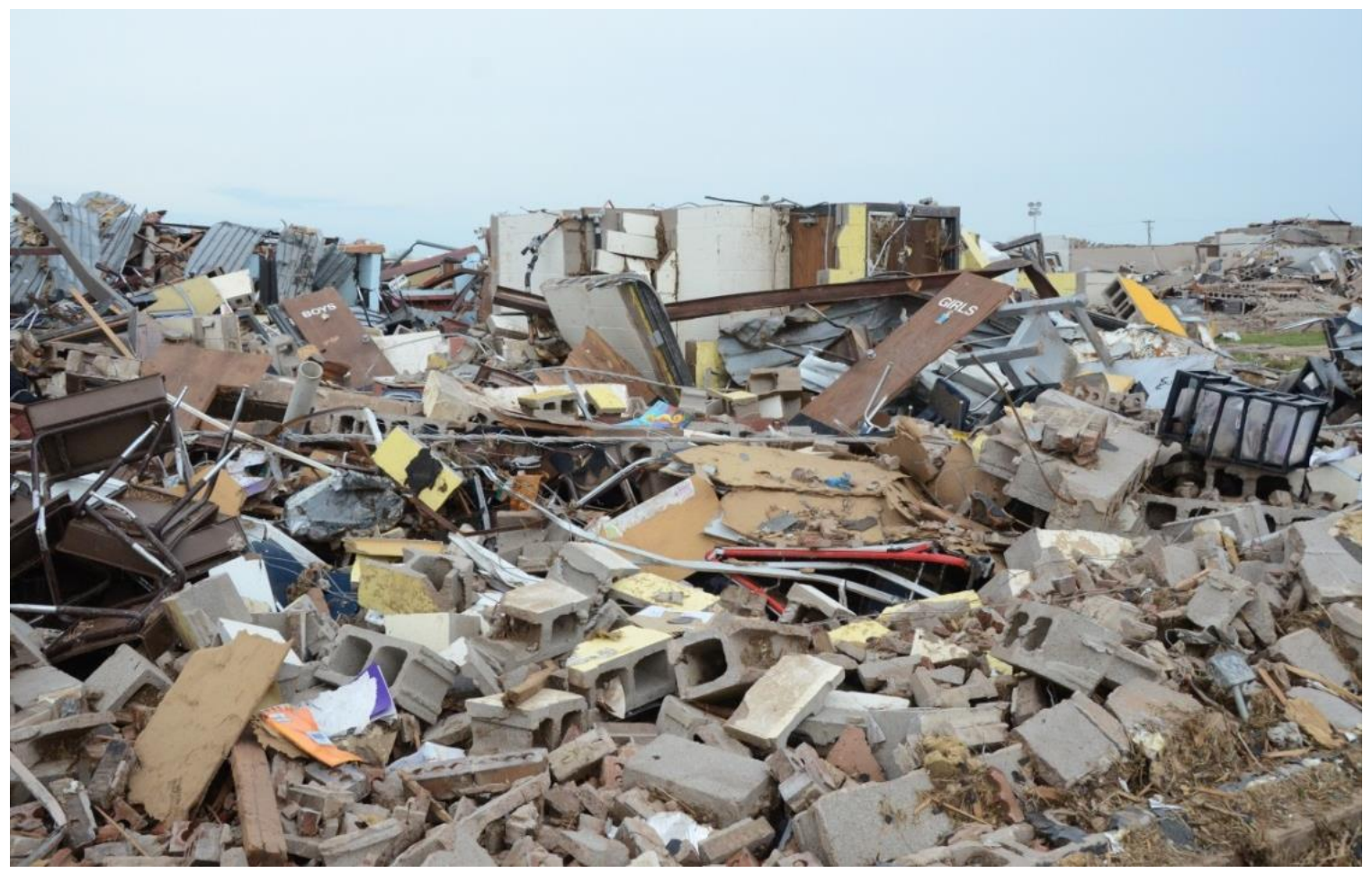

Figure 4-16. Building 200 (completely demolished, with only the boy's and girl's bathrooms remaining standing).

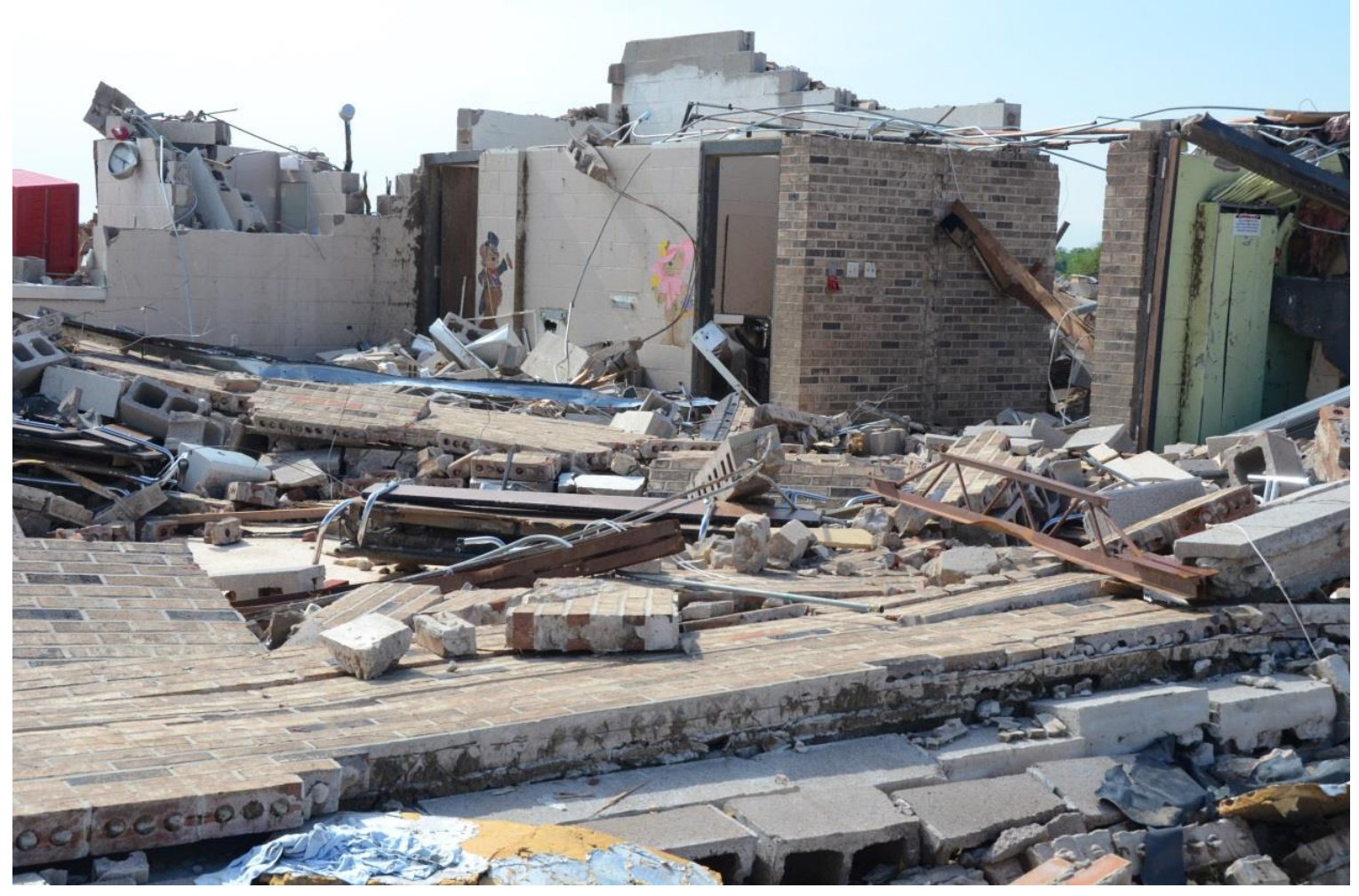

Figure 4-17. Cafeteria. Complete structural failure with only the interior bathroom remaining standing. 


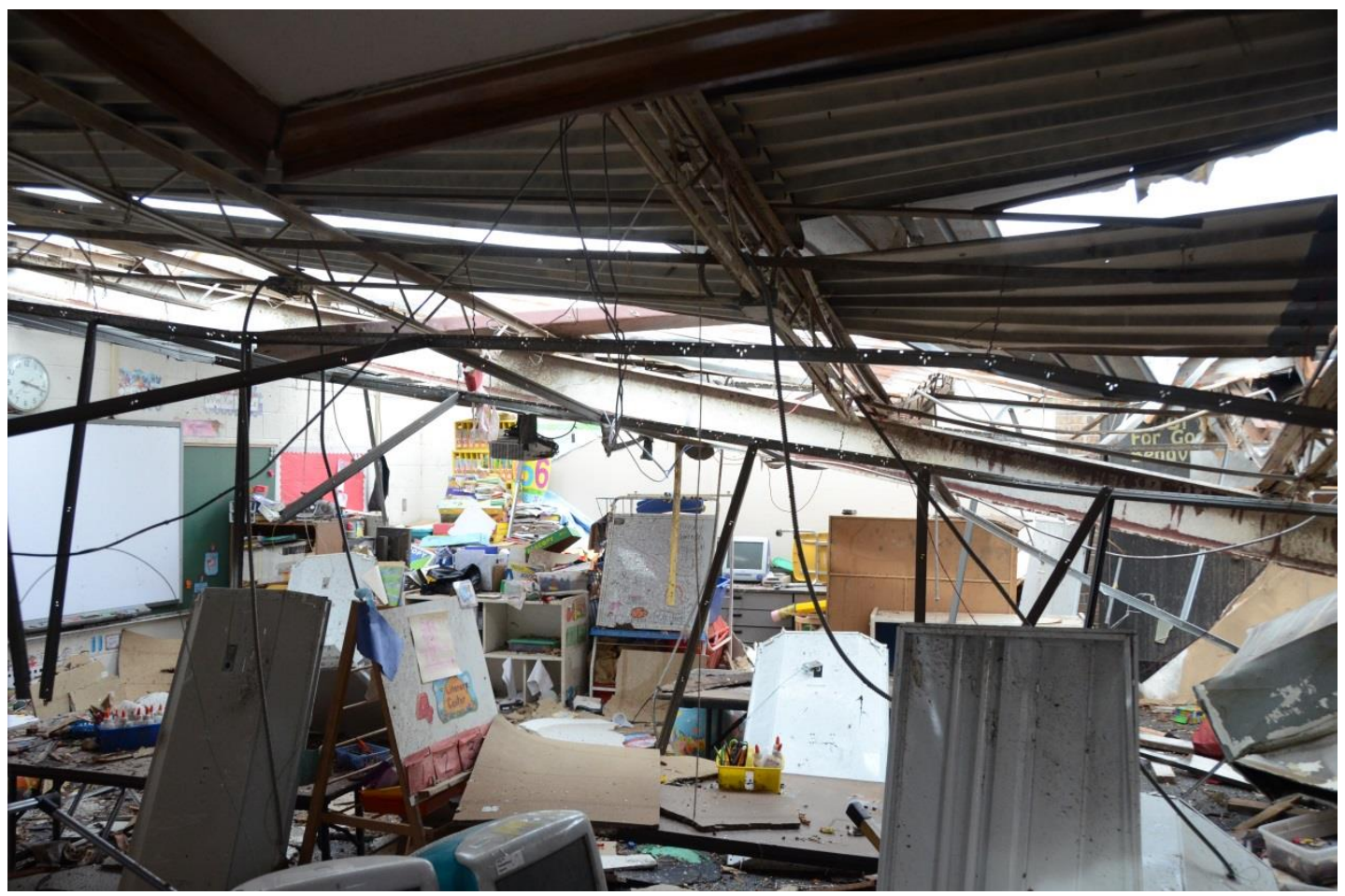

Figure 4-18. An interior view of a classroom in the 400 Building where portion of the building's metal roof system was lost.

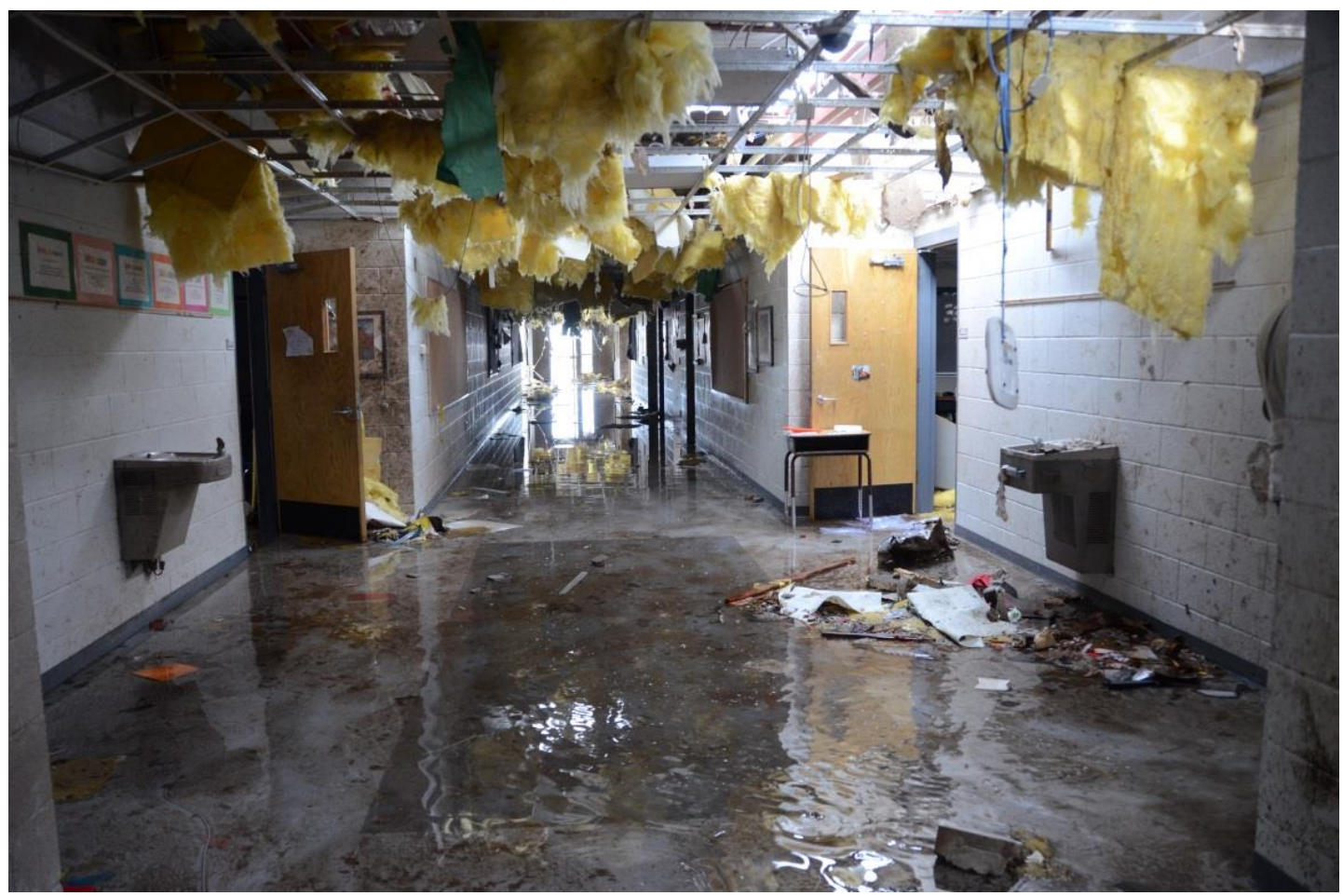

Figure 4-19. Hallway of Building 400 after the tornado (designated tornado safety area and initial location of Building 400 occupants before moving to the bathrooms just before the tornado struck) 


\subsection{Moore Medical Center}

\section{Facility and Tornado Sheltering Plan Description}

The Moore Medical Center is part of a health care system called Norman Regional Health Care. The original facility was constructed in 1988 and consisted of the North Medical Office Building (North MOB). The North MOB was a two-story precast concrete structure, with a precast concrete second floor and roof. In 2002, a two-story, steel frame building was added to the facility. The newly added building consisted of a 45-bed hospital (center section) and the South Medical Office Building (South MOB). ${ }^{49}$ The structural system consisted of a steel braced frame (for lateral load resistance) with simple shear beam-to-column connections, cladded by reinforced CMU and brick curtain walls, and a metal roof system (for gravity load resistance) that consisted of open-web steel joists supporting a metal roof deck covered with rigid thermal insulation. The first story of the 2002 building has a larger plan area than the second story.

According to the Medical Center's "Code Black Plan" for emergencies, the tornado sheltering procedure was to move all bed patients away from external locations throughout the medical center into interior hallways (away from windows). Ambulatory patients and visitors were to be relocated to a "designated protected area," which was the first floor cafeteria in the hospital.

\section{Emergency Operations, Facility Performance, and Life Safety Outcomes}

In terms of the tornado emergency procedures for this hospital, the Manager of Safety for Moore Medical Center, ${ }^{50}$ who also has safety/security responsibility for Norman Regional Hospital and Healthplex (both located in Norman), and the Executive Secretary from Moore Medical Center ${ }^{51}$ provided the following information on the events that took place on May 20, 2013 inside Moore Medical Center.

On May 20, 2013, although the medical center had capacity for 45 patients, one entire wing of the hospital was empty, and only 13 patients (not including newborn babies) were located in the hospital that day. The following outlines the emergency communications timeline on May 20, 2013 for Moore Medical Center:

- 1:53 pm CDT: "Code Black Watch" "52 was issued by the Manager of Safety for Moore Medical Center for all Normal Regional Health System locations (including Moore Medical Center).

- 2:20 pm CDT: "Code Black Warning” was issued by the Manager of Safety for Moore Medical Center for all Normal Regional Health System locations (including Moore Medical Center).

\footnotetext{
${ }^{49}$ Plans for the 2002 addition reflect that it was designed to the 1996 edition of the National Building Code (BOCA 1996), having wind design parameters as follows: $80 \mathrm{mph}$ fastest-mile basic wind speed; exposure category B; and 1.15 importance factor.

${ }^{50}$ NIST Interview \#10 (Manager of Safety, Moore Medical Center).

${ }^{51}$ NIST Interview \#24 (Executive Secretary, Moore Medical Center).

${ }^{52}$ See Appendix for more information on watch, warning, and alert as used by the Normal Regional Health System.
} 


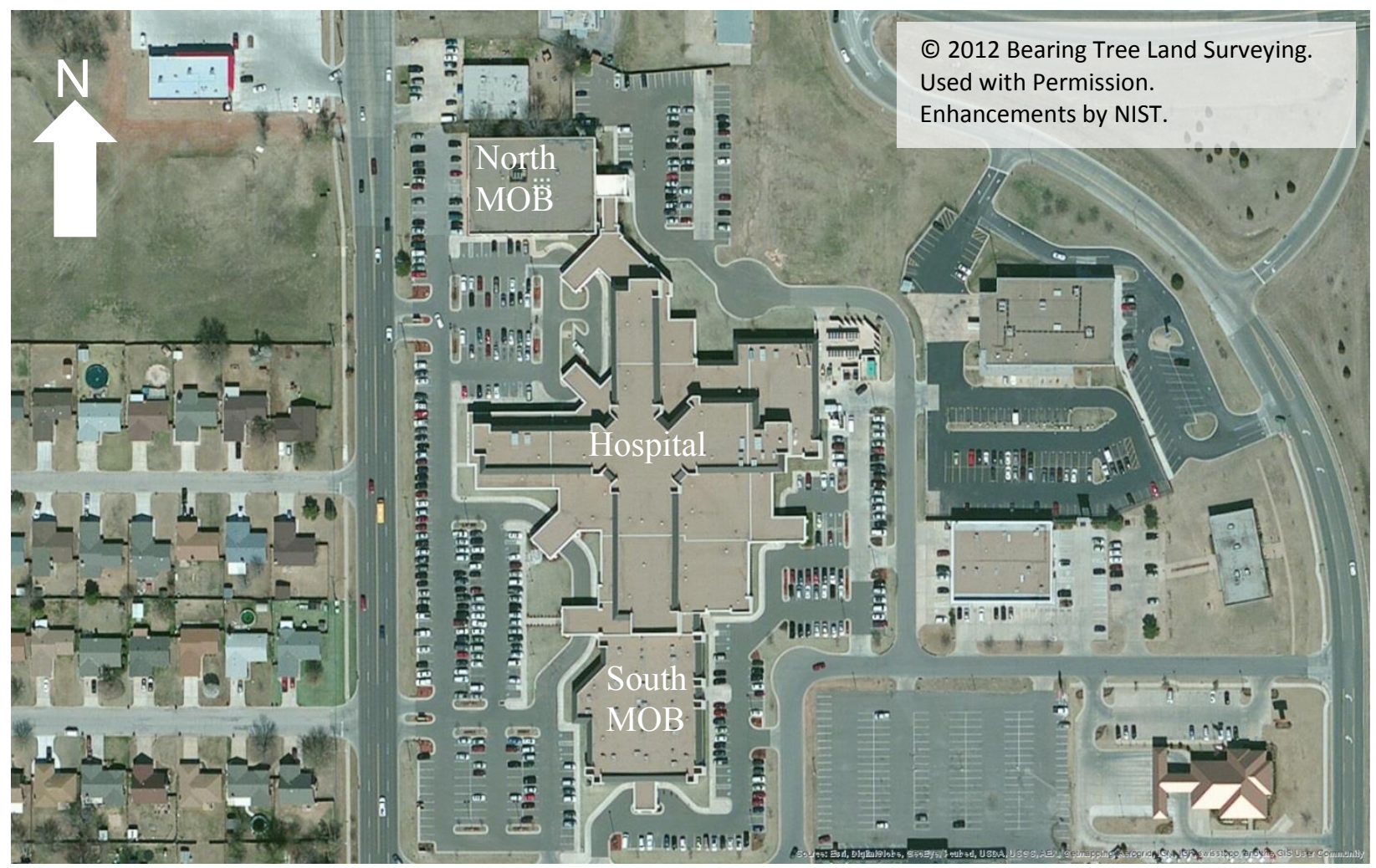

Figure 4-20. Aerial photograph of Moore Medical Center before the tornado.

- 2:34 pm CDT: "Code Black Alert" was issued by the Manager of Safety for Moore Medical Center for Moore Medical Center. When the Manager of Safety was asked why he issued the "Code Black Alert" at 2:34 pm CDT, even before a tornado warning was issued by NWS (at 2:40 pm CDT), he could not say why he made that decision.

According to the Manager of Safety, he just had a feeling that he should issue the "Code Black Alert" for Moore Medical Center.

- 2:40 pm CDT: NWS issues a tornado warning that included the city of Moore.

- 2:44 pm CDT: "Code Black Alert" issued by the Manager of Safety for Moore Medical Center for Healthplex and Norman Medical Center (however, the "Code Black Alert" was not recorded at Norman Medical Center, and the text for the alert was not received due to the storm until 7:37 pm CDT).

- Around 3:16 or 3:17 CDT: The Executive Secretary for Moore Medical Center, who was monitoring the tornado by local news (television), emails (from City of Moore's Emergency Management Director), the YouTube briefing by the Norman WCM, and the hospital emergency warning system through communication with the hospital's Manager of Safety (regarding Code Black Watches, Warnings, and Alerts), received a unique "Code Yellow" overhead page also from the Manager of Safety. A "Code Yellow" alert is the hospital's "Disaster Preparedness Code," and the Executive Secretary perceived this page as meaning that conditions had become serious; i.e., that a tornado was headed right for them.

- 3:21 pm CDT: A tornado strikes the Moore Medical Center. 
Once the "Code Black Alert" was issued for Moore Medical Center at 2:34 pm CDT, the procedure was to move all bed patients from external locations throughout the facility into interior hallways (away from windows). On May 20, 2013, the Manager of the Family Birth Center and the Manager of Med Surg/Peds/PCU decided that patients and staff should relocate to certain areas on the first floor. This decision was made for two reasons: 1) both managers were feeling uneasy about the weather; and 2) there were reports from weather stations that there was a tornado on the ground at Newcastle. ${ }^{53}$ Before the tornado hit, with the exception of one patient in the Labor and Delivery Department and a few staff members assisting her, ${ }^{54}$ all patients and hospital staff relocated to the first floor of the hospital. According to the medical center's Executive Secretary, patients, hospital staff, and community members generally took refuge in accordance with the Medical Center's emergency plan with the following exceptions:

- One group of 5 to 6 people was located in the Imaging Department.

- One large group, including most hospital patients, took refuge in the cafeteria, according to the emergency plan. However, upon the receipt of the Code Yellow alert, the Executive Secretary, who was also located in the cafeteria, decided to instruct all physicians to relocate from the cafeteria to the walk-in refrigerator (located in a room adjacent to the cafeteria, but still internal to the hospital). The Executive Secretary made this decision to further protect the physicians because she thought that the physicians and their skills might be required during the recovery stages of this tornado.

- A larger group from the City of Moore (i.e., individuals who were not originally located at the medical center, but traveled to the medical center for shelter) was located outside of the cafeteria doors in the surrounding hallways.

All of the shelter areas were interior spaces, mostly surrounded by interior reinforced CMU. Despite extensive damage to the building exterior and much of the interior, none of the areas where people took shelter sustained significant damage, and according to official sources at the Moore Medical Center, no deaths or injuries due to the effects of the tornado occurred in this building on May 20, 2013.

The estimated centerline of the tornado damage path passed close to the center of the facility (Figure 4- 23). The damage across the entirety of the exterior of the Moore Medical Center is shown in Figs. 4-24 through Figure 4-26. The figures show severe damage to much of the interior of the hospital and the medical office buildings. Similar to the two elementary schools discussed earlier in the report, the Moore Medical Center was also subjected to both wind and wind-borne debris impact loading; however, the structural damage to the Medical Center was minimal compared to the schools. Debris hazards included automobiles (and automobile parts) tossed against, into, and onto the building, and a large steel trash dumpster that landed on top of the second story of the west nursing wing of the hospital, damaging the roof deck and supporting bar joists (Figure 4-28).

\footnotetext{
${ }^{53}$ NIST Interview \#24 (Executive Secretary, Moore Medical Center).

${ }^{54}$ One patient was in labor and had already received her epidural and so she had to stay on the second floor in the Labor and Delivery Department. The patient was with a few nurses, who covered her during the storm. The tornado did take out a wall where they were located, but they did not receive any injuries from the storm.
} 
Other damage sustained by the Moore Medical Center included:

- Partial loss of roof system in isolated areas including disconnection of metal roof deck and/or joist-to-frame connections on both the first and second stories (see circled areas in Figures 4-24 and 4-28)

- Extensive damage to roof architectural elements and partial loss of roof coverings (Figures 4-24 and 4-25)

- Significant damage to the building envelope, including collapse of curtain walls, broken window glazing, broken exterior doors, damaged wall cladding, etc. (Figures 4-24 and 426)

- Significant damage to the building interior, including damaged partition walls, suspended ceiling systems, furniture, equipment, and building systems (e.g., electrical, lighting, plumbing, heating, ventilation and air conditioning, communications, and others) as shown in Figure 4-27

- A high level of damage to interior doors, even in areas where the overall level of interior damage was not very intense. All of the observed broken interior doors were constructed of particle board (Figure 4-29).

The damage to the building envelope systems, and subsequent damage to the interior construction, contents, equipment, and building systems due to wind, rain, and debris penetration deep into the buildings caused the Moore Medical Center to suffer a complete loss of functionality. Despite the fact that the structural frame system of the building remained largely intact, the entire facility was demolished, leaving the City of Moore without a hospital.

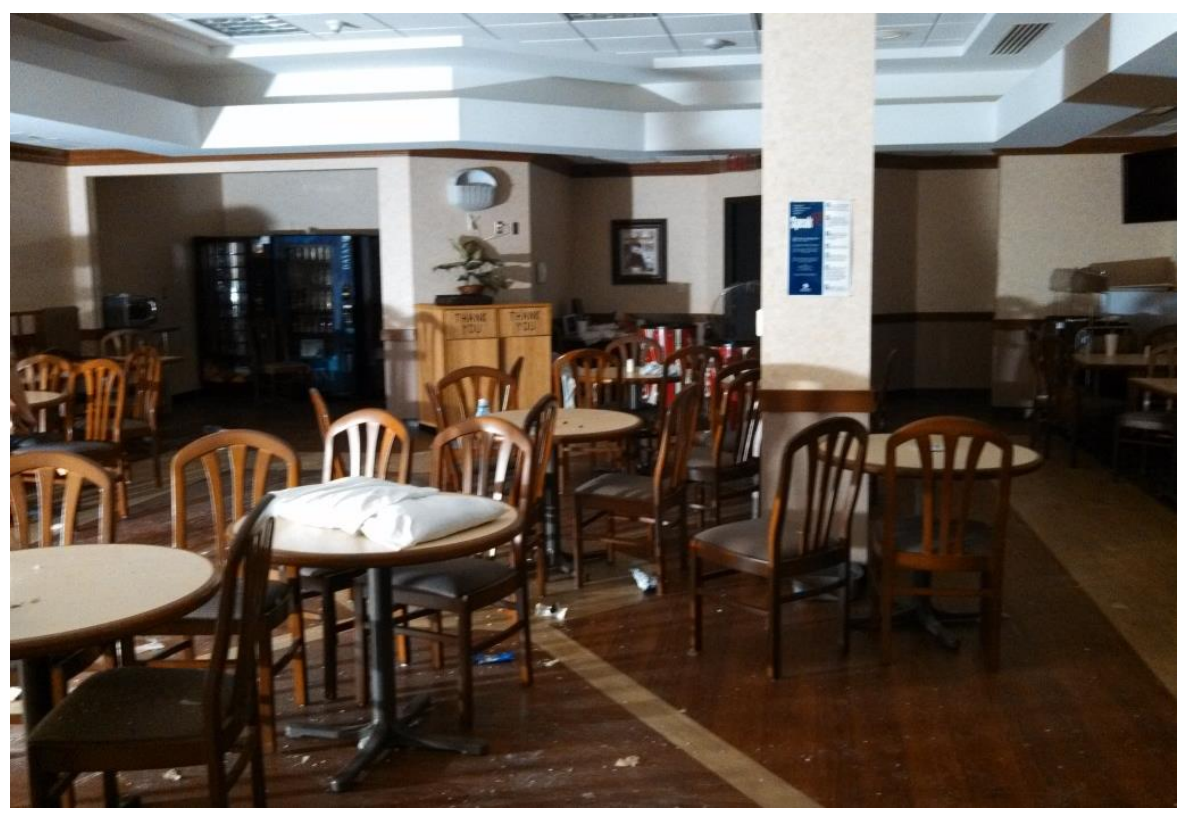

Figure 4-21. Cafeteria located on the first floor interior of the Moore Medical Center hospital where patients sheltered during the tornado. 


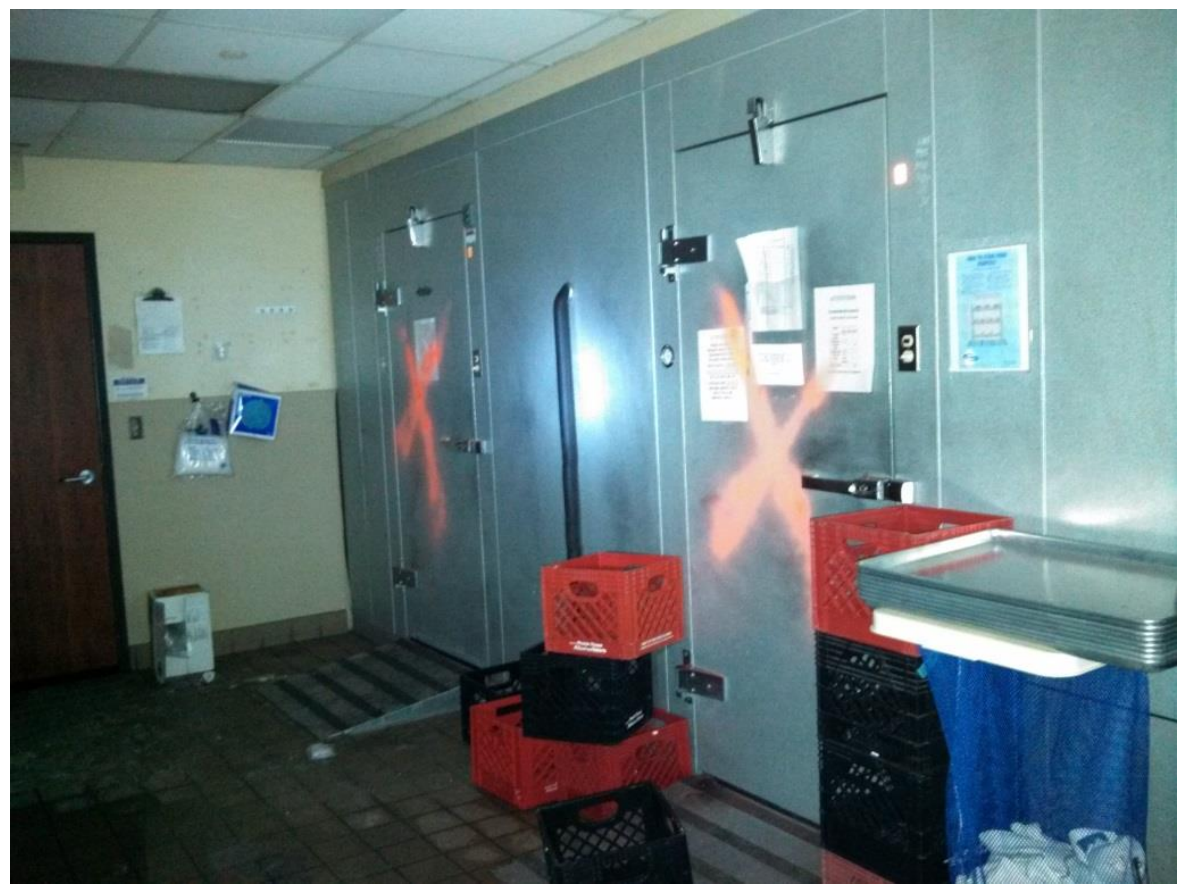

Figure 4-22. Physicians were relocated from the cafeteria to these walk-in freezers for anticipated additional level of protection for staff that would be needed for response and recovery.

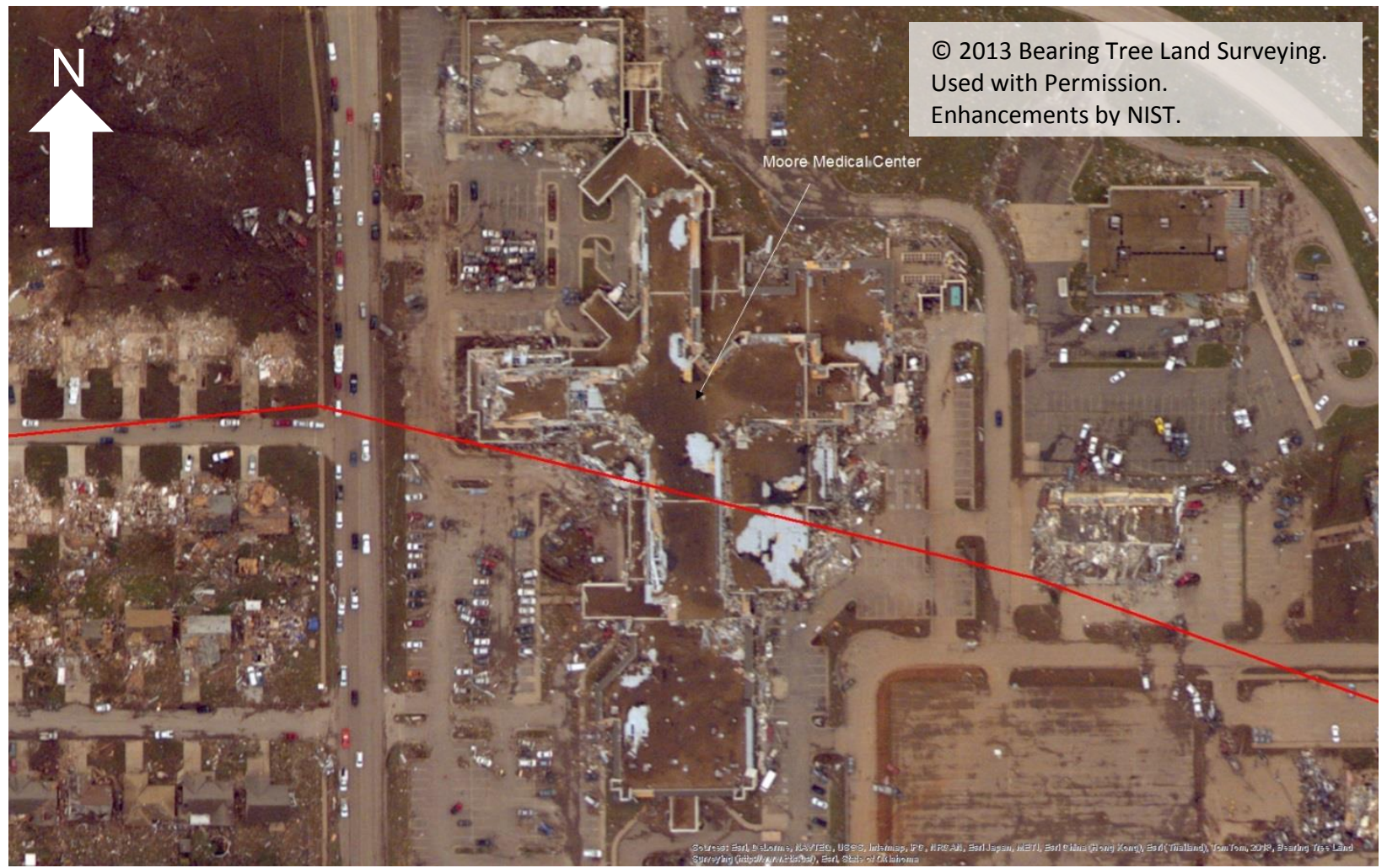

Figure 4-23. Aerial photograph of Moore Medical Center shortly after the tornado struck, showing estimated centerline of the tornado damage path (in red). 


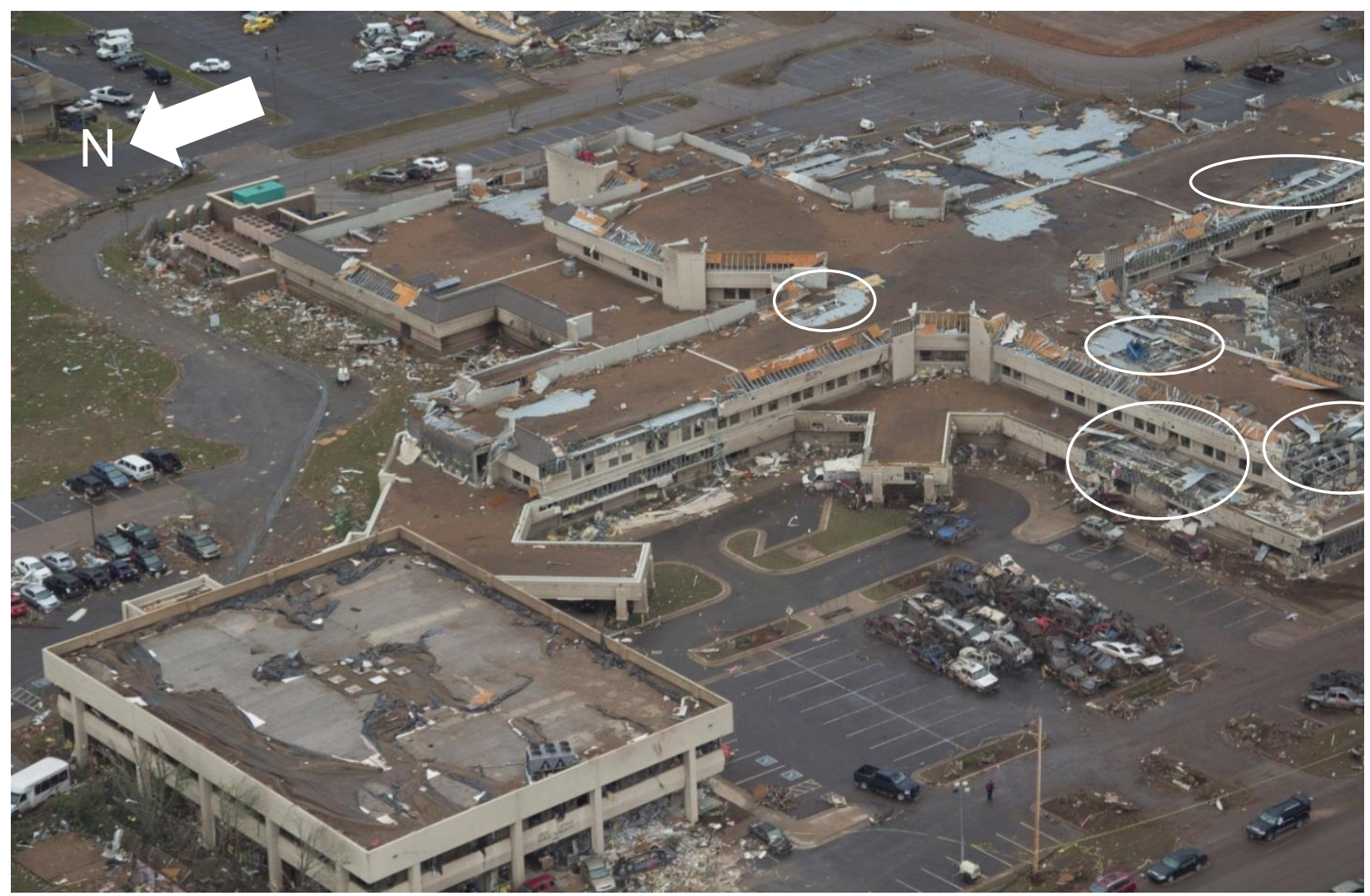

Source: NOAA. Enhancements by NIST.

Figure 4-24. Aerial view of the heavily damaged Moore Medical Center (looking south-east). Circled locations indicate areas of roof deck damage.

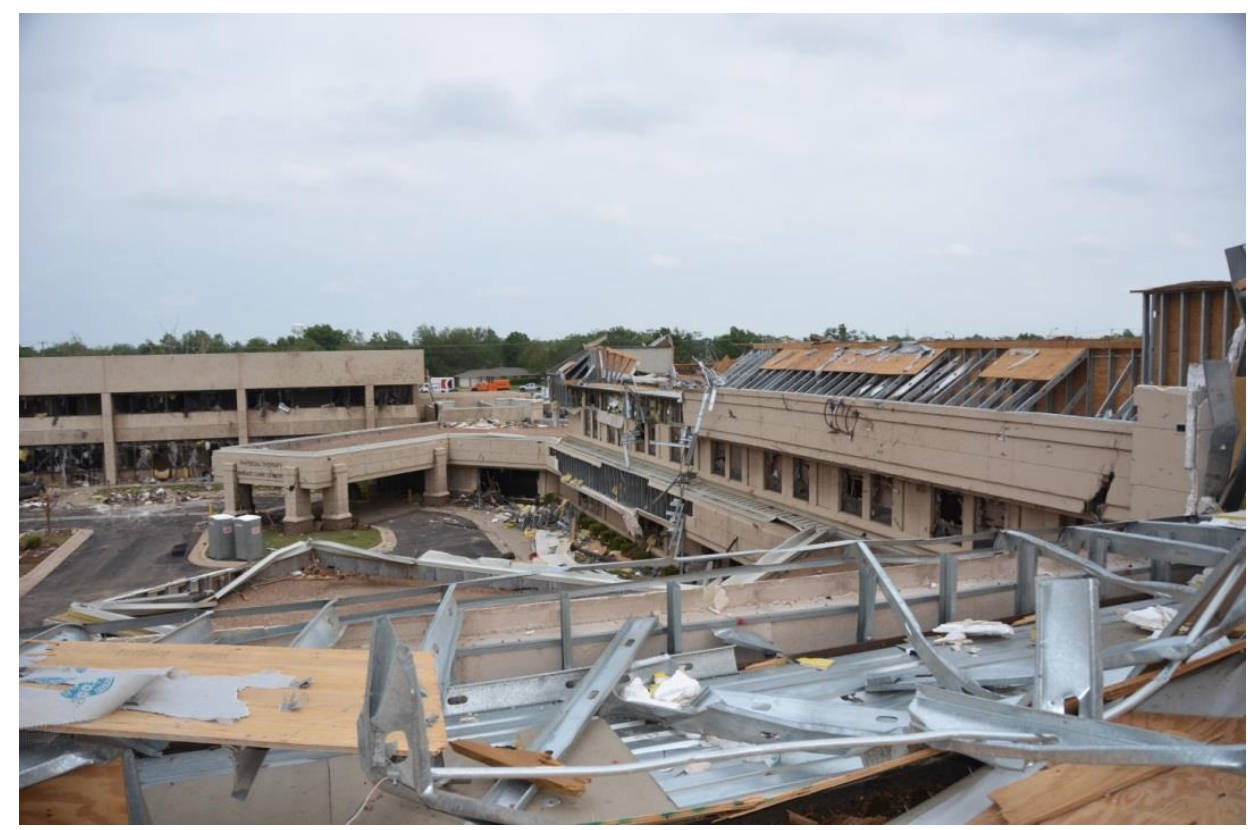

Figure 4-25. Damage to the building envelope and rooftop architectural elements of Moore Medical Center. 


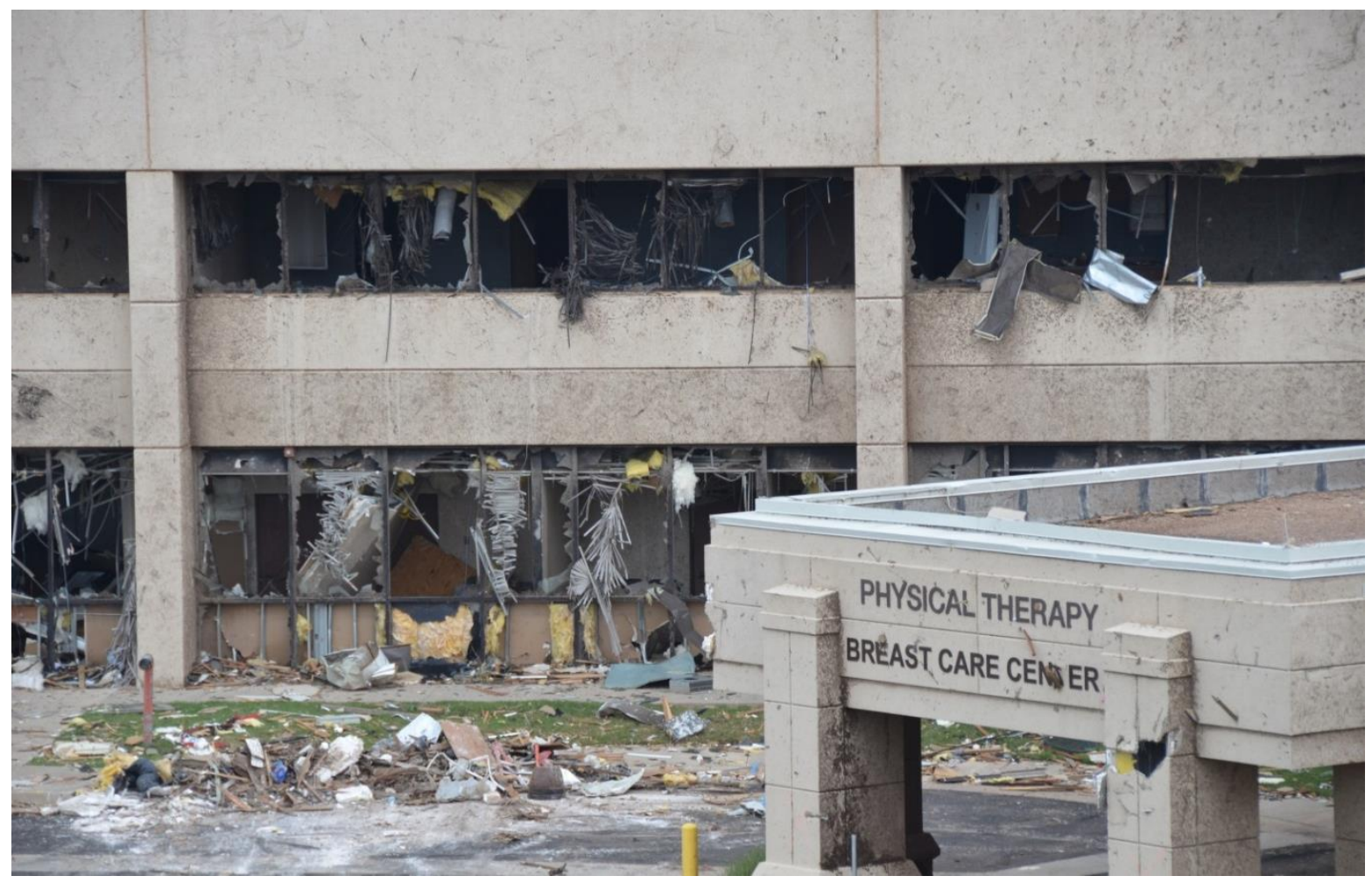

Figure 4-26. Damage to the envelope of Moore Medical Center (glazing).

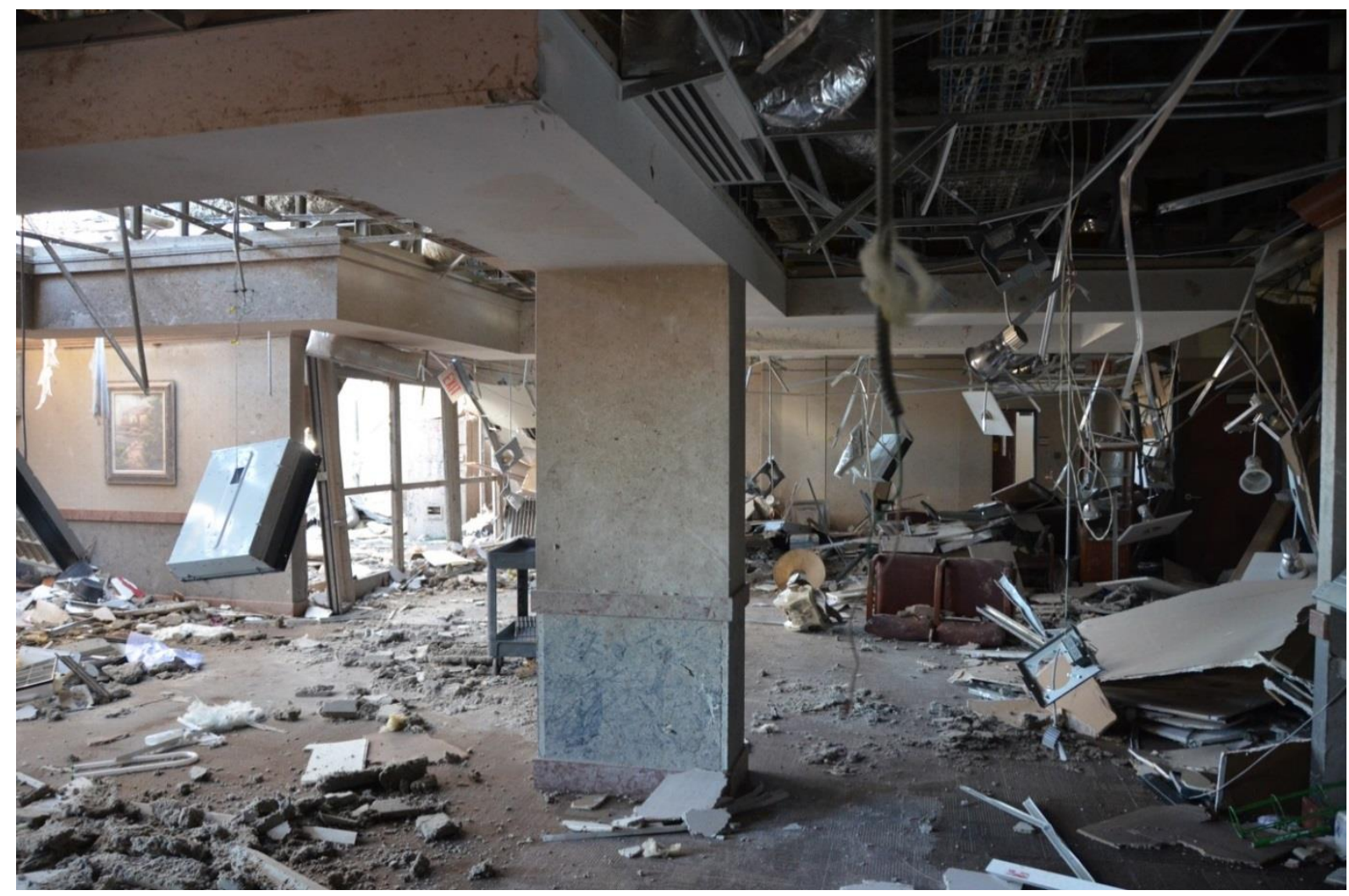

Figure 4-27. Damage to the interior of the Moore Medical Center due to wind and debris infiltration. 


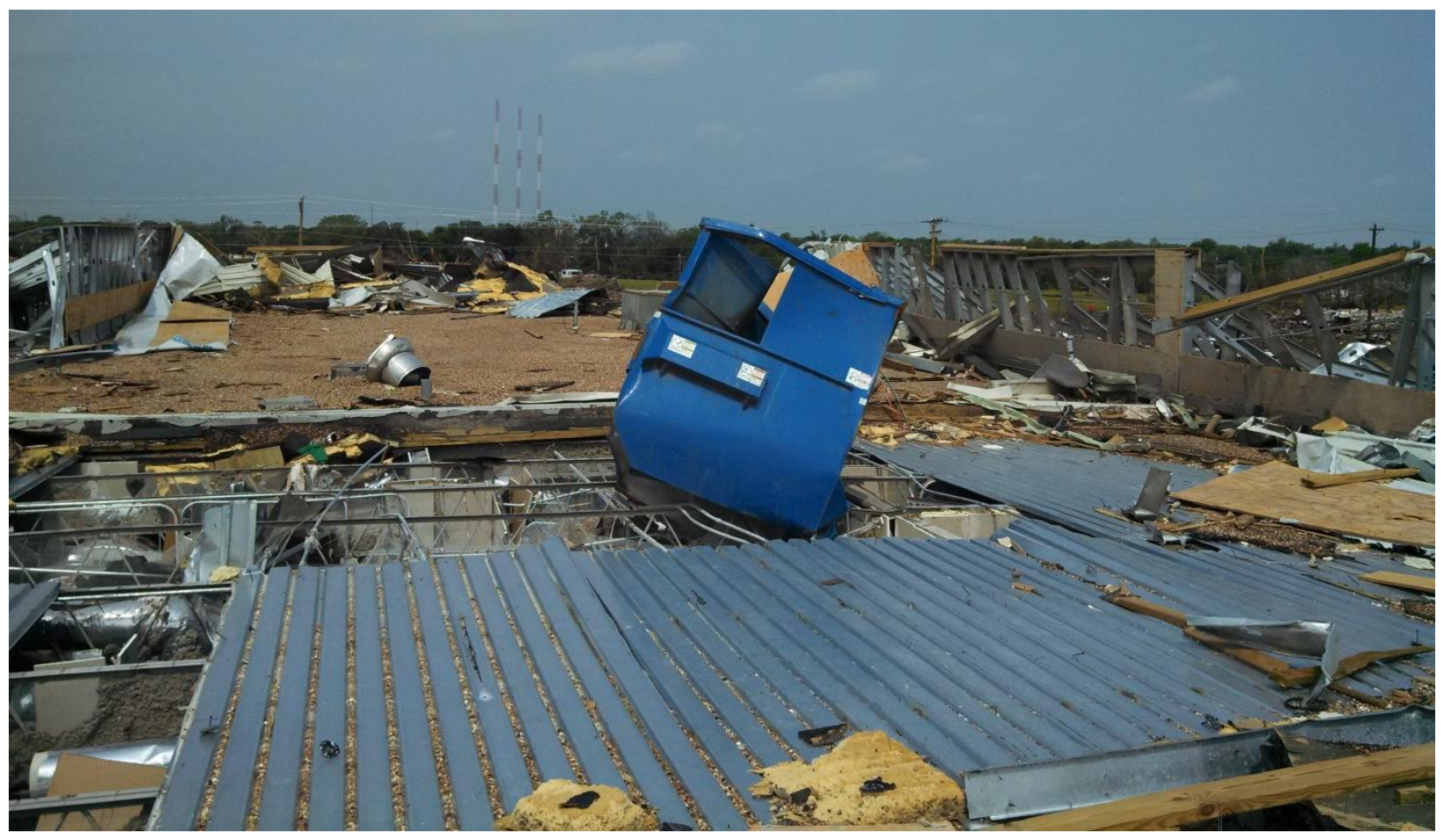

Figure 4-28. Impact damage to hospital roof bar joists from steel trash dumpster, and loss of steel roof decking.

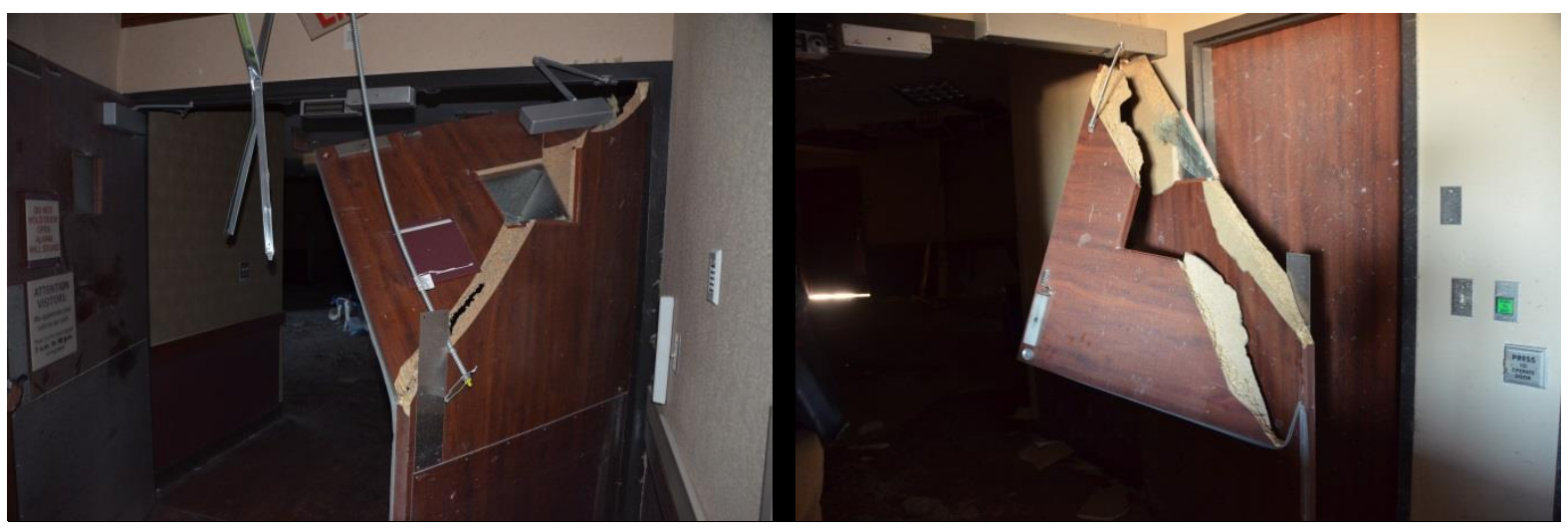

Figure 4-29. Examples of broken interior doors at the Moore Medical Center. 
The page intentionally left blank. 


\section{CHAPTER 5. OBSERVATIONS}

Observations based on data and information collected during the course of this Preliminary Reconnaissance are presented below. They are arranged in five groups, the first three providing context, and the last two addressing the specific objectives of the Preliminary Reconnaissance.

\section{Tornado History and Preparedness}

- The City of Moore (and surrounding areas) have had much experience in recent years with tornado disasters, including strikes by one F-2, two F-4/EF-4, and two F-5/EF-5 tornadoes since 1998 (a Fujita Scale F-2 tornado in 1998, an F-5 tornado in1999, an F-4 tornado in 2003, an Enhanced Fujita Scale ${ }^{55}$ EF-4 tornado in 2010, and the May 20, 2013, Newcastle-Moore EF-5 tornado). Moore is one of just a few communities nationwide to have ever been struck by two F-5/EF-5 tornadoes.

- Moore's work to prepare for tornadoes has included implementing storm monitoring and education and training programs, becoming a NWS certified StormReady Community in 2001, and maintaining that certification since. It was most recently recertified in 2012. Elements of the program include maintaining a 24-hour emergency operations center; having multiple methods to receive severe weather warnings and forecasts and to alert the public; promoting the importance of public readiness through community seminars; and maintaining a formal hazardous weather plan, which includes training severe weather spotters and holding emergency exercises.

- While some research has shown that high false alarm rates can contribute to complacency by the public in response to warnings, the false alarm rate for official tornado warnings in Moore in recent years was considerably lower than the national average. During the era of storm-based warning polygons (as opposed to earlier county-wide warnings), between October 2007 and May 19, 2013, 16 official tornado warnings were issued for all or some parts of Moore, 12 of which were followed by verified tornadoes. This yielded a false alarm rate for the Moore area of 25 percent (4 false alarms out of 16 warnings), compared to the national average false alarm rate of 74 percent for 2010.

\section{Building Codes and Storm Shelters}

- Moore had adopted national model codes governing design and construction of buildings, and was enforcing the 2009 International Code Council (ICC) International Building Code (IBC) and the 2009 ICC International Residential Code for One- and Two-Family Dwelling (IRC) at the time of the Newcastle-Moore tornado.

- Tornadoes are not explicitly considered in either the 2009 IBC or 2009 IRC for any types of buildings, except storm shelters. Although design wind speeds required by those

\footnotetext{
${ }^{55}$ The National Weather Service (NWS) switched from rating tornado intensity using the Fujita Scale to the Enhanced Fujita Scale in 2007 (see Section 2.3 for more information).
} 
codes are in the range of EF-1 tornadoes, the codes do not address potentially greater lateral and roof uplift pressures in tornadoes compared to other types of windstorms, and do not address windborne debris, which is a significant contributor to building damage in tornadoes.

- There were no public or community shelters in Moore at the time of the NewcastleMoore tornado. The City's strategy was to recommend shelter-in-place, except for occupants in mobile homes or portable buildings, who were advised go to a substantial structure. The City's stated rationale was twofold: there were no public buildings having a suitable location for a shelter; and the overall risk was less to shelter-in-place in a reasonably well-constructed residence (considering available warning time, travel time to a shelter, traffic, and other factors).

- Over 3,000 residential shelters have been constructed in Moore and were registered with the city at the time of the Newcastle-Moore tornado, perhaps the highest number of residential shelters per capita in the U.S.

- Installation of storm shelters in homes or other buildings is strictly voluntary; neither the national model building codes adopted by Moore nor local amendments require storm shelters.

\section{Events Immediately Prior to the Tornado}

- The threat of severe weather for the Moore area on May 20, 2013, was identified as early as May 15 by the NWS Storm Prediction Center (SPC). The Hazardous Weather Outlook on May 15 indicated the possibility of severe storms on May 19-20, which was expanded to include possible destructive hail and tornadoes in the May 16 Outlook. The Convective Outlook issued at 1:00 am CDT on May 20 indicated a 10\% or greater probability of EF2-EF5 tornadoes occurring within 25 miles of a point for the central Oklahoma region on the afternoon of May 20.

- The tornado touched down while Moore schools were still in session. However, many parents had picked up their children earlier in the day in response to increasing concerns about the weather, significantly reducing the number of students at the schools when the tornado struck. Due to the threat of severe weather that afternoon, Moore Public Schools made the decision by 9:00 am CDT to cancel all afterschool activities on May 20. By 1:30 pm, the decision was made to shelter-in-place (i.e., not run the buses or release the students at the normal 3:00 pm dismissal time).

\section{Observations on Objective 1: Performance of the emergency communications systems immediately prior to and during the tornado}

- The NWS Weather Forecast Office (WFO) in Norman made extensive use of nontraditional communications on May 20 to provide more frequently updated information about the possibility of severe weather and about the tornado warnings. 
These new communication methods included recorded severe weather briefings on YouTube, direct emails to stakeholders (e.g., emergency managers, school administrators), and Twitter and Facebook posts.

- The first official tornado warning for the Moore area was issued at 2:40 pm CDT, and the tornado touched down at 2:56 pm, for a lead time of 16 minutes. The 2010 national average tornado warning lead time is 14 minutes (latest available data). The leading edge of the tornado reached Briarwood Elementary School at approximately 3:15 pm, Plaza Towers Elementary School a few minutes later, and the Moore Medical Center at approximately 3:20 pm.

- An official Tornado Emergency warning, the most urgent official warning type, was issued by NWS at 3:01 pm CDT. This terminology, reserved by NWS for "exceedingly rare situations," had only been used twice previously by the Norman WFO, for the 1999 F5 and the 2003 F4 tornadoes, both of which struck Moore and surrounding areas.

- The tornado sirens in Moore were sounded six times. The initial siren was sounded shortly following the first NWS tornado warning at 2:40 pm CDT, and the last at approximately 3:20 pm. The sirens in Moore are only meant to alert/warn those located outdoors and are used to indicate the urgent need to take shelter. Moore's outdoor warning system is also capable of transmitting pre-recorded messages from its sirens. This feature was used only once, for the 3:11 pm activation, informing the Moore community that the tornado warning was still in effect.

Observations on Objective 2: Response of critical and educational facilities (specifically, the Moore Medical Center and Briarwood and Plaza Towers Elementary Schools) to the tornado, including emergency operations, the physical performance of the buildings and designated safe areas, and life safety outcomes.

- At both Briarwood and Plaza Towers Elementary Schools, most designated tornado safe areas were severely damaged or destroyed. Some of the designated safe areas at the Moore Medical Center had significant damage due to collapse of interior walls and ceilings on the second floor and due to infiltration of windborne debris in hallways on the first floor. None of these buildings had facilities specifically designed for use as storm shelters ${ }^{56}$ or safe rooms, ${ }^{57}$ and none had basements.

- The designated safe areas in the new main classroom building at Plaza Towers Elementary School did not provide life safety. Seven schoolchildren died when part of the building's designated safe area, in which they were located, collapsed. Two adults and one student were also significantly injured in the new main classroom building. No fatalities occurred in the original main classroom building at Plaza Towers Elementary School; however, two teachers and one child suffered significant injuries.

\footnotetext{
${ }^{56}$ As defined by the ICC 500 Standard for the Design and Construction of Storm Shelters (ICC, 2008).

${ }^{57}$ As defined by FEMA 361, Design and Construction Guidance for Community Safe Rooms (FEMA, 2012)
} 
- Extensive damage to the building envelope of the Moore Medical Center allowed wind, debris, and water inside the building, causing severe damage to the interior and rendering the hospital and medical office buildings completely nonfunctional. Damage to the structural systems (pre-cast concrete and steel framing) was negligible.

- There were no reported fatalities at Briarwood Elementary School or Moore Medical Center. Two teacher's assistants suffered significant injuries at Briarwood Elementary School (in the 100 Building) and no significant injuries were reported at Moore Medical Center.

- For the most part, designated safe areas as identified in emergency plans were used at the three facilities surveyed by NIST. In some cases, last-minute decisions were made to use smaller interior spaces or rooms, which were not previously identified in the building's emergency plans as designated safe areas, such as bathrooms and closets in the two elementary schools and a walk-in freezer in the Moore Medical Center.

- Smaller interior spaces (e.g., bathrooms) surrounded by reinforced masonry (CMU) walls at both schools performed better when compared with adjacent hallways and classrooms. The CMU walls that surrounded these interior spaces were found to more often remain standing and thereby provide some protection against wind-borne debris.

- Multiple buildings at both elementary schools suffered complete collapse or severe damage. The elementary school buildings with box-type construction typically sustained loss of the roof system and diaphragm, leading to partial or total collapse of the supporting walls. Pre-engineered metal gymnasium and multipurpose buildings sustained total structural failure. 


\section{REFERENCES}

Bender, C. (May 21, 2013). Bloomberg. Oklahoma tornado alert gave residents 36 minutes warning. Retrieved from http://www.bloomberg.com/news/2013-05-21/tornado-alert-gavemoore-oklahoma-residents-36-minutes-warning.html.

BOCA (Building Officials and Code Administrators International, Inc.). (1996). National Building Code. Country Club Hills, IL.

City of Moore. (2012). Emergency Operations Plan, Moore Oklahoma. Retrieved from http://www.cityofmoore.com/sites/default/files/mainsite/2012\%20Emergency\%20Operations\%20Plan.pdf.

Cliff Mass Weather Blog. (May 21, 2013). The Lessons of the Moore Oklahoma Tornado. Retrieved from http://cliffmass.blogspot.com/2013/05/the-lessons-of-moore-oklahomatornado.html.

FEMA (Federal Emergency Management Agency). (2012). Spring 2011 Tornadoes: April 2528 and May 22, Building Performance Observations, Recommendations, and Technical Guidance. Mitigation Assessment Team Report. FEMA P-908. Washington, DC, May.

FEMA (Federal Emergency Management Agency). (2013). Senior Leadership Briefing, Oklahoma Tornadoes 2013, Thursday, May 23, 2013 (6:00 p.m.) FINAL.

Fernandez, M. Healy, J. (May 21, 2013). The New York Times. Drama as alarm sirens wailed. Retrieved from http://www.nytimes.com/2013/05/22/us/oklahomatornado.html?pagewanted=all\&_r=0.

Haan, F., Jr., Balaramudu, V., and Sarkar, P. (2010). "Tornado-Induced Wind Loads on a LowRise Building.” J. Struct. Eng., 136(1), 106-116.

Hauser, A. (May, 31, 2013). Is Moore, Okla. Ready for Another Tornado? The Weather Channel. Retrieved from http://www.weather.com/news/tornado-central/moore-okla-ready-anotherstorm-20130529.

ICC (International Code Council). (2008). ICC/NSSA Standard for the Design and Construction of Storm Shelters. ICC 500-2008, American National Standard. Washington, DC, June.

ICC (International Code Council). (2009a). International Building Code. Falls Church, VA.

ICC (International Code Council). (2009b). International Residential Code for One- and TwoFamily Dwellings. Falls Church, VA.

Mike Smith Enterprises Blog. (May 21, 2013). One more time: Moore had plenty of warning. 
Retrieved from http://meteorologicalmusings.blogspot.com/2013/05/one-more-time-moorehad-plenty-of.html

Moore, Oklahoma. Emergency Operations Plan. Retrieved from http://www.cityofmoore.com/sites/default/files/mainsite/2012\%20Emergency\%20Operations\%20Plan.pdf.

Romano, A. (May 22, 2013). The Daily Beast. When the sirens wailed. Retrieved from http://www.thedailybeast.com/newsweek/2013/05/22/moore-oklahoma-again-in-a-tornado-spath.html.

Simmons, Kevin M. and Daniel Sutter. (2011). Economic and Societal Impacts of Tornadoes. American Meteorological Society. Boston, MA.

Sistek, S. (May, 21, 2013). How tornado victims got 36 minutes of precious warning time. Komonews. Retrieved from http://www.komonews.com/weather/blogs/scott/Howtechnology-helped-give-nearly-30-minutes-warning-of-impending-tornado-208363551.html. 


\section{APPENDIX. TORNADO EMERGENCY PROCEDURES FOR SURVEYED FACILITIES}

Moore Public School District:

The Moore Public Schools provided NIST with the information documented in this section on the school's emergency procedures in the event of a tornado. All schools are required to prepare a tornado plan, including instructions to take cover against an inside wall, away from windows. Additionally, the school district's plan states that all schools should coordinate their specific emergency preparedness plan with the City of Moore's Emergency Management Department. All schools are required to have a NOAA weather radio, which should be monitored in the school by a staff member, e.g., in the school's main office, which is normally continuously staffed.

The Moore school's response or action plan in the event of a tornado involves five steps:

1. Monitor the proximity of the tornado. The individual responsible for this action is the Building Administrator or Superintendent. The resource needed for this action is a television or radio.

2. If a tornado watch is issued, the Building Administrator or equivalent designee should monitor all outdoor activities and curtail activities if the weather conditions warrant.

3. If a tornado warning is issued, the Building Administrator (or equivalent designee) and/or the Director of Transportation should summon all persons into the buildings. This involves getting staff and students off of the playgrounds, stadiums, and practice fields, as well as out of the portable buildings, if the school contains these types of buildings. The Superintendent's office is responsible for relaying this information to the schools' Building Administrators and Directors of Transportation.

4. If tornado sirens are activated or if a tornado is sighted in the vicinity of the school, the Building Administrator (or equivalent designee) should institute the tornado emergency plan. According to the Plaza Towers Elementary School's tornado emergency procedures (and similar to those at Briarwood Elementary School), the teachers and staff are made aware of the need to take shelter from a tornado by the initiation of "one long continuous ringing of the bell." After this signal, the students and school staff must institute the "duck and cover" plan, which is outlined below.

a. Teachers and administrators lead students immediately and orderly to the school's specific designated shelter areas.

b. Students and others should stay clear of all glassed areas (e.g., windows). This includes reinforced glass sections near the doors of the schools.

c. Teachers should take with them their class record book to use for roll call after the tornado has passed.

d. Students, who are located in designated areas, should assume the following position: "Face the wall, get down on knees, and lean forward, covering face with hands and arms." Additionally, the emergency procedures state that since tornadoes move fairly quickly (i.e., at a high rate of speed), students can crowd close together for protection since they will not necessarily need to hold this position for long. 
5. The principal or administrator will then determine when the all-clear signal will be announced at the school.

Moore schools hold tornado/severe weather drills every semester. Another policy of Moore Public School District is that during a tornado watch or warning, teachers and administrators will not dismiss a student to go home unless the student's parent comes to the school to pick up him/her. Students not picked up are automatically sheltered in the school where they are located.

Moore Medical Center:

Information on the Moore Medical Center's tornado emergency procedures described in this section was provided by the Center's Manager of Safety. ${ }^{58}$ In this hospital's system, called the Code Black Plan, there are three levels of alert for a weather-related emergency: Code Black Watch; Code Black Warning; and Code Black Alert.

In the event of a "Code Black Watch," all health system personnel are to begin preparation for the possibility of a tornado or a severe weather warning. Under a "Code Black Watch", hospital staff must begin preparation activities, as follows:

- Check in with supervisor/manager and coordinate actions and responsibilities if conditions are upgraded to a warning or alert.

- Move all unnecessary equipment, carts, etc. from hallways, elevator areas, and exits, and ensure that no doors are locked or blocked.

- Locate all emergency supplies, including flashlights, oxygen cylinders, wheelchairs/stretchers, etc.

- Keep telephone calls to a minimum.

Additionally, the Nursing House Supervisor (or a designee in charge that day) should determine which patients can be safely relocated and which need to remain in place. This includes determining a path of travel that will be followed if patients need to be moved.

In the event of a "Code Black Warning," all health system personnel should do the following:

- Check in with the supervisor/manager.

- Close all doors, including the fire and smoke doors, windows, blinds, and draperies in his/her area and surrounding hallways.

- Unplug or shut off any non-essential electrical equipment.

- Ensure that all cash boxes, cash registers, medicine and narcotic cabinets are locked and secure.

- Keep telephone calls to a minimum.

- Stay away from all outside windows/doors.

The third and final level in this "Code Black Plan" is a "Code Black Alert." In a "Code Black Alert," all health system personnel should do the following:

- Move bed patients to the hallway against the walls and away from outside windows. If possible, the head of the bed should be elevated. Also, the patient should be facing away

\footnotetext{
${ }^{58}$ NIST Interview \#10 (Manager of Safety, Moore Medical Center).
} 
from the window at the end of the hallway.

- Transfer or relocate ambulatory patients to "designated protected areas" along with all visitors. Patients and visitors are instructed to remain there until the "ALL CLEAR" is sounded.

- All personnel not in their work area or on a patient floor should report to the nearest nursing station and remain there until the "ALL CLEAR" has been announced.

Additionally, under "Code Black Alert," visitors are advised to either remain with the patients or take shelter in specific locations within the medical center.

According to the emergency operations plans, a "Code Black" watch, warning, or alert must be declared by the Safety Officer, Nursing House Supervisor, or Administrator on Call. Decisions on issuing watches, warnings, or alerts are made by obtaining information on the weather emergency via multiple sources and means of communications, including weekly webinars provided by the WCM from the NWS Forecast Office in Norman, $800 \mathrm{MHz}$ radios, NWS radar imagery obtained via the web or phone, local news radar and spotter/helicopter information provided via television or radio, and automated weather updates obtained via phone or email. Once a decision is made, emergency information and instructions are then relayed to health system personnel and patients via an overhead page to the entire hospital campus.

Before the May 20, 2013 Newcastle-Moore tornado, hospital staff and leadership met monthly to review plans and preparations for severe weather. On average, "Code Black" alerts were issued for Moore Medical Center two times each spring. 


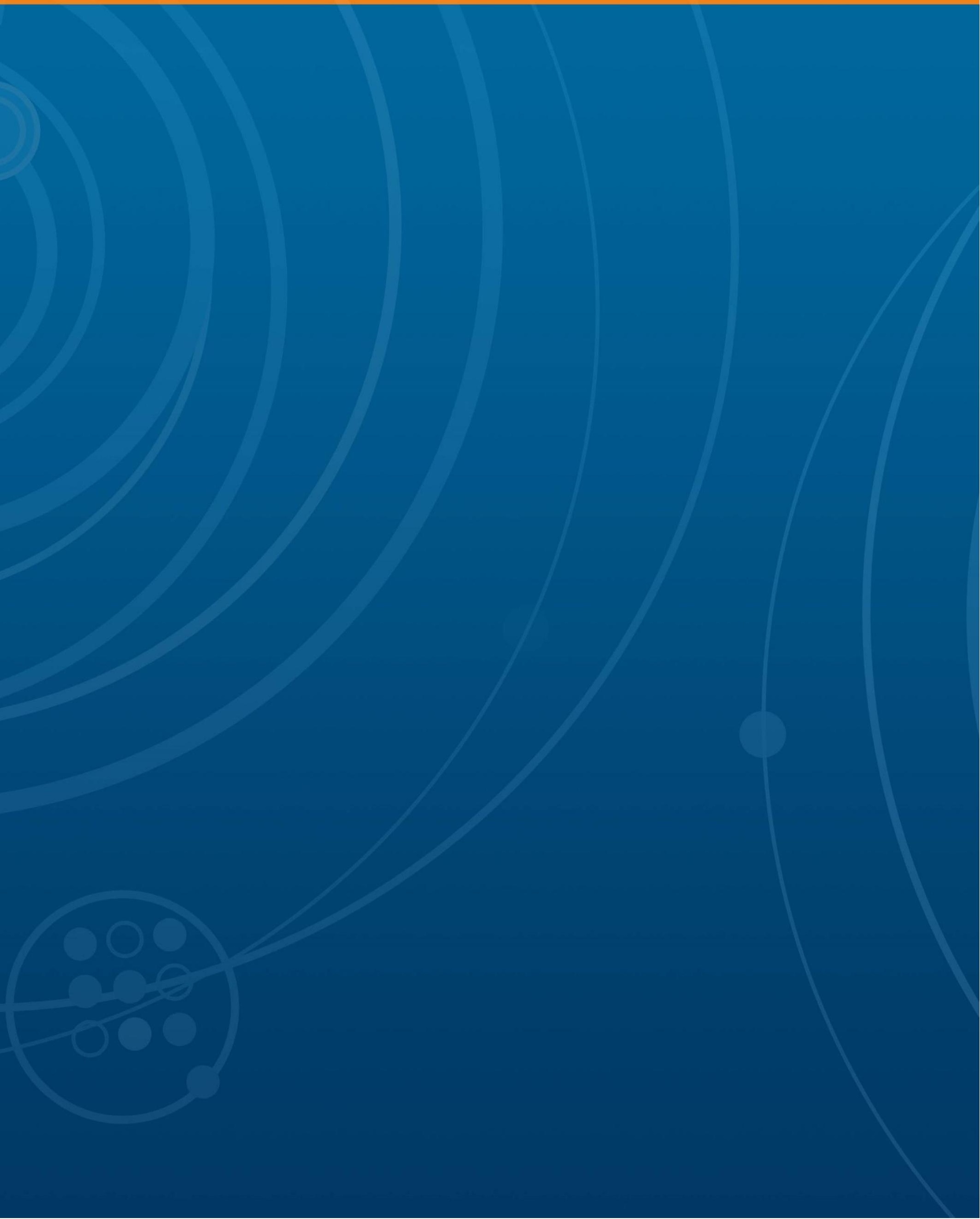

